\title{
HENCLASSTEC?
}

\section{PACIFIC NORTHWEST LABORATORY MONTHLY ACTIVITIES REPORT FOR AUGUST 1967}

\author{
DIVISION \\ OF \\ REACTOR DEVELOPMENT \\ AND TECHNOLOGY PROGRAMS
}

SEPTEMBER, 1967

\section{AEC RESEARCH \& \\ DEVELOPMENT REPORT}

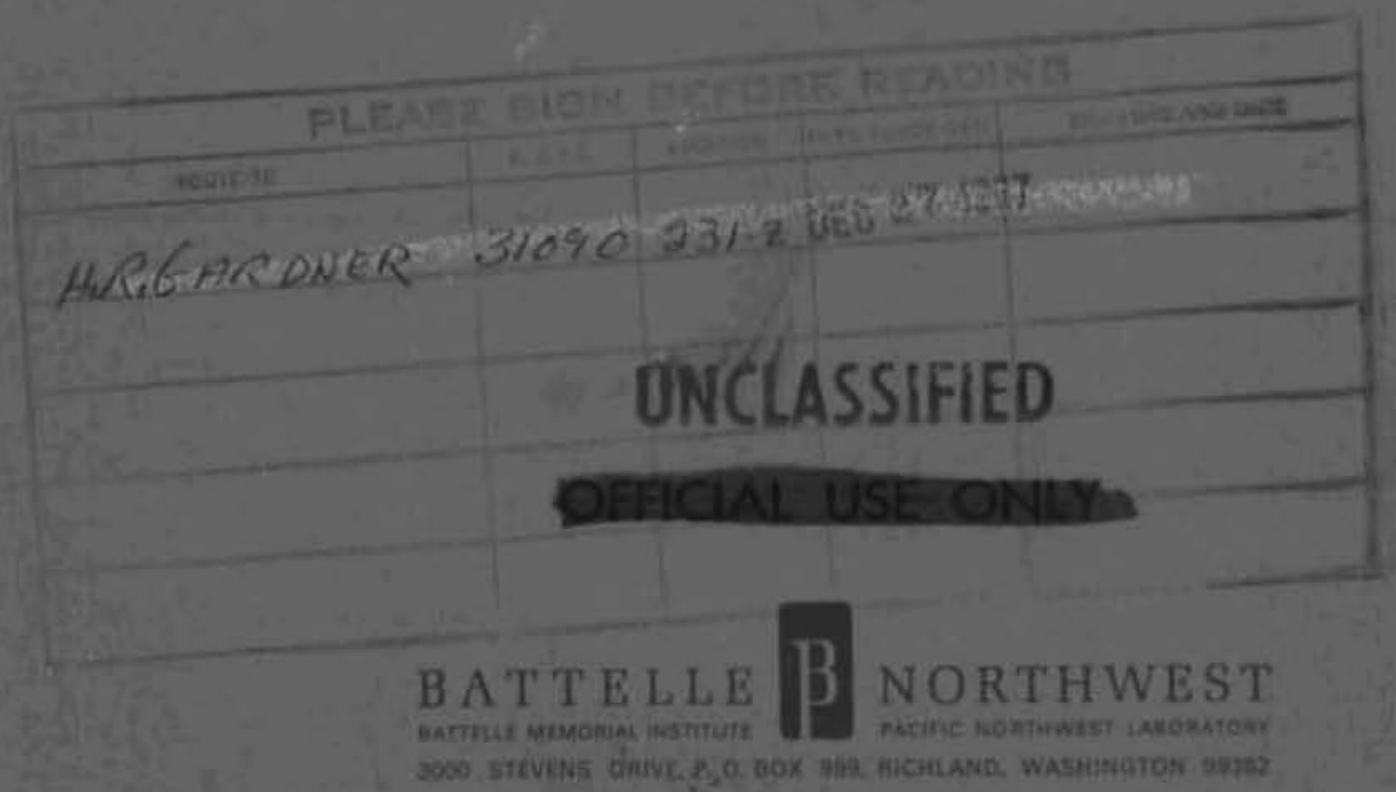




\title{
BATENT STATIS
}

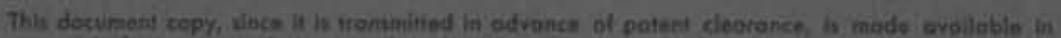

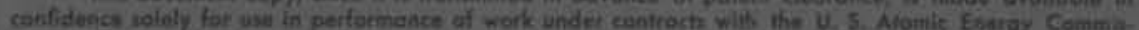

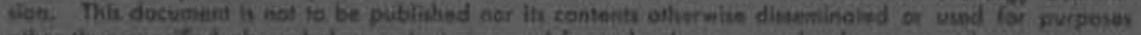

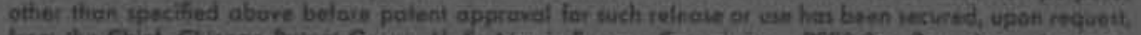

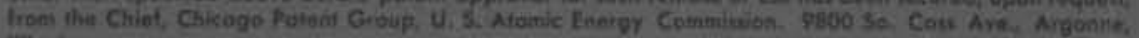
IIIinait.

\section{PREIIMINIRY REPokT}

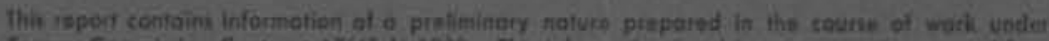

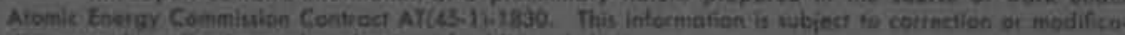
fion upon the colisction and r ralumiton of additianal dato.

\section{HEGAL NoTret}

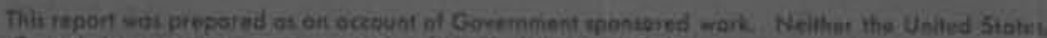
for the Comitwion, we ony perten gctind on betiolt of the Commivich

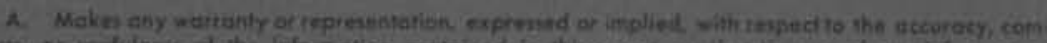

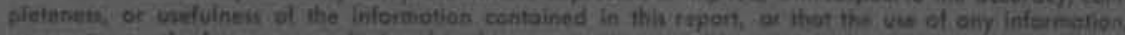

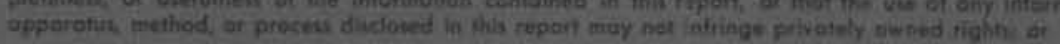

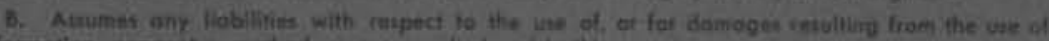
any information upporatur, meithed, ar process disclosed In thil report.

As wied in the obove. "Potsen patine on befolf of the Commisian" Inclodts any smplome un

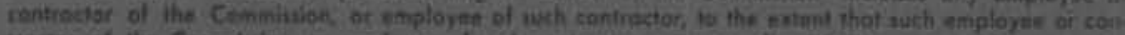

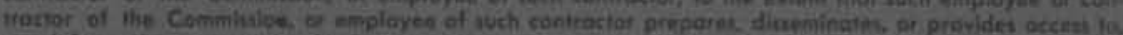

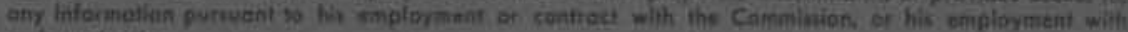
weh controcter.

\author{
PACIFIC NORTHWEST LABORATORY \\ RICHLAND, WASHINGTON \\ operated by \\ BATTELLE MEMORIAL INSTITUTE \\ for the \\ UNITED STATES ATOMIC ENERGY COMMISSION UNDER CONTRACT AT(45-1)-1830
}

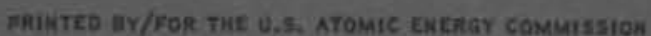


TO: Pecipients of Pacific Northwest Laboratory Monthly Activities Report for $P E C$ Division of Reactor Development and Technology

This report is seing discontinued with the August issue. The information presented will now be covered in a series of quarterly reports: Fuels and Materials, Reactor Physics, Nuclear Safety, Reactor Engineering Development, and Plutonium Utilization Program. 


\section{UNCLASSIFIED}
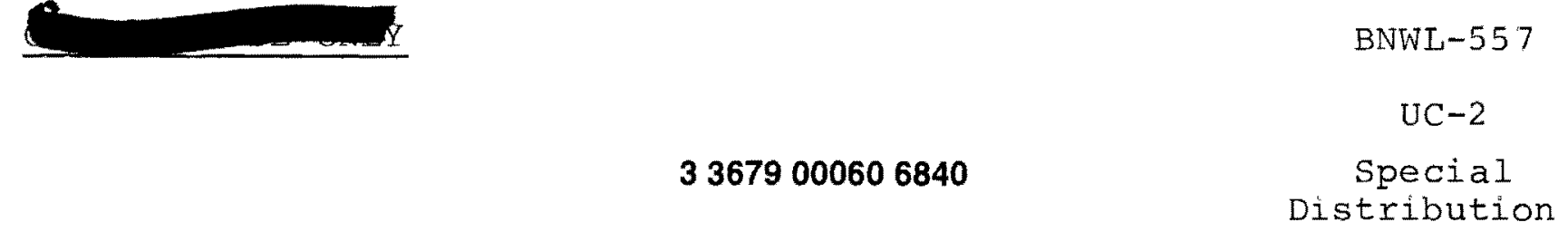

PACIFIC NORTHWEST LABORATORY

MONTHLY ACTIVITIES REPORT

FOR AUGUST 1967

AEC DIVISION OF

REACTOR DEVELOPMENT AND TECHNOLOGY PROCRAMS

By

The Staff of Battelle-Northwest

S. I. Fawcett, Director

September 1967

PACIFIC NORTHWEST LABORATORY RICHLAND, WASHINGTON 
CIVILIAN POWER REACTORS

Liquid Metal Fast Breeder Reactor . . . . . . 18

Power Reactor Design Studies and Evaluations . . . 18

USAEC-AECL Cooperative Program , , , , , , , , 19

Heavy Water Reactor Program Office . . . . . . . . 23

APPLIED AND REACTOR PHYSICS

Plutonium Criticality Studies .............. 23

Phoenix Fuel Reactor Program _. . . . . . . . 25

High Temperature Reactor Lattice Physics Studies : . 30

REACTOR FUELS AND MATERIALS

Fast Fuels Oxides and Nitrides . . . . . . . . 35

Basıc Swelling Studies . . . . . . . . . . . . . . 37

Nondestructive Testing ........., . , . . . 38

Nuclear Ceramics . . . . . . . . . . 43

Nuclear Graphite , . . . . . . . . . . 44

Irradiation Damage to Reactor Metals . . . . . 46

ATR Gas Loop Operation and Maintenance ......... 54

Metallic Fuels Development ............. . . . 56

Fast Reactor Dosimetry and Damage Analyses . . . . 59

ENGINEERING DEVELOPMENT

Neutron Flux Monitors . . . . . . . . . . . . 60

Microwave and Infrared Detection of Coolant Impurities

and Measurement of In-Reactor Temperature . . . 62

PLUTONIUM UTILIZATION PROGRAM

Fueis Development

Physics Measurements

Reactor Physıcs

Reactor Engineering

Materials Development

Cycle Analysis

Test Reactor Operation

NUCLEAR SAFETY

Containment Systems Experiment

Radioactive Residue Process Development . . . . . 94

Fission Product Aerosol Containment . . . . . 100

Columbia River Sedimentation Studies . . . . . . 103

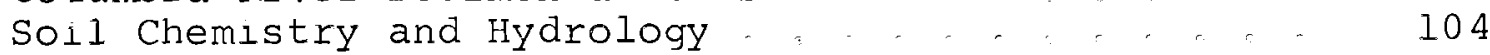

Pressure Vessel Crack Monitoring ........... 105 


\section{SUMMARY}

\section{CIVILIAN POWER REACTORS}

\section{Liquid Metal Fast Breeder Reactor}

Irradiation of $12 \mathrm{UO}_{2}-25 \mathrm{wt} \frac{\mathrm{P}}{\mathrm{PuO}} 2$ fuel pins with $\mathrm{O} / \mathrm{M}^{\prime} \mathrm{s}$ of 1.92, 1.97, 1.99, and 2.00 is in progress. One capsule containing pins with $O / M^{\prime}$ s of 1.92 and 2.00 was discharged from the reactor and sent to Radıometallurgy for metallography.

Variations in structure and fission-fragment distribution in molten center $\mathrm{UO}_{2}$ fuels discharged from the reactor at various controlled rates are being studied. Capsules for ten such experiments were fabricated, and the $\mathrm{UO}_{2}$ fuel is being pressed and sintered.

\section{Power Reactor Design Studies and Evaluations}

Gross heat capacity calculations have been completed for the major streams in the following areas: Ohio River Basin, Cumberland River Basin, Tennessee River Basin, St. Lawrence River Basin, Hudson Bay Basin, Upper Mississippl River Basin, Missouri River Basin, Colorado River Basın, Pacific Slope Basin (California), Alaska.

The parametric study is being done to show the effect of pressure and temperature on a conservative, optimistıc, and inter.. mediate design. Geometry and design criteria are being included by sensitivity studies around the intermediate desion.

\section{USAEC-AECL COoperative Program}

Creep rate results for both in-reactor and unirradiated control tests are summarized in tabular form.

Hydrogen absorption data are reported for $51 \mathrm{x}$ zirconium alloys exposed eight cycles 174 days) in the ETR G-7 loop. In-flux corrosion results are reported for three zirconium alloys prefilmed in various media and exposed four cycles 84 days: in the ETR G-7 loop.

A heat transfer test section used in earlier studies of coolant mixing in rod bundle fuel elements was modified to enabie the study of the influence wart-type spacers on mixing during boiling. The spacers being considered are $1 / 8$ inch wide, $\frac{1}{2}$ inch large, and are shaped to approximate the BLW 250 reactor spacer design. Installation of this test section in the heat transfer apparatus is nearly complete, and experiments are scheduled to start immediately. 


\section{Heavy Water Reactor Program Offlce}

Information retrieval teciniques and some existing information centers have been studied to help set up a Heavy Water Reactor Information Center at Batteile-Northwest.

The Uniterm system of Coordinate Indexing is recommended for the organization, storage, and retrieval of information to be processed by the Center.

A first draft of a report on this study has been completed and is now being typed in rough draft form.

\section{APPIIED AND REACTOR PHYSICS}

\section{Plutonlum Criticality Studies}

Data from previous experiments performed with PuO 2 -polystyrene compacts having an $\mathrm{H} / \mathrm{Pu}$ ratıo of 5 and contalning 11.5 wt $\%$ Pu-240 were analyzed, ylelding values for the following: critical or material buckling, critical thickness of infinite slab reflected with Lucite, and the extrapolation length for an infinite slab reflected with Iucite.

Further tests were done with the smali spherical proton recoil spectrometers that were obtained for neutron spectrum measurements. The tests were performed at th: Unlversity of Washington using the neutron beam port from the reactor to check resolution and calibration.

Further comparisons were made between experlments and calculations using the British Monte Carlo GEM 3 code. With few exceptions, for the cases compared, agreement between computed and measured criticality has been good. The cases compared include interacting arrays of U-235 metal and U-233 solution arrays, and single units comprised of Pu solution and Pu-plastic mixtures.

In connection with required containment tests, further work was done to improve the leaktightness of tine reactor room. Despite the fact that many small leaks have now been detected and sealed, the leakage rate remains signiticantly higher than when the building was new. Further work wll be done to effect more improvement.

\section{Phoenix Fuel Reactor Program}

Experiments have continued in the PRCF-Phoenix fuel core, with measurements of (a) the reactivity changes associated with loss of coolant and loss of fuel plates, (b) shutdown margin, (c) reactor 
nolse, (d) temperature coefficients, and (e) simulated MTR regulating rod.

Preliminary PRCF-Phoenix reactivity calculations on the unrodded critical core are about 6\% high.

Calculations have been completed that indicate the MTR can be operated at $37 \mathrm{MW}_{\mathrm{t}}$ with the Phoenix core if a pressure head of 73 psia is maintained.

A handling device has been designed for removing the flux monitoring wands from the Phoenix fuel elements.

The Phoenix Fuel Element and Shlm Rod Specifications have been completed and forwarded to the AEC and IIV for review. The shim rod fuel section has been redesigned to contain 13 tuel plates, and a 13-plate element was fabricated for testing in the PRCF experiment. Charging of the MTR irradiation test plates fabricated in June has been cancelled due to questionable end bonding on the fuel plates. The lrradiation test has been redesigned utilizing full length prototyplcal plates utilizing higher reductions and increased annealing times to obtain the desired bond line grain growth. Vendor response to bid requests for fabrication of a shim rod dummy fuel section was unfavorable. Negotiations are being held with vendors in an attempt to lower cost and improve delivery. pared.

A proposal to irradiate a Phoenix plate test element was pre-

Work continues on the very complex methoảs usea by ORNL for the HFIR calculations.

Cost calculations to see the effect of pin diameter, fuel volume fracton, and plutonium composition are nearing completion.

A burnup calculation for a Phoenlx fuel (Al-Pu) batch core fuel $\left(\mathrm{UO}_{2}-\mathrm{PuO}_{2}\right)$ loading in the PRTR has been made.

\section{Hıgh Temperature Reactor Physics stuảies}

All construction personnel left the High Temperature Lattice Test Reactor during the month.

The experimental oscillators were installed, but final checkout under program control still remains.

Work on the horizontal control rods and the vertical safety rods resulted in consistent scram times which are within specifications. 
The NUCLEAR programs were tested in large part with the flux monltoring equipment and the two roa systems. Only the flux level and period monitoring program remains incomplete. Final debugging can, of course, only be completed curing the approach-to-critical experiments.

Planning for the startup and calibration experiments and the $\mathrm{U}-2330_{2}-\mathrm{ThO}_{2}$ experiments continued.

\section{REACTOR FUEES AIND MATERIALS}

\section{Fast Fuels Oxides and ivitrides}

Ignition studies indicate that at a sugar-to-uranium ratio of one or above, a very nonuniform powcier is produced in the spray calciner. Analytical results on the carbon-to-uranium ratios of the resultant produce have not been received to date.

Carbon removal from mixed uranıum-plutonium carbonıtrides is being investigated.

The use of pure hydrogen at $1000{ }^{\circ} \mathrm{C}$ reduced carbon contents in mixed nitrides from 0.7 응 to $0.4 \%$ after 20 minutes and to 280 ppm after 60 minutes.

The UN synthesis cycle was modified to yleld nearly $100 \%$ fine grain UN powder.

T'wo experimental tuel capsules $(\mathrm{GEH}-14-745 \& 746$ containing mixed nitrides (UN - 20 wto PuN) were discharged from the MTR after attaining exposures of approximately 20,000 MWd/ton.

\section{Basic Swelling Studies}

Capsule P-16 (625 OC, 1000 psi, 0.35-0.7 at.\% BU) was discharged after a successful irradiation. One other capsule continues to operate as designed, and construction has either started or is complete on four more capsules.

\section{Nondestructıve Testing}

Conceptual design for a device for automatically setting the matrix coefficient potentiometers in the multiparameter eddy current tester was formulated, and the design of circuits for use in a feasibility test of the concept is in progress. The prototype multichannel eddy current tubing tester has been mounted in lts 
carrying case, and this work is essentially completed. Analysis of circults used in the multichannel eddy current tubing tester, and analysis of an idealized eddy current mode $\perp$ representing the multiparameter edäy current tester, has given new insight into the capabilities of the techniques being used.

Changes were made in the EDPM program for predicting ultrasonic pulse data using Kautz function analysis. Initial results indicated that only the first two terms of the series were being correctly evaluated, and subsequent terms were not effective in reducing the residual signals indicating that the program still contalns an incorrect computation. These results are somewhat discouraging, and additional consideration will be glven to the problem of finding acceptable methods for predicting ultrasonlc pulse behavior.

The ultrasonlc test system for detecting irradiation-induced shift in nil-ductility-transition temperature in structural steels has been set up for operation in the hot cell facilities. Design work for attachment of a Schlieren optical imaging system on this test tank is in progress. This optical system is expected to reciuce the system set-up time and provide additional precision in the ultrasonıc measurements. Specimens irradiated in ETR cycle 89 have been recelved, de-encapsulated, inspectea, and loaded in a cask for transfer to the hot cell examination facilities. Additional specimens irradlated during ETR cycle 90 were discharged and expected to ar 1 ve at PNL later this month. Specimens irradiated to date include tirree high-exposure, Low-temperature groups; one hlgh-exposure, higntemperature group; and one low-exposure, high-temperature group.

Development efforts continued toward providing Improvea relıability and sensitivity for thermal wave transjucers. A silicone rubber backed unit has been completed, and inltial test results inälcate that satisfactory sensltivity has been achievec. Varlous coupling media such as helium, water, and oil are being experimentaily investigated for possible use wlth this transaucer.

\section{Nuclear Ceramics}

An electron-beam gun was installea in the ternary evaporator for use in $\mathrm{Pu}-\mathrm{O}-\mathrm{N}$ phase studıes.

A high temperature creep loading apparatus was designed and is being fabricated.

Ten samples of $\mathrm{UO}_{2}-25 \% \mathrm{PuO}_{2}$ of $\mathrm{O} / \mathrm{M}$ ratio 1.96 and $i .97$, sodium and helium bonded in 304 stainless steel claddıng, were piaced in furnaces for heat treatments of 100 and 1000 hours at $650 \circ \mathrm{C}$ and $1000{ }^{\circ} \mathrm{C}$ to determine the compatibility of these components. 
Tests were conducted on two types of secondary emission electron microscopes to determine applicability to PNL materials research programs.

\section{Nuclear Graphite}

The leak in the GEH-13-14 capsule was repaired, and the capsule is now in the ETR awalting startup.

A subassembly contalning three graphite pins, two thermocouple pins, and one dosimetry pin is being inserted in a Row 6 position in EBR-II to obtain fast flux irradiation information. The subassembly will probably remain in the reactor many cycles and hence acquire high exposure.

Changes in electrical resistivity, sonic moduli, and thermal expansion have been measured or several samples of SGBF graphite stressed in tension to various percentages of the nominal breaking strength. The results qualitatively agree with a model previously proposed. Similar tests have started on some poco graphite samples of higher density and uniformity. Stressing to 1400 psi produced no significant change in the properties being measured in this materıal.

A spark machining technique which has been used to prepare thin samples for electron microscopy can also be used to study high temperature graphite oxidations. Passing oxygen through the high temperature area of the spark discharge and then impinging on the sample gave structures which appeared to be due to oxygen atom attack.

The radiolysis of mixtures of carbon dioxide and hyärogen has been reported to yield small quantities of methane as well as larger amounts of water and carbon monoxide. The methane yleld appears to be largely due to small quantities of organic impurities in the reactants. Purification of the hydrogen to at least $99.9995 \%$ purity and the carbon dixolde to $99.99 \%$ gave a $\mathrm{G}\left(\mathrm{CH}_{4}\right)=0.01$ molecules/loo ev. This value is lower than has been reported earlier by a factor of two.

Irradiation Damage to Reactor Metals

The liquid metal capsule GEH 22-5 has been discharged from the ETR after four days of operation due to excessive temperature readings. The cause of malfunction will be investıgated.

In-reactor creep tests are being conducted on 304 stalnless steel at temperatures of 400 and $450{ }^{\circ} \mathrm{C}$ to determine the effects of neutron irradiation on creep at temperatures where rapid recovery does not take place. 
Experimental thermal-mechanical treatments have been applied to 304 and 316 stainless steels to optimize their resistance to radiation damage. Irradiations will be conducted at elevated temperacures in Hanford reactors and the ETR. Metallographic characterization of the microstructures resulting from the experimental thermal-mechanical treatments has begun, and irradiations in the ETR will commence after the cycle 93 shutdorn.

Preliminary stress-rupture àta have been obtained for thermomechanical $\perp y$-treated Hastelloy $x-280$ specimens (including controls) irradiated at 1250 of $1675 \circ^{\circ}$ to a fast fluence of $1 \mathrm{x} 1020 \mathrm{n} / \mathrm{cm}^{2}$. These data revealed that thermal exposure caused only silght reductions in rupture life compared with factor of 10 reductions caused by irradiation. No helium bubbles were revealed by transmission microscopy of a specimen that had veen irradiated at $1250 O_{F}\left(675 \circ^{\circ}\right)$ to a fast fluence of $1 \times 10^{20} \mathrm{n} / \mathrm{cm}^{2}$.

Four adiltional structural materials pins have been charged in the EBP-II. Provisions for monitoring flux are emphasized in two o: these pins. The remaining two pins are directed at evaluating flowing sodium effects. Two papers on fast reactor irraailation effects have been accepted for national professional society presentations.

The hydrogen permeation, alffusivity, and solubility characteristics of $\mathrm{A} 302-\vec{B}$ pressure vessel steel have been investigated for the 250-525 ${ }^{\circ} \mathrm{C}$ temperature range. The activation energy for diffusion (-1.5 kcal/g-atom) is approximately halt that for hydrogen diffusion in alpha iron.

Construction of the orototype creep-rupture cell is nearing completion. A test rig, capable of remote operation at temperatures to $1832 \mathrm{OF}^{\mathrm{F}}(\mathrm{i} 000 \mathrm{O})$ with inert atmosphere is undergoing final bencin operational tests. A design ior a remotely-operated stress rupture apparatus with static sodium environment has been completed. Approval to complete renovation and construction in Building $321-i$ : was submitted to the contractor by the AEC during the month. A minlaturized stress-rupture apparatus has been ciesigned and 15 currently being machined. The apparatus will be installed in 324 Building clad test facility.

Operation of the model gas loop has been resumed; an accumulated total of 4963 operating hours have been completed. The current test program includes the evaluation of a device for the remote insertion of test specimens from a cool zone into the hot zone while the ioop is at operation conditions. The initial test run was accompilshed without difficulty.

The transfer of oxygen to niobium from an acjacent superalloy oxide film has been shown to occur readily in 80 Torr hydrogen at $11000^{\circ} \mathrm{C}$. Such a contamination mechanism coulc be a potential problem in the ATR gas Ioop. 
Corrosion samples inserted into the model loop heater after attalnment of operating temperature show ili no effect on the evaporation of Hastelloy $x-280$ and Haynes 25 , 12) a slight decrease in the welght gain of nloblum, and (3) marked decrease in the welght gain of tantalum, comparea with previous corrosion tests conducted in helium representing loop startup conditions.

To investigate the effect of fissionable species on the influx corrosion rate of zirconlum alloys, several alloys will be exposed in the Battelle-Northwest ATR water loop before fissionable materials are charged into the loop. The ATR critical assembly for the corrosion experiment has been sent to the National Reactor Testing Station for critical tests.

A 5\% $\mathrm{HCl}$ solution has been used to satisfactorlly machine a reduced section on an iron tensile specimen by electrolytic machining. This will be used for the preparation of single crystal iron tensile specimens.

\section{ATR Gas Joop Operation and Malntenance}

Contract submittals for the ATR gas loop are being reviewed for compliance to specifications and service. Planning is presently under way on the formulation OI an ATR gas loop survelilance program.

Modiflcations are being macle to the dummy tube in the ATR to allow insertion of an lonization chamber for gamma heating measurements.

\section{Metallic Fuels Development}

Three Th - 2.5 wto U - 1.0 wto $z r$ tuel elements continue their irradiation in the $\mathrm{P}-7$ hot water loop at the ETR. Exposures range from 9700 to $18,900 \mathrm{MWd} /$ ton with corresponding volume increases from 1.5 to $3.6 \%$.

Hollow core uranium fuel elements have been successfully irradiated in the ETR $M-3$ hot water loop to a maximum exposure of 5585 Mwd/ton. All elements thus tar irradiated continue to show slight volume decreases. Hot cell measurements show decreases of diameter and length whlch are in agreement with the volume changes calculated from the immersed weight measurements.

\section{Fast Reactor Dosımetry and Damage Analyses}

The Spectrum Analysis of iveutron Detector Computer Code II ISAND II! is being adapted for operation on the UNIVAC 1108 Computer. This code accepts as input a set of measured foll activities 
(approximately 10 to 15) along with an initial neutron flux spectral approximation and yields a new solution flux spectrum which is consistent with the measured foil activation data.

Consideration is being given to the use and development of an improved neutron spectral-fluence monitor for fast reactors. A small set of properly selected foil reactions that reach radioactive saturation auring the last few days or weeks of a reactor power would provide the necessary neutron flux spectral ciata to calculate appropriate spectrum-averaged cross sections for subsequent use with one or more stable reaction product (or long half life) fluence monitors. The successful development of this neutron spectralfluence monitor would eliminate the need to know the time history of an irradiation in order to interpret foil activation monitor data..

\section{ENGINEERING DEVELOPMENT}

\section{Neutron Flux Monitors}

Necessary fabrication and testing, essentially completed, readied the test capsule containing U-234 - U-235 regenerative detectors and several other types for comprehensive reactor in-core evaluation at the ETR.

Microwave and Infrared Detection of Coolant Impurities Measurement of In-Reactor Temperatures

High temperature measurements witin a microvove ravegulde and resonant cavity fajricated of special high temperature metal demonstrated a linear temperature to frequency relation, using microwave frequency shift techniques, to $1200^{\circ} \mathrm{C}$ with an achieved sensitivity of $330 \mathrm{kHz} /{ }^{\circ} \mathrm{C}$.

\section{PLUTONIUM UTILIZATION PROGRAM}

\section{Fuels Development}

Two of four fuel rods instrumented to measure fuel rod gas pressure and temperature continue to operate satisfactorily in PPTR.

Equipment is being installed in the new basin facility of the PRTR to handle the eight-rod FERTF fuel elements. 
Visual observation of two vibrationally compacted $\mathrm{UO}_{2}$ (5.01 at. 0 U-235) fuel rods, immediately after transient irradiations in the TREAT Facility, indicates that the rods apparently have developed high temperature bands at the top center, and bottom of their fuel columns during irradiation. Approval in principle to conduct a series of experiments, designed to establish the failure threshold of thermal reactor oxide fuel rods, was obtained from the Laboratory Director's Office of ANL.

A document describing a proposed irradıation testing program for evaluating some of the radiation effects in oxide fuels le.g., $\mathrm{UO}_{2}, \mathrm{UO}_{2}-\mathrm{PuO} 2$ l is being prepared.

An experimental seven-rod cluster fuel element containing low density mixed oxide pellets (0.500-inch diameter) was fabricated. The 33-inch long cluster contains cold pressed and unsintered pellets (73\% TD) and is to be irradiation tested in the P-7 Loop of the ETR.

Destructive examination of $\operatorname{six}$ additional PRTR fuel rods indicates that (1) structural evidence of fuel melting is erased in less than 72 hours of operation under nonmolten conditions; (2) fission product distribution patterns indicative of oncemolten operation are not erased by 72 hours of operation under nonmolten condltions; and 13) fuel structures formed in different rods irradiated under the same nonmolten conditions are comparable.

Postirradiation examination of an intentionally defected fuel rod contalning vibrationally compacted enriched $\mathrm{UO}_{2}$ was started. Preliminary observations indicate no change in appearance on fuel rod diameter.

Adaption of the Lawrence Radiation Laboratory computer program for energy spectra photo peak analysis is partially operational. Surface dose rate measurements are continuing on a monthly basis to define dose rate increases with time on $\mathrm{PuO}_{2}$ samples trom three different reactor types.

A total of 41 experimental fuel rods were fabricated for FERTF experiments in the PRTR.

Commercial procurement is nearing completion under the twostep procedure to obtain a large quantity of (4 wt: $\mathrm{PuO}_{2}-\mathrm{UO}_{2}$ test fuel rods required for critical experiments in the PRCF. Requests for prices (Step twol were sent to five companies, and responses are due by september 15, 1967.

Reactor Physics

Experiments in the PCTR with $\mathrm{H}_{2} \mathrm{O}$ moderated mixed oxide fueled lattices have been initiated. 
A series of calculations to study loadings of half inch 0.90 wt: $\mathrm{PuO}_{2}$ mixed oxide rods in light water in the PCTR water tank have been completed. Values for the PCTR prompt neutron lifetime and effective delayed fraction are reported for a 1.0 inch square lattice spacing in addition to the effects on the PCTR of varying and collapsing this inner water tank spacing of the mixed oxide fuel.

The use of the two foil method to determine spatial variations is under investigation.

Two summaries entitled "Power Tests with the $\mathrm{UO}_{2}-2$ wt: $\mathrm{PuO}_{2}$ Batch Core in the PRTR" and "Temperature Coefficients of $\mathrm{PuO}_{2}-\mathrm{UO}_{2}-$ $\mathrm{H}_{2} \mathrm{O}$ Lattıces," have been accepted for presentation of papers at the 1967 Winter Meeting of the American Nuclear Society.

Batch Core Power Test No. 6, Transient Fission Product Polsoning in PRTR, has been repeated. Analysis of the test is in progress.

Preparation of fuels and core hardware for the joint USAEC-CNEN cooperative program is about $80 \%$ complete. Analog simulation studies for the planned lattices are in progress.

CAF experiments with the $\mathrm{UO}_{2}-4$ wt: $\mathrm{PuO}_{2}$ fuel rods are being delayed pending $A E C$ acceptance of the safeguards documentation for the CAF.

Gamma scanning of EBWR fuel rods has continued. The results have guided selection of rods and sampling locations for destructive analysis. Installation of the Ge(LI) detector in the PNL gamma scanner has been completed.

Analytıcal-experimental correlations of reactor multiplication values for $\mathrm{UO}_{2}, \mathrm{Al}-\mathrm{Pu}$, and $\mathrm{UO}_{2}-\mathrm{PuO}_{2}$ fueled $\mathrm{H}_{2} \mathrm{O}$ moderated lattices are being performed.

A set of four mixed oxide fuels contalning 2 wto 100-micron size $\mathrm{PuO}_{2}$ spheres, enriched $24 \% \mathrm{Pu}-240$, uniformly distributed in $\mathrm{UO}_{2}$ powder, were fabricated and delivered to the PCTR.

ETOM, the code for processing ENDF/B data into multigroup format as required by MUFT and HAMMER, has been successfully converted to the UNIVAC 1108.

EDIT, the processing code for editing the ENDF/B Llbrary tape has been modified to permit editing of secondary energy distributions.

A short code has been written to compare HRG data tapes and assist in the detection and elimination of errors. Improved processing methods for generating HRG data tapes from the BNW Master Library are being incorporated into the processing code, BARNS II. 
An 1108 version of the computer code THESEUS modified to calculate collision probabilities and THERMOS type T-matrixes for cylindrical lattices with arbitrary radial leakage is now available. An estimated savings in THERMOS running time of over $50 \%$ may well be possible using THESEUS as a subroutine.

A series of codes to be used for space-time kinetics studies, neutron thermalization studies, and reactor burnup studies have been imported and compiled for use on the UNIVAC-1108 system.

Several codes which are used for reactor calculations have been improved.

\section{Reactor Engıneerıng Deve Lopment}

Duplication of existing $1000 \mathrm{MWe}$ bolling water and pressure water reactors using the thermal hydraulics design code, PEPP, is currently in progress preparatory to study of the thermal hydraulics of these reactor designs using mixed oxide fuels.

During the handling of I r.adiated FERTF 8-rod bundle fuel elements in the PRTR fueling vehicle, it will be necessary to introduce a water stream from above the element to provide the desired cooling of the fuel. Experiments were undertaken in the Hydraulics Laboratory to determine minimum water flow rates required to assure uniform fuel rod coverage using this proposed cooling method. It was found that with proper alming of the water stream a flow rate of 2 to $3 \mathrm{gpm}$ would be adequate to insure complete coverage of all fuel surfaces.

\section{Materials Development}

The deuterium-hydrogen ratıos of two zircaloy-2 specimens exposed in the PRTR coolant $\left(D_{2} O\right)$ were determined by mass spectrometer analysis of gases extracted from the specimens. The deuterium content agreed with the in-fiux corrosion in $\mathrm{D}_{2} \mathrm{O}$.

An assembly of Zircaloy-2 corrosion specimens is being prepared to be charged into a PRTR fuel rod position. The assembly will be avallable for charging in september.

Pressure tube surface replication technıques were improved, and test specimens were being prepared during the period. No new results were developed during the period.

\section{Test Reacior Operation}

The PRTR operated to $51.5 \mathrm{MW}$ to produce $912 \mathrm{MW}$ d during August. The maximum reactor power remalned at a specific rod power limit of $17.1 \mathrm{~kW} / \mathrm{ft}$ on a "maximum tube" basıs. 
The total output from the PRTR is 2813 MWd of which 2360 MWd have been accumulated by the 55-fuel element batch core.

Batch Core Power Test \#6 (Transient Fission Product Poisoning) was completed while tests \#4 (Temperature Coefficients of Reactivity) and \#5 (Reactor Total Power Generation Measurement) were continued.

Radiation measurements made at selected locations of the PRTR systems show moderate increases in radlation level since May 1967.

There were ten unscheduled outages which required $11 \frac{1}{2}$ days. Included was one outage of eight days to replace an unusual size gasket in the primary heat exchanger steam export line. Six FERTF outages were experienced.

Seven process tubes were examined. There were no significant changes observed since their previous examination.

\section{NUCLEAR SAFETY}

\section{Containment Systems Experiment}

Additional analyses of data taken during air leakage rate tests of the CSE containment vessel were analyzed to assess the significance of temperature lags between containment alr temperature and the temperature of the centrally located reference vessel tubing. The calculated leakage rate over the test duration was not significantly different with or without treatment of the small observed temperature differences. It was concluded that temperature lag errors compensated over the test duration.

Aerosol sample Maypacks used in the Aerosol Development Facility (ADF) were compared with ORNI Maypacks during a run in the ADF with iodine, cesium, ruthenlum, and Zircaloy clad $\mathrm{UO}_{2}$ aerosols. Such comparisons are desirable to increase confidence in results of aerosol transport experiments carried out at different laboratories. The ADF and ORNI Maypacks showed nearly equal alrborne concentrations later in the run. Early samples in the ORNL Maypacks showed lower concentrations than the ADF Maypacks. This is believed to result from larger losses in the in let manifold of the ORNL sampler.

Analysis of blowdowns in the CSE reactor simulator vessel under saturated and subcooled initial coolant conditions was begun to compare experimental results with those predicted by existing mathematical models. Reasonable agreement with models was obtained in both cases through use of nozzle coefficients determined from single phase flow tests and applied to the model predictions. 


\section{Pressure Vessel Crack Monitoring}

Noise accompanying crack formation and growth in A212B steel will be studied using piezoelectric transducers on fatigue cracked single edge notch fracture specimens.

A jolnt experiment with Battel le-columbus on a 24 " diameter by 1.64 " wall A-106-B carbon steel plpe was successfully completed. The acoustic emission monitor system permitted confident anticipation of the actual, and spectacular fallure by several minutes. This test also provided an opportunity to obtaln acoustic emission data during boiling conditions, and the results were most encouraging since boiling noise emission ail appears to be below the frequencies associated with flaw growth and propagation. Detalled analysis of the data obtained during this test is in progress.

Work was initiated on a system analysis study of the acoustic emission concept, and the varlous critical parameters associated with the concept are being identified and evaluated. A set of basic detection assumptions was formulated, and their validity will be testea using both empirical and analytical methods.

\section{Fission Product Aerosol Contalnment}

Techniques developed earlier permitted measurement of rate constants for the reactions of several addıtıonal compounds with methyl lodide. Most rapid reaction rate was shown for ammonium. sulfide. A correlation was established which relates the rate constant of a reaction of a compound with methyl lodide to the nucleophilic constant of the reactive compound. This relation will help predict the expected rate constants for potential scavenging reactions.

Washout of methyl iodide by 140-mlcron droplets of 5\% hydrazine was found to occur with a half-life approximately that predicted by a model which takes into account the reaction rate constants.

\section{Columbia River Sedimentation Studies}

Inventories of radionuclides in Columbia River sediment between the reactors and Pasco, Washington, were calculated from weekly depletion data and found to range from 2000 curies in July to 20,000 curies in April. Cr-5 I accounted for 0.8 of the total inventory during the winter and spring but was rapidly removed by the spring freshet. 
Soil Chemistry and Hydrology

Soll column and equilibrium experiments showed that both cesium-137 and strontium-90 in 340 Bullding wastes adsorb well on soll. The results of these and previously reported studies show that this waste is suitable for ground disposal if radionuclide concentration limits are not exceeded.

The ultimate, steady-state water table elevations resulting from Irrigating the upper cold Creek Valley-RIverland area (northwest sector of project) would se about 40-80 feet higher beneath 200 west Area and 10-15 feet higher beneath 200 East Area than presently exist.

\section{$\underline{\text { Radioactive Residue Process Development }}$}

Pot calcination Run PC-5 was successfully completed with $1,200,000$ curies of radioactivity solidified in an 8-inch diameter pot. The 4300 watts of self-generating heat in the $86 \mathrm{Kg}$ of calcine produced a maximum temperature drop within the pot of $495{ }^{\circ} \mathrm{C}$.

The failed melter furnace for the WSEP spray solidifier is being repaired remotely.

Heat evolution rate on pot from WSEP runs and SS-2 was measured to be 1.5 kilowatts.

The melt receiver pot foamed over during a spray calcinercontinuous melter run using a PW-2 flowsheet. The present assessment of the situation is that the foaming resulted from the particular combination of a relatively high flux concentration, a relatively high melt temperature, and the geometry (high L/D ratio) of the receiver pot. The phenomena will be thoroughly explored to define more closely the parameters affecting foaming in this system and thus minimize the possibility of such an occurrence during the hot cell demonstration runs.

A run was made with $\mathrm{PW}-1$ flowsheet wherein a considerable amount of melt leaked through one of the thermowelis inserted from. the pot bottom. The pot is being $x$-rayed to determine if and where the thermowell tailed. A complete ultrasonic scan is also being made to look for pot wall corrosion, and the thermowell tubing is being analyzed to confirm whether the alloy is the specified 304-L SS. 
DIVISION OF REACTOR DEVELOPMENT AND TECHNOLOGY PROGRAMS (F.W. Albaugh)

\author{
CIVILIAN OWER REACTORS
}

Liquid Metal Fast Breeder Reactor (R.E. Nightingale)

Stoichiometry Effects in Oxide Fuels

Irradiation of $12 \mathrm{UO}_{2}-25$ wto $\mathrm{PuO}_{2}$ fuel pins with $\mathrm{O} / \mathrm{M}$ 's of $1.92,1.97,1.99$, and 2.00 is in progress. Purpose of the experiments is to assess stoichiometry effects on the heat rating required for melting. One capsule containing pins with O/M's of 1.92 and 2.00 was discharged from the reactor and sent to Radiometallurgy for metallography. Forty-eight flux-monitor wires (Al - 0.l wto Co) from this capsule were removed and analyzed to provide a complete three-dimensional flux map for the capsule during irradiation.

Composition gradients in nonstoichiometric $\mathrm{UO}_{2}$ fuels irradiated with nonmolten centers are being studied. Capsules containing $\mathrm{Un}_{1.90} \mathrm{UO}_{2.00} \mathrm{UO}_{2.02} \mathrm{UO}_{2.05} \mathrm{UO}^{\prime}$ and $\mathrm{UO}_{2.15}$ were 1 rradiated at ' ${ }^{\mathrm{T}} \mathrm{T}_{\mathrm{S}} \mathrm{K}$ dt's of approximately $53 \mathrm{w} / \mathrm{cm}$ and sent to Radıometallurgy. Sections were cut from each specimen for metallography, autoradiography, and radial o/U sampling.

Cooling Rate Effects in Molten Center Oxide Fuels

Varlations in structure and fission-fragment distribution in molten center $\mathrm{UO}_{2}$ fuels discharged from the reactor at various controlled rates are being studied. The rate of movement of the solidliquid interface for scram times of $0.01,1,5,10,20,40,60,180$, and 360 seconds was calculated using the Tiger $V$ computer code. The rate for all cases was nearly constant and increased uniformly with scram time. Solutions for $10,20,30$, and 40 minute scram times are in progress. When these are completed, a series of irradiations will be chosen to best study porosity and impurity segregation in terms of zone-refining parameters. Capsules for ten such experiments were tabricated, and the $\mathrm{UO}_{2}$ fuel is being pressed and sintered.

\title{
Power Reactor Design Studies and Evaluations (J.C. Fox)
}

Thermal Sink Limitation Study

Gross heat capacity i.e., the amount of heat required to raise the temperature of the stream $1 O_{F}$ ) calculations have been completed for the major streams in the following areas: Ohio River Basin, 
Cumberland River Basin, Tennessee River Basin, St. Lawrence River Basin, Hudson Bay Basin, Upper Mississippi River Basin, Missouri River Basin, Colorado River Basin, Pacific Slope Basin (California), Alaska.

Streams studied in these areas include the Ohlo, Wabash, Cumberland, Tennessee, Menominee, St. Joseph, Manlstee, Black, St. Lawrence, Oswego, Upper Mississippl, St. Crolx, Chippewa, Wisconsin, Rock, Illinols, Missourl, Colorado, Green, Sacramento, and Klamath Rivers.

\section{Steam Cooled Fast Reactor}

The parametric study is being done in the manner we feel will produce the most useful information in the limited available time. Three designs are being examined to determine the effect of pressure and temperature on their performance. The designs could be generally described as conservative, optimistic, and intermediate. The effect of geometry variables and design criteria on the performance of the intermediate design at an intermediate pressure is being examined. The effect of fuel streamlining, clrculator efficlency, and plutonium cost are being included in the sensitivity studies around the intermediate design,

\section{USAEC-AECL Cooperative Program (J.J. Cadwell)}

In-Reactor Measurements of Creep in Zr-2.5 Nb Alloy

Plotting and calculating of creep rates for in-reactor and unirradiated control tests have been brought up-to-date and are summarized in tabular form. These results cover a temperature range of 300 to 400 OC at stress levels ranging trom $25: 6$ to $52.7 \mathrm{~kg} / \mathrm{mm}^{2}$. Work is continuing to fill in the gaps where data are nonexistent and to determine the stress and temperature dependence of the minimum creep rate. Where it is known that the minimum creep rate was not achieved, the creep rate is inciexed with a "T". 
Summary of Creep Rates and Test Conditions

\begin{tabular}{|c|c|c|c|}
\hline$\underset{{ }_{\mathrm{C}}}{\text { Temp. }}$ & $\begin{array}{l}\text { Stress, } \\
\mathrm{kg} / \mathrm{mm}^{2}\end{array}$ & $\begin{array}{r}\text { In-Reactor } \\
\text { Strain Rate, hr } 1 \\
\end{array}$ & $\begin{array}{l}\text { Unirradiated Control } \\
\text { Strain Rate, hr-l }\end{array}$ \\
\hline 300 & 25.6 & $4 \times 10^{-7}$ & $1.5 \times 10^{-7} \mathrm{~T} *$ \\
\hline 300 & 31.6 & $4 \times 10^{-7}$ & $1.0 \times 10^{-7} \mathrm{~T}$ \\
\hline 300 & 38.7 & $6 \times 10^{-7}$ & $2.0 \times 10^{-7}$ \\
\hline 300 & 52.7 & -- & $1.3 \times 10^{-5}$ \\
\hline 320 & 38.7 & $1.3 \times 10^{-6}$ & $9.0 \times 10^{-7}$ \\
\hline 350 & 25.6 & $4 \times 10^{-7}$ & $5.5 \times 10^{-7}, 5.0 \times 10^{-}$ \\
\hline 350 & 31.6 & $1.5 \times 10^{-6}, 1.4 \times 10^{-6}$ & $1.6 \times 10^{-6}$ \\
\hline 350 & 38.7 & $1.2 \times 12^{-5}$ & $1.1 \times 10^{-5}$ \\
\hline 375 & 25.6 & -- & $2.1 \times 10^{-6}$ \\
\hline 375 & 31.6 & $8.3 \times 10^{-6}$ & $1.2 \times 10^{-5}$ \\
\hline 375 & 38.7 & $7.0 \times 10^{-5}$ & $8.1 \times 10^{-5}$ \\
\hline 400 & 25.6 & $7.6 \times 10^{-6}$ & $8.5 \times 10^{-6}, 1.1 \times 10^{-}$ \\
\hline
\end{tabular}

*T signifies strain rate measured during first stage creep and would be lower if it were measured during steady-state stage of creep.

In-Reactor Corrosion of Zirconium Alloys

In the preceding monthly progress report (July 1967), corrosion data were reported for specimens of six zirconium alloys exposed eight cycles (174 days) in the G-7 loop of the Engineering Test Reactor (ETR). Exposure conditions were $\mathrm{pH}-10 \mathrm{NH}_{4} \mathrm{OH}$, $0.05 \mathrm{ppm} \mathrm{O}_{2}$, 270-280 ${ }^{\circ} \mathrm{C}$. To summarize the hydrogen absorption data:

- Zircaloy-2 and the prefilmed Zr-Cr-Fe alloy showed a marked upturn in oxidation rate at the high flux position; these alloys also show a proportional upturn in hydriding rate. While hydrogen absorption has not yet been determined for the Zr-Cu-Fe alloy, the alloy was obviously embrittled. The percentages of corrosion hydrogen absorbed at the high flux position were less than 50\%, and in the case of the prefilmed $\mathrm{Zr-Cr}-\mathrm{Fe}$ alloy the value was only $18 \%$.

- Hydrogen absorption at the high flux position was relatively low for Zircaloy-4, Zr-3Nb-ISn, and etched $\mathrm{Zr}-\mathrm{Cr}-\mathrm{Fe}$. The absorption values were factors of 3 to 5 lower than the values for Zircaloy-2.

- Hydrogen absorption was lowest for the Zr-2.5Nb alloy. Prefilming had a pronounced adverse effect on hydrogen 
absorption in the Zr-Cr-Fe alloy. On the other alloys prefilming had only a slight adverse effect.

- At the low flux and out-of-flux positions, hydrogen absorption was lower than at the high flux position. on etched speclmens, percentage values were comparable at the out-of-flux and in-tlux positions.

A 4-cycle test (Quadrant 243: was exposed in the ETR G-7 loop to investigate effects of prefilm conditions on the in-flux corrosion of zirconium alloys. Time at temperature was 84 days. The estimated fast fluence was $7 \times 10^{20} \mathrm{n} / \mathrm{cm}^{2}$. The prefil $1 \mathrm{~m}$ conditions are summarized in the table. Three zirconium alloys were tested: Zircaloy-2 (conditions a-f); Zr-2.5Nb (conditions a-1); Zr-1.2Cr$0.08 \mathrm{Fe}$ (conditions $c, d$, and $f$ ). Exposure times were adjusted for the three alloys in an attempt to arrive at the same prefilm welght gains. Summarizing the weight gain results:

- Accelerated corrosion occurred on all Zircaloy-2 and Zr-Cr-Fe specimens. Corrosion on $\mathrm{Zr}-2.5 \mathrm{Nb}$ specimens was accelerated for conditions a through $e$, For condltion $f$, the weight gains were similar to out-of-flux welght gains from a previous 4-cycle G-7 loop test.

- Welght galns on the $\mathrm{Zr}-2.5 \mathrm{Nb}$ alloy were consistentiy lower than welght gains on the other two alloys. Highest influx welght gains occurred for conditions $a$ and $b$. However, condition b specimens had relatively high welght galns after the prefilm treatment, which may have influenced the in-flux exposure, Differences in in-flux welght galn between prefilm conditions $c, d$, and $e$ were not appreciabie. The most beneficial treatment for $\mathrm{Zr}-2.5 \mathrm{Nb}$ specimens was prefilming in oxygen at $400{ }^{\circ} \mathrm{C}$.

- Weight gains on Zircaloy-2 specimens were higher than corresponding welght gains on $\mathrm{Zr}-2.5 \mathrm{Nb}$, and lower than weight galns on the Zr-Cr-Fe alloy. The in-tlux welght gains were relatively insensitive to inltial pretreatment condition and resulted in the lowest weight gain on Zircaloy-2,

- Highest weight gains occurred on prefilmed Zr-Cr-Fe specimens. The least deleterlous treatment for Zr-Cr-Fe alloy was condition $d$, as in the case of Zircaloy-2.

$\underline{\text { Prefilm Conditions }}$

\begin{tabular}{|c|c|c|}
\hline Temp., ${ }^{\circ} \mathrm{C}$ & Time, hr & Medı um \\
\hline a. As-etch & & \\
\hline b. $\quad 280$ & $240-304$ & Water \\
\hline 360 & $60-120$ & Water \\
\hline 400 & $24-72$ & Steam (100 psl) \\
\hline 400 & $85-120$ & Steam 100 psi \\
\hline 400 & $305-216$ & Oxygen (i atm) \\
\hline
\end{tabular}


Effect of Wart Spacers on Parallel Channel Flow Mixing

Data for all-liquid flow through rod bundles have shown that fuel rod spacers (warts, wire wraps, grids, etc.) may cause a threefold increase in mixing of the coolant in adjacent coolant subchannels. The validity of extending this observation for single phase flow to two-phase flow cannot be established analytically. Therefore, information is required to define the effects of spacers during two-phase flow. The purpose of this program is to develop this information for wart-type spacers.

Experiments will be performed on an electrically heated test section used in earlier mixing studies. This test section simulated two adjacent channels formed by 0.563-inch diameter rods on a square pitch array. This test section is 5 feet long and is capable of simulating rod spacings of 0.020 and 0.084 inch. Modifications have been completed on this test section to simulate wart spacers 1/8 inch wide, $\frac{1}{2}$ inch long, and have a height dimension corresponding to a 0.020 inch rod spacing. The ends of the spacers are shaped to approximate the BLW 250 reactor spacer design.

Installation of the test section with the 0.020 inch spacers is nearly complete, and experiments are scheduled to start immediately. Experimental conditions for these tests are expected to be the same as in the previous tests so a direct comparison can be made to determine the influence of the spacers.

Operation of the test section will be about the same as in the previous experiments performed without spacers. The amount of mixing will be determined by injecting tracers into one of the two parailel channels and measuring the tracer concentrations at the exits of the channels. A combined tracer solution will be used for the experiments, consisting of heavy water containing lithium hydroxide. The heavy water also contains tritium which acts as a tracer with the same behavior as heavy water but with higher measurement accuracy. Injection of these three tracers will allow simultaneous tracing of the lıquid and vapor phases and permit a more efflcient and accurate experiment.

The heavy water and tritiom tracers will be used to determine the total mixing of both phases between the adjacent channels during bolling. The concentration of heavy water in the samples taken at the exits of the channels will be measured by means of infrared spectrophotometry. This technique compares the infrared absorption band of hydrogen-deuterium against a predetermined standard. The tritium concentration will be measured by determining the radioactivity of the water sample. The lithium tracers will be used to determine mixing between only the liquid phases, since the lithium will remain in the liquid phase during vaporization. Lithium concentrations will be measured by flame photometry. This technique compares the emission of exclted lithium to a laboratory standard. 


\section{Heavy Water Reactor Program Office (H. Harty)}

Heavy Water Reactor Information Center

Information retrieval techniques and the general structure and operation of some existing information centers have been studied to help set up a Heavy Water Reactor Information Center (HWRIC) at Battelle-Northwest.

It is recommended that the Uniterm system of Coordinate Indexing be adopted as the method for the organization, storage, and retrieval of information processed in the HWRIC. Coordinate indexing may be defined as a process or procedure in which information items are filed or retrieved by correlating, or bringing into correlation, those terms or concepts which best describe the information they contain.

The Uniterm System is simple to use, is very effectıve, and is economical. It is extremely effective as a manual system, and it can be converted easily to a computer operation. This is the type of system now advocated b: the Amerlcan Institute of Chemical Engineers (AIChE) and the Engineers Jolnt Council (EJC) for personal fling systems.

The staft selected to set up and operate the HWRIC should be predominately technical. It should have a high percentage of competent specialists in the varıous technical disclplines which make up a heavy water reactor technology.

A preliminary draft of a report on this study has been completed and is now being typed.

APPLIED AND REACTOR PHYSICS

Plutonium Criticality Studies (E.D. Clayton)

Criticality Studies of Plutonium Compounds in Undermoderated Range

Data from previous experiments performed with plutonium-plastic mixtures have now been analyzed, yleiding values of critical buckling and extrapolation length. The experiments are part of the basic criticality studies for determining the critical dimensions and masses of undermoderated Pu systems and the effect of $\mathrm{Pu}-240$ on criticality. The fissile material was in the form of $\mathrm{PuO}_{2}-\mathrm{poly}-$ styrene compacts wrapped with 7 mil MMM \#471 tape for contamination control. The H/Pu ratio was 5 with the $\mathrm{Pu}-240$ isotopic content being $11.5 \mathrm{wt}$. The assemblies were comprised of Lucite reflected rectangular prisms. The average stack density of Pu over the cores was $2.17 \mathrm{~g} / \mathrm{CC}$. 
The material or critical buckling was determined from measurements on four different core configurations as $19,600 \times 10^{-6}$ $\mathrm{cm}^{-2}$. Making use of constant buckling conversions, the extrapolation length for an infinite slab reflected with Lucite was found to be $8.25 \mathrm{~cm}$. The critical thickness for a lucite reflected infinite slab with the above fuel composition was determined to be $\because 6.5 \mathrm{~cm}$.

\section{Studies of Neutron Spectrum}

Further tests were done with the small spherical proton recoil spectrometers that were obtained for neutron spectrum measurements. These counters were tested at the University of Washington using the neutron beam port from the reactor to check resolution and calibration. To facilitate calibration nitrogen was added to the filling gas in one of the counters; the ${ }^{1} 4_{N}\left(n_{1} p\right){ }^{14} \mathrm{C}$ reaction provides an additional measure of resolution. The resolution of the counter contalning nitrogen was found to be worse than before; which is indicative of contamination in the filling gas. This will necessitate refilling the counter. In connection with the further testing and calibration of the counters. preliminary measurements of the neutron leakage spectra are currently being made on an unreflected homogeneous $\mathrm{PuO}_{2}$-polystyrene assembly having an $\mathrm{H} / \mathrm{Pu}$ atomic ratio of 15

Theory and Analysis

Further calculations were made on the IBM-7090 with the British Monte Carlo Code, GEM 3, to check the code"s applicability and reliability for computing criticality of complex geometries and interacting arrays. With few exceptions "for the cases compared thus far " agreement between computed and measured criticality has been very gooä. Criticality factors (keff) ranging between 0.99 to l.01 have been obtained for various systems that include interacting arrays of $\mathrm{U}=235$ metal, U-233 solution arrays; Lucite reflected parallelepipeds of $\mathrm{PuO}_{2}$-polystyrene ( $\mathrm{H} / \mathrm{Pu}$ of 15$)$, and $\mathrm{Pu}\left(\mathrm{NO}_{3}\right)_{4}$ solution in an unreflected stainless steel slab shaped vessel. Standard deviations of about $\pm 1 \%$ can be obtained by running 2500-3500 neutron histories. The computer time involved is about one minute per one hundred his tories.

Although most geometries can be described using the standard GEM input, there are several types of problems that will require writing a special "hole" routine in order to describe the geometry of the system

Containment Tests of Reactor Room

In connection with the required containment tests, further work was done to improve the leaktightness of the reactor room Numerous small leaks inere located; by means of a freon detector, in the 
electrical condults piping, door seals, and in the walls via halrline cracks. Liberal use of silicone rubber and epoxy around condults and cracks inside the room met with moderate success Epoxy was also applied to cracks on the outside of the building but this has not been entirely successful. The current leakage rate $(12$ volo/hr) is between 3 - 4 times that of the bullding when new. The remaining leaks are distributed around conduits and also involve cracks in the walls, but these are generally quite small. Further efforts will be made to improve contalnment of the reactor room -

\section{Phoenix Fuel Reactor Program (D. D. Lanning)}

PRCF-Phoenix Fuel Experiments

Reactor noise data were recorded in the PRCF-Phoenix core, with detectors in three locations: (1) center of the core, (2) in the beryllium reflector, and (3) in the $\mathrm{H}_{2} \mathrm{O}$ top reflector No interpretable results were obtained from the chambers in the $\mathrm{H}_{2} \mathrm{O}$ top reflector. Satisfactory results were obtained from the chambers in the beryllium reflector and in the center of the core. Results of the analysis of the recordings are listed below

\section{PRCF-Phoenix Fuel Reactor Noise Analysis}

$\begin{array}{lcccc}\text { Excess Reactivity } & (p) & 0.0 \$ & -0.88 \$ & -1.65 \$ \\ \text { Core } & \frac{E-p}{\ell} & 62 \pm 3 & 102 \pm 4 & 143 \pm 4 \\ \text { Center } & & & \end{array}$

Analysis of the data from the chamber in the beryllium reflector recorded at critical only: produced results not significantly dif= ferent from the chamber located at the center of the core

Measurements were made of the reactivity worth of removal of a whole element from the center of the core $(Y=5)$, and of removal of single plates from an element at the center of the core $(Y-5)$ and at the side of the core $(x-5)$. The results are listed in the table There are 16 plates in an element, numbered sequentially 1 through 16. The accumulated worth of removing the central five plates sequen-

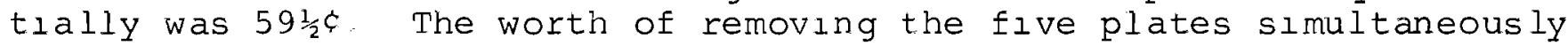
was $58.2 c$. 
Reactivity Worth of Fuel Elements and Fuel Plates

\begin{tabular}{|c|c|c|c|c|}
\hline Location & Plate No & Reactivity & Change & upon Removal \\
\hline$Y=5$ & Entire element & $=6.3$ & & \\
\hline$Y=5$ & $\begin{array}{l}8 \\
9 \\
7 \\
10 \\
6\end{array}$ & $\begin{array}{l}+42.9 \\
+18.6 \\
+19.6 \\
-0.7 \\
-21.0\end{array}$ & 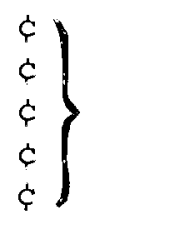 & $+59 \frac{1}{2} \&$ \\
\hline$Y=5$ & $6,7,8,9,10$ & & & $+58.2 \xi$ \\
\hline$x=5$ & 8 & $+243 /$ & $14 \%$ & \\
\hline
\end{tabular}

Additional measurements were made of the reactivity worth of a simulated MTR regulating rod. Total rod worth was $26-7 \dot{c}$; with a worth over the normal MTR operating range of $2 \xi$. Translation of the rod from the position of the measurement in the mockup to the actual MTR location in the reflector would increase the worth by perhaps a factor of 1 . 8. Measurements with the regulating rod at a point six inches further out in the reflector produced no detectable reactivity change.

Measurement of the temperature coefficient of reactivity was extended to $458{ }^{\circ} \mathrm{C}$. The coefficient was negative over the entire range from 30 to $58 \mathrm{\circ}^{\circ}$, and became more negatıve with increasing temperature: with values ranging from $=2.2 \mathrm{c} /{ }^{\circ} \mathrm{C}$ to about $-4 \xi /{ }^{\circ} \mathrm{C}$.

Measurements of the shutdown margin of the shim rods were completed. Withdrawal of all four interior shims was possible without achieving criticality. However, withdrawal of two peripheral and two interior shims on the same end of the core produced a critical core

An extensive series of measurements has been made of the reactivity changes associated with loss of coolant from the core. $\mathrm{H}_{2} \mathrm{O}$ coolant was excluded from selected coolant channels in selected elements by inserting aluminum or Teflon strips. The results of the measurements are summarized in the table. The strips were as long as the fuel plates and were either partial width $(0,267$ void fraction) or full width ( 0.80 void fraction). The partial width strips were positioned either at the center of a coolant channel or at one side of the channel. 
Reactivity Worth of Simulated Volds (in cents)

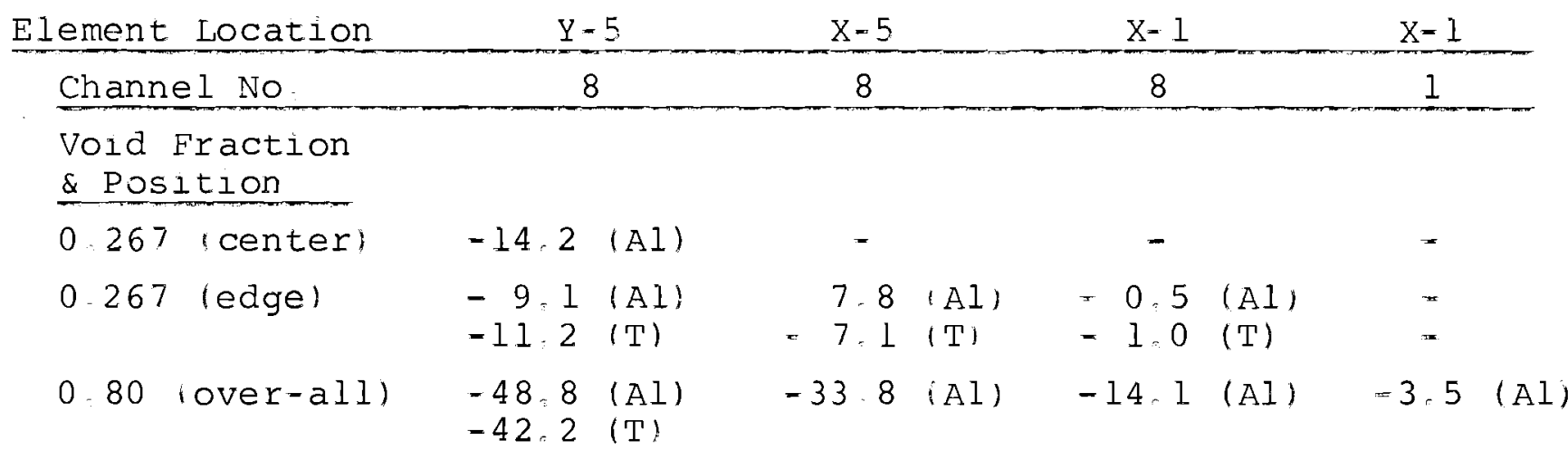

The results show a reduction in the magnitude of the vold effect as the position of the vold was moved from interior of the core toward the edges.

PRCF-Phoenix Fuel Calculations

A two-dimensional diffusion theory calculations in four energy groups and 729 spatial mesh points was completed using two different codes. A homogeneous model of the rod-free PRCF core as described in the previous monthly report was used. A value of keff which was 6\% high was calculated with both codes (TWENTY GRAND and EXTERMINATOR). The same set of nuclear data which was used in the CAF analysis was used in the present calculations. Experience with the CAF calculations leads one to believe that a large part of the discrepancy between the calculation and the experiment can be removed by refining the energy mesh in particular, but also, perhaps, the spatial mesh. A systematic investigation of the space-energy mesh dependence is therefore currently under way. The CAF analysis showed that the change from 4 to 17 energy groups lowered the computed keff by 1 , 5\% The PRCF computed core spectrum is much harder than the CAF; hence. one would expect that a much greater group dependence would in fact exist for the PRCF experiment.

Another possible source of the 6\% discrepancy is the much greater Pu-240 content of the PRCF fuel: actually $20 \%$ versus on ly $18 \%$ for the CAF. This eftect can be investigated using multiple thermal groups, although this calculation is somewhat cumbersome to perform. One dimensional diffusion theory calculations to estimate the magnitude of the effect will, therefore, be attempted.

While performing the two-dimensional diffusion theory calculations, a factor of 425 increase in speed was noted for TWENTY GRAND as currently implemented on the 1108 versus the 1107 . Compared to EXTERMINATOR implemented on the 7090 and considering the difference in price for main frame time, the 1108 two-dimensional calculation is about half the former cost. Unfortunately, $20 \mathrm{G} 15$ limited to 
on ly six groups. Some real savings in computation time could be realized if EXTERMINATOR could be implemented on the 1108 .

MTR Core - Thermal Hydraulic Analysis

Calculations have been completed that indicate the MTR can be operated at $37 \mathrm{MW}$ with the Phoenix core if a pressure head of 73 psia is maintained. The nominal heat flux at the hot spot in the hottest channel under these conditions is 1 x $10^{6} \mathrm{Btu} / \mathrm{hr}-\mathrm{ft}^{2}$ which is the limiting factor. Neither inclpient nucleate boiling nor burnout heat flux limits are controlling criteria.

MTR Core - Mechanical Design

An attempt was made by MTR operations to determine the status of the position L-42 shock absorber. The attempt was unsuccessful due to the numerous monitor tubes and inadequate lighting to determine even if a shock absorber was in place. They feel they will be unable to determine the condition of the shock absorber until the MTR beryliium pieces are changed during the Phoenix core loading. It therefore must be assumed that the $L=42$ shock absorber is gone or unusable and a mechanically coipled rod must be designed that will not scram.

The shipping date for the two simulated MTR Phoenix fuel elements has been changed to 9/15/67. The delay appears to have been caused by the nonstandard side plates and fuel plates which created some special procurement problems.

The handling device has been designed for removing the flux monitoring wands from the Phoenix fuel elements. A simplified version will be fabricated at BNW and tested when the simulated fuel pieces arrive. This testing will be done before the elements are sent to Idaho for hyảraulic testing.

\section{MTR Phoenix Experiment}

Specifications Phoenix fuel Element and Shim Roa Specifications have been completed and forwarded to the AEC Reactor Development and Technology Division and to INC for review and concurrence. While these specifications are in final format, there are several areas still subject to modification--depending upon the results of Physics tests and fuel development work now in progress.

Shim Control Rod Fuel Section. At the request of Reactor Physics; the design of the shim control rod fuel section has been modified to contain thirteen fuel plates instead of twelve. The plate spacing was changed to duplicate that used in the fuel element. A thirteenplate element was fabricated aid delivered to the Nuclear Experiments and Analyses group for testing in the PRCF experiment. 
MTR Irradiation Test In June, an irradiatıon test element was fabricated and shipped to INC for charging, pending results of destructive testing of representative fuel elements. The destructlve testing revealed questionable bond areas on the clad to frame and clad to core bond interfaces. Although the test plates passed all standard blister and ultrasonic testing the charging of the test element was cancelled due to the questionable nature of the bond interfaces. The following actions were taken to eliminate potential bond problems and expedite fabrication of a new test element

1. A study of bonding requirements and the experience of plate fabricators revealed that while a metallurgical bond is a universal standard in metallic plate fuels, there is no universally accepted method of measuring bond quality:

2. Rolling tests were performed with 6061 aluminum coupons at temperatures of 500,530 ; and $560{ }^{\circ} \mathrm{C}$ and reductions of $6: 1,8: 1,10.1 ;$ and $12: 1$

Shim Rod Dummy Element. Commercial fuel fabricators were requested to quote on the fabrication of a dummy fuel section for the Phoenlx shim control rod to provide a roll swaged and welded fuel section for drop and hydraulic testing. Only one vendor, National Lead, quoted on the job, and the price was considerably higher than estimated. Negotiations are being held with National Lead in an at tempt to obtain a more favorable price and delivery.

Phoenix Plate Test Element

A proposal to irradiation test a Phoenix plate element in MTR was prepared. The test is designea to allow experimental Phoenix fuel plates of near-prototypic size to operate close to the maximum allowable hot spot-hot channel conditions in the MTR. The objectives of the test are to demonstrate that Phoenix fuel plates will operate satısfactorily at MTR design conditions and to provide 1 rradiated fuel plates for evaluation of fuel stabllity at high burnups. The primary testing parameters are:

Fue 1

Burnup

Max hot spot cladding temp Max hot spot surface heat flux
Al-20 wto $\mathrm{Pu}$ (high exposure) alloy To $30 \%$ burnup of $\mathrm{Pu}$ atoms $(6 \mathrm{MTR}$ cycles) $321 \mathrm{OF}$ $1.08 \times 10^{6} \mathrm{Btu} / \mathrm{hr}=\mathrm{ft} \mathrm{t}^{2}$ 


\section{Phoenix Fuel Applications}

HFIR Calculations. Information has been received from oak Ridge National Laboratory regarding their standard method for analyzing the High Flux Isotope Reactor (HFIR). Their usual method of approach involves a thirty-three energy group; twenty-five region, one-dimensional diffusion calculation in cylindrical geometry. The epi-thermal cross sections are obtained from the GAM code and the thermal cross sections come from the THERMOs code.

Four-group, twenty-five region diffusion calculations are in the initial stages to determine the feasibility of analyzing the HFIR core by simpler procedures. The geometry and nuclear densities from the Oak Ridge data are being used in these HFIR calculations since this description of the core is the most detailed. The case under investigation is the standard HFIR uranium core, using boron=10 as a burnable poison, with no target material in the flux trap

CNSG studies. A number of CNSG heat transfer limited cores are being examined to fina the effect of pin diameter, fuel volume fraction, and plutonium composition on fuel cycle cost. The cost calculations for the various designs have not been completed. It appears that the nuclear advantage of going to tighter lattices is negligible compared to the increase in the number of fuel pins required and the increased pressure drop.

PRTR Caìculations. A burnup calculation was performed using the $z \overline{O D I} \overline{A C}$ code for a PRTR loading of $19 \mathrm{UO}_{2}-2$ wto $\mathrm{PuO}_{2}$ ceramic Iuel elements surrounded by $66 \mathrm{Al}$ - 10 wto Pu metallic fuel elements All of the fuel elements had a 60-inch active length. Initially: the ceramic elements were assumed to have an average exposure of 13.000 MWd/ton and the metallic elements were unirradiated. The Ilfetime of this core was calculated to be 400 days at 70 Mv power level. At the end of core life, the average exposure on the ceramic elements was increased to $20,000 \mathrm{MWd} / \mathrm{ton}$.

\section{High Temperature Reactor Lattice Physics Studies}

Reactor construction

(R.E. Heineman)

The construction jobs described be low were exceptions to the Project which were required for nuciear startup. With these items completed, all construction forces left the HTLTR facility about mid-month.

After installation of the horizontal control rods: the insertion times were longer than expected. This was found to result from alignment problems and from dimensionai limitations on the gas seal. These were corrected, and the installation of all nine rods was accepted. 
Installation of all wirlng and piping to both osclilators was completed. and the installation was accepted.

The four pneumatic switch devices which monitor the position of the vertical safety rods were installed, checked out; and accepted.

The installation of the vibration monitor and the ammeter for the main gas blower was completed

Reactor Equipment

Oscillators. The oscillators have been installed in the 318 Bullding, and all electrical, hydraulıc, and cooling connections have been completed.

Vertical Safety Rods Installation of the gas jet type inlimit switches was completed on all four rod housings. The auxiliary plping and equipment was installed Assembly numbers "one" and "four" had no output; therefore; the differential regulator feeding these two switches was removed and disassembled. The small passages in the seat area were almost filled with teflon tape (apparently from the threaded connections in the plping system). After the regulator was cleaned and installed; all swltches had satisfactory output. With the inlet pressure set at 1.5 psi differential; the output readings were VSR $1 ; 0.22 \mathrm{ps}$, VSR-2.0.22 psi, VSR-3; $0.24 \mathrm{ps} 1$; and VSR-4, 0.16 psi. The assoclated pressure swltches were adjusted and operated satisfactorlly with these pressures

Modiflcation of the VSR drives was completed during the month. VSR-l drlve (the one damaged accldently at the reactor) was dis assembled completely; and all parts checked for damage. A new main shaft: brake disc; cam plate; cable and brake release cylinder were fabricated and/or procured and the unit was reassembled.

During subsequent testing of the four-rod assembiles at the reactor. erratic operation of the drives was observed. This erratic operation consisted of fallure of the drives to pull the rods and occasionally to reverse while pulling a rod, thus inserting the rod. At no time did a rod fall to scram. The drive that appeared to be most erratic was removed and partially disassembled to check alignment of the components. Significant misalignment was measured between the transmission output shaft iand attached clutch stator and rotor assemblies, and the maln shaft Apparently: adequate allgnment of these components was never achleved by the manu= facturer even though the assemblies were inspected and tested betore being accepted. The drlve was realıgned and worked much better. subsequently, the other three drives were removed and checked; and misalignment was corrected in all 
A simple pull test was conducted on the clevis, yoke, and pin that attach the cable to the VSR element. Three types of pins were tested. These were: (I) a standard roll pin (roll pins were specified in the original design), (2) hardened steel pins, and (3) nonhardened steel pins. Both steel pins were drilled for cotter keys to hold them in place. Tests were not run to destruction, but the roll pin was loaded to 1000 pounds and the steel pins to 1100 pounds. None failed. It is recommended that ${ }_{F}$ when using the solid pins and cotter keys, either the cotter keyhole be moved in or washers be used between it and the clevis to prevent the clevis from spreading. No tendency for this to happen was observed in the test, but if the pin were to bend slightly under repeated loading, this tendency would exist.

Horlzontal Control Rods. During testing of the HCRs installed in the reactor, some difficulty with the deceleration rolling diaphragm was noted. Inspection of the troublesome drives revealed marginal tolerance on some mating parts and misalignment of the actuating rod and latch block. Increasing the clearance on the parts associated with the rolling diaphragm and careful alignment of the drive components made the drives operate satisfactorily.

Programmed Measurement and Control system (PMACS). Arcing with subsequent early failure is occurring on the rod drive relay contacts Contact arc suppressors will be installed.

The aural core alarm has been modıfied to prevent spurıous oscillations and is now in full service.

The excessive noise on the flux digltizer has been eliminated by additional power supply filtering that was overlooked by the manufacturer.

A redesign of the safety circuit power amplifier is currently under way to provide additional current output. This will allow all rods to be driven simulatneously. Vendors were contacted to determine delivery dates for parts.

Since a part of the problems with the vertical safety rods was caused by the digital motors not being able to pick up the full weight of the rods immediately upon demand, a ramp input to the motors is being designed. Thus, the motors will pick up the load s low $\perp$,

\section{Reactor Operations}

The Operating Safety Limits were approved and issued by the Richland Operations Office.

The final draft of the Operating Specifications was completed. 
The reactor heating system was recalibrated after relocation of the heater control units in the basement

The locks for the bullding were changed upon completion of work by construction personnel

The horizontal control rods were tested finally. Their scram times were all less than 1.1 seconds for tull travel including deceleration time. Several minor modifications were required on two rods. These changes will also be made in the other rods later as malntenance work

The vertıcal safety rods were aiso tested finally. All rods scram in less than 1.3 seconds for full travel, including electrical delay and deceleration times. The pneumatic (gas jet) "in-Iimit" switches were calibrated and included in the rod operating programs.

During the initial calibration of the osclilators, the irregular response of both units to the control signal was attributed to dirt in the hydraulic pilot valves. These units were removed and sent to the vendor for cleanup and reassembly. Cleanliness in the hydraulic fluld is critical; and this will require strict operating an à malntenance procedures.

The recommended changes in the gas, heating, valve, and ADC programs which were discussed last month were completed. The output logging programs were essentially completed.

Work on the nuclear program was contınued. Observation of fluctuations in neutron signal and nolse was made possible by putting four high level PuBe sources next to the ion chambers. Observation of the automatic change in range of the flux signal was also possible on the lowest three ranges. However, a ramp signal was used to simulate the flux signal over the upper ranges. The final checkout of the nuclear program can of course, proceed only during the approach to critical experiments

The reactor doors were installed at the end of the month in preparation for the reactor and systems demonstration run. The purpose of this run is to:

1. Demonstrate automatic controi through GAS-HEAT and control through NUC-ROD with ali systems simultaneously operational.

2. Observe and record for future reference operating parameters of all systems

3. Demonstrate operability of rods and flux systems at temperature 
4. Allow inspection and observation by nuclear safety personnel from the Richland Operations office and Battelle-Northwest

Reactor Physics

Startup and Calibration Experiments. The document describing the startup and Calibration Experiments: BNW-CC-851, was reproduced and distributed.

Fabrication of the support tables which carry the weight of the experimental pieces was completed. Work was begun on the fabrication of the central and adjacent cells. Installation of these pleces will be done after the demonstration run. The design of the poison drawer was modified to use a l4-foot piece of graphite available from the heater material. Use of this material will eliminate the high precision machining necessary with the former design.

The drıver fuel load was shipped to the reactor storage facility. It contalned 264 fuels of 6 -inch length, 528 fuels of 10 -inch length, and 88 fuels of 60 inches length. The driver fuel load contained 1388,000 grams of 5. 1\% enriched in graphite cladding.

$\mathrm{U}^{233} 0_{2}-\mathrm{ThO}_{2}$ Experiments. Planning of the first lattice continued. The new design is close to the HTGR desıgn, but GA would prefer to use a hexagonal lattıce as approved to the square lattice proposed. Further consultation with GA on the actual lattice design is under way.

Development of calculational models to analyze the $\mathrm{U}^{23} 3^{3} \mathrm{O}_{2}-\mathrm{ThO}_{2}$ experiments has continued. In addition to incorporating the Nordheim integration scheme for treating resonance absorption, as previously reported the GAMTEC II code has been extended to include resonance capture by small spheres distributed randomly in a fuel channel. The technique utilized is similar to that applied by Czerniejewski in the GRAIN code; however, the new code has several advantages. (1) resonance parameters are directly used to evaluate resonance integrals, (2) Doppler broadening is included directly rather than requiring generation of a new cross section library, (3) hydrogen is treated in the NR approximation. The code as presently programmed is limited to absorbers in the spheres being different from the $a b-$ sorbers exterior to the spheres. The next step is to permit identical absorbers interior and exterior to the small spheres. 
REACTOR FUELS AND MATERIALS

Fast Fuels oxides and Nitrides (R, E. Nightingale)

UN - PuN Synthesis

The experimental program using the 8 - 1 nch spray calciner was curtailed during the month to awalt quantitative analytical data on the carbon content of the powders. One experimental run was made at a feed composition of $1.5 \mathrm{lM}$ uranium, $1.5 \mathrm{M} \mathrm{HNO}_{3}$; and $360 \mathrm{~g}$ sugar/l This composition corresponds to a sugar-to- uranium welght ratio of one. Run conditions and feed concentrations were essentially identical to earlier runs, but the run was made to provide fresh powder for analytical studies on nonunlformity of the powder at this sugarto-uranium ratio. As in two earlier runs, the powder was a heterogeneous mixture of fine black powder and brownish agglomerates roughly $1 / 16$ to $1 / 4-1 n c h$ in diameter. No quantitative analytical data on carbon content of the powder are yet avaliable, but lgnition studies indicate a wide variation in weight loss which is proportional to the carbon content. Welght losses were $6,2,114,20,5$, and 2.5\%, respectively. for a composite sample at the top of the collection pot, a composite sample at the bottom of the coliection pot, a sample of the agglomerates, and a sample of the fines after screening. These data along with ignition results now avallable from earlier runs indicate that at a sugar to-uranium ratio of one or above, a very nonuniform powder is produced. Future work will be directed towards producing powder with an adequate carbon content using lower sugar-to=uranilim ratios.

UN-20 wto PuN Peilet Fabrication

Process development on the fabrication of UN-20 wto PuN pellets was severely restricted this month because of excessive air leakage into the high purity atmosphere glove box used in pellet pressing Most of the period was spent in locating and repalring leaks in the gas purification system and in the glove box itself. A helium leak checker was used to locate leaks in the glove box. When a satis= factory gas atmosphere can agaln be malntalned in the glove box. pressing and sintering of pellets will be resumed

Mixed Nitride Synthesis

Carbon removal trom mixed uranıum-plutonıum carbonıtrides is being investigated. Thermodynamic and kinetic data indicate that pure hydrogen wll react with elemental carbon at a reasonable rate between 1000 and $1200^{\circ} \mathrm{C}$. The goal of this current study is to estabilsh whether carbon present with or dissolved in mixed nitrides could also be removed under these conditions. 
Two experiments at $1000^{\circ} \mathrm{C}$ were completed The first experiment with a two-gram sample of carbonitride containing 0 . 7\% carbon showed a decrease to 0 -4\% after a 20 minute hydrogen treatment The second experiment with six grams of carbonitride of similar initial carbon content was reduced in carbon content to $280 \mathrm{ppm}$ after a $60-m i n u t e$ reaction

The second experiment indicates that the hydrogen treatment is an effective method for removing carbon. More experiments are planned to determine the extent and the kinetics of the carbonhydrogen reaction,

Fast Fuels Mixed Nitrides

The UN synthesis cycle was modifled to yield nearly $100 \%$ fine graln UN powder Hydriding temperature was decreased from 300$325{ }^{\circ} \mathrm{C}$ to $200225{ }^{\circ} \mathrm{C}$ Upon completion of hydriding, the temperature was increased to 300-325 OC for dehydriding Nitriding of the $U$ powder was iniclated in a 50-50 mixture of $\mathrm{A}+\mathrm{N}_{2}$. Nitrogen was then added as the reaction proceeded. No exothermic peaks were observed as compared to previous cycles utilizing pure nitrogen. Efforts are being directed towards shortening the nitride cycle.

Since PuN powders are considerably coarser than UN powders. several charges of PuN were milled separately to improve milling efflclency It is believed that milling of the PuN (coarse) in a matrix of fine UN powder is not as effective as the above method. The milled PuN and UN - after blending and additional miling, resulted in sound green pellets which sintered to approximately $82 \%$ TD at $1800^{\circ} \mathrm{C}$. Resintering these pellets at $18750^{\circ} \mathrm{C}$ for four hours increased their density to approximately $87 \%$ TD.

Approximateiy 300 grams of UN powder and 75 grams PuN were prepared. About $350 \mathrm{mixed}$ nitride pellets were pressed and sintered in the NRC furnace elght runs). Pellets were readily centerless ground to dimensions by utilizing a medium hard, 220 grit aluminum oxide wheel. Because of the high carbon content (1500-3000 ppm): the pellets were rejected for irradiation testing. The source of the high carbon is presently being investigated

Irradiation of Mixed Nitrides

Two experimental fuel capsules (GEH-14-745 \& 746) containing mixed nitrıdes (UN-20 wto PuN) were discharged from the MTR after attaining exposures of approximately 20,000 MWd/ton. This makes a total of four such capsules that have now been discharged. Ir= radiation conditions for these capsules are summarized in the following table 
Operating Conditions for Mixed Nitride Test Capsules

$\underline{\mathrm{GEH}}=14=743 \mathrm{GEH}-14=744 \quad \mathrm{GEH}=14=745 \mathrm{GEH}=14=746$

Fuel-to- $\mathrm{Cl}$ ad Bond

Max Power kw/ft

Max Pin Surtace Temp ${ }^{\circ} \mathrm{C}$

Full Power Days In* Reactor

Exposure, Mwd, ton

Reactor

$\begin{array}{rc}\mathrm{Na} & \mathrm{He} \\ 35 & 23.8 \\ 800 & 519 \\ 5.9 & 33.2 \\ 2500 & 9500 \\ \text { ETR } & \text { MTR }\end{array}$

$N a$
31.5
697
55.6
20,200
MTR

$\mathrm{He}$

30.3

651

19,400

55.6

Inltial postirradiation examination of GEH=14-743 revealed that the fuel pin ruptured during irradiation projection radiography of the Irradiated capsule showed that a large vold formed in the outermost sodium annulus at a position coincldent with the end of the fuel column and that the pin cladding and some tuel melted in this area. This vold apparently formed during a reactor scram early in the irradiation. Calculations show that the sodium void in combination with the flux peaking that might be expected at the end of the fuel column could cause the pln cladding to melt. Destructive examination of this capsule is continuing.

\section{Basic Swelling Studies iR. D. Leggett:}

The purpose of this program is to characterlze and understand the behavior of tissionabie mareriais during irradiation. The theorles developed provide a basis for tre engineering exploitation of metallic tuel materials in advanced seactor applications. Specimens under study at the present tıme inciude uranıum with and without. dilute alloy additions and thorium=uranium alloys

Irradiation Program

Capsule P 16 was discharged atter operatıng successfully at design conditions of $625^{\circ} \mathrm{C}$ and 1000 psi to an estimated burnup of 0.35 at $\%$ in the $0.72 \%$ U-235 specimens and 07 at $\%$ in the specimens containing 1 4 4 \% U-235. The capsule contains several "Britishadjusted" specimens and high purity urarium.

Construction has started on capsuie $\mathrm{F}: 18,825{ }^{\circ} \mathrm{C} .50$ psi. $0.1=$ 0.7 at $\%$ BU) which contalns specimens of high purity uranium; several dilute uranlum base alloys and $T h=U$ alloys The status of capsules currently active is indicated below. The three 5000 psi capsules 'P-11 $\mathrm{P}-12$ and $\mathrm{P}-13$ ) will be charged as soon as the new regulator is installed in the high pressure controi system. 


\begin{tabular}{|c|c|c|c|c|}
\hline $\begin{array}{c}\text { Capsule } \\
\text { No. } \\
\end{array}$ & $\begin{array}{c}\text { Control } \\
\text { Temp : } \\
{ }^{\circ} \mathrm{C} \\
\end{array}$ & $\begin{array}{r}\text { Control } \\
\text { Pressure } \\
(\mathrm{psi}) \\
\end{array}$ & $\begin{array}{l}\text { Goal } \\
\text { Burnup* } \\
\text { lat : }\end{array}$ & Status \\
\hline$P=10$ & 450 & 5000 & $0,2=0,8$ & Shipped to Radiometallurgy \\
\hline$P=11$ & 550 & 5000 & $0,2=0.8$ & Construction complete \\
\hline$P=12$ & 625 & 5000 & $0,2-0,8$ & Construction complete \\
\hline $\mathrm{P}=13$ & 700 & 5000 & $0,2=0,8$ & Construction complete \\
\hline$P-14$ & 700 & 500 & $0.2=0.8$ & Under irradiation \\
\hline$P=16$ & 625 & 1000 & $0.35=0.7$ & Discharged \\
\hline$P=18$ & 825 & 50 & $0-1-0.8$ & Under construction \\
\hline
\end{tabular}

* Different burnups are achieved in a single capsule by including specimens of various enrichments.

The above irradiation capsules wil provide data needed to evaluate the effects of temperature lalpha beta. and gamma phase in uranium base alloys). pressure; burnup, burnup rate and minor alloying additives on the irradiation behavior of uranium and thorium-uranium.

Nondestructive Testing ( $J$ Co Spanner)

Eddy Current Methods

Multiparameter Studies. Conceptual design of a device for auto. matic setting of the matrix coefticient potentiometers in the multi. parameter eddy current tester was formulated and the design of cir. cuits for use in a feasibility test of the basic ideas is in progress. A sixteen potentiometer summing network using dials adjustable by tinger tip operation has been added to the test arrangement which is being developed to demonstrate the application of the multiparameter test principles to a pulsed eddy current test system. The prototype multichannel eddy current tubing tester has been mounted in its carrying case and is essentially completed Analysis of clrcuits used in the multichannel eddy current tubing tester, and analysis of an 1 dealized eddy current model representing the multiparameter eddy current tester have resolved some questions which arose in the course of laboratory evaluation of these two testers. These analyses have given new insight into the capabilities of the techniques being used.

First evaluation tests of an automatic method of setting the matrix coefficient potentiometers in the multiparameter eddy current tester will be made in a single channel of the present four parameter eddy current tubing tester. Eventual application is planned for multiparameter testers reading more than four parameters where manual adjustment becomes impractical. The method chosen for implementation is a variation of the Gauss-Seidel method. Logical design of the device is completed, and circuit design is weli under way with most of the critical circuits for a single channel test version awaiting final construction. 
The pulsed eddy current muitiparameter test equipment is now functioning satisfactorily up through the generator R-C lines simulating the eddy current test and null balance network, a differential amplifier; and an exponential generator. The sampling circuits which sample the output of the exponential generator were found to require some modification to more satısfactorily sample signals of either polarity. Corrective changes are now being made. A summing network using finger tip controls for ease of adjustment has been added following the sampling unit. The present arrangement uses 16 potentiometers and 12 assoclated operational amplifiers and should have the capability of ldentifying four separate potentiometers.

The two sections of the prototype multichannel eddy current tubing tester have been mounted in their respective carrying cases Tests of the completed instrument were satisfactory. Final circuit drawlngs have been made and are being checked for accuracy. Analysis of the clrcults used for the successive elimination and separation of the parameter signals in this instrument have been made The analysis shows the close relationship between the instrumentation scheme used and the ciassical Guassian method of solving simultaneous equations. The analysis also resolves some questions met during equipment tests concerning the best circult arrangements for glving good signal-to-nolse ratios. All possible circult com= binations were delineated, and tentative crlterla for selection of the best arrangement were studied.

An analysis of an idealized eddy current model having depth of location of defect and size of defects as variables showed that the number of test parameters lor varlablesi which can be identified (separated) by the multiparameter test is equal to twice the number of test frequencies used. This result is basea on the use of two orthogonal components of the resulting signal for each test frequency If only one component of the resulting signal at each test frequency is used; the number of parameters which may be iajentified is equal to the number of test frequencies. As the number of frequencres and parameters is increased; the difilculty of separating the parameters increases and $1 r_{1}$ creased cross talk can be expected.

\section{Ultrasonic Methods}

Wave Propagation Studies In the previous month's report. revisions that were expected to improve the ability for estimating ultrasonic pulse data with the Kautz function analysis were discussed. These changes were made; and extensive revision of the EDPM program was necessary. Results indicated that the first two terms of the series were being correctly evaluated. However subsequent terms were not effective in reducing the residual signals indicating that the program still contains an incorrect computation.

The results did indicate that more terms than previously expected would be required for a good fit to the pulse data. It was believed 
that good results should be obtalnable with six or less terms. In view of these discouraging results and the present difficulties with long computer turn-around times; some reconsideration of the problem of finding acceptable methods for estimating ultrasonic pulse behavior is in oräer.

Basic Studies of Surface Waves. Ultrasonic studies are in progress to increase our present know ledge of surface waves and critical angle phenomena. An attempt to develop an optimum method for observing and measuring the Rayleigh critical angle is in progress as a part of the "nil-ductility" program. It may also be useful in detecting changes in heat treatment, cold working, surface hardness, and ultrasonic attenuation.

Using an optical Schlieren system and a 1-inch diameter flat lithium sulphate transducer, the null in reflected intensity near the crltical angle can be measured with a relative accuracy of about \pm 0.05 degree. Smaller transducers may give slightly larger errors due to diffraction effects. Further studies in this area are planned

The reflected amplitude versus incident angle has been measured at frequencies of 5 to $25 \mathrm{MHz}$ for angles near the critical angle. These data are presently being compared with numerical solutions for the wave propagation model with attenuation, which were calculated for the sample under investigation. Additions to the computer program for frequencies not previously calculated are also in progress. Initial analysis indicates a slight discrepancy in the position of the null near the critical angle. Further analysis will be necessary to resolve this difference and/or alter the testing method to more nearly approach the assumptions of the theory.

An optical schlieren system. to be used in conjunction with this program; is being built and will be mounted in the "nilductility" test facility.

Detection of Irradiation-Induced Shift in Nil-Ductility-Transition Temperature. Ultrasonic apparatus has been assembied and steel specimens have been and are being irradlated for the purpose of de:veloping a test method for the assessment of irradiation damage to structural steels

Experiments have been performed on algaecide and rust inhibitor solutions to determine any adverse effects on materials used in the test tank. No corrosion was noted but a very slight buildup on nickel-silver components was noted-mpossibly due to amalgamation of the mercury contained in the algaecide.

Final debugging and modifications were completed on the electronic apparatus. Transducers and oscillator coils are now available to enable testing at $2 \mathrm{MHz}$ " $5 \mathrm{MHz}$, and $10 \mathrm{MHz}$. Transducers are being 
procured to allow testing also at $1 \mathrm{MHz}$. Design work for attachment of a schlieren apparatus to the test tank is partially completed. A Schlieren apparatus will enable easier, faster, and more precise measurements to be made. Work performed in the $1 \mathrm{ab}$ using a schlieren apparatus indicates the upper frequency limit for using the "null-balance" application of the critical-angle method will be about $7 \mathrm{MHz}$ (on $304 \mathrm{SS}$ ). At frequencles above $7 \mathrm{MHz}$, the amount of re-radiated displaced energy is very small compared to directly reflected energy, and it may be difficult to obtain a balance of these two components.

Components to be used for heat treatment of control standards have been desıgned and are being fabricated. It is planned to heat treat specimens from each of the four groups of materials used in the specimen irradiation program for about 21 days (approximate time of one ETR cVclel at temperature increments of 100 OF from 250 to 750 o F--the temperature range expected for the ten irradiation groups (seven different neutron fluence levels at temperatures less than $450{ }^{\circ} \mathrm{F}$ and three different neutron fluence levels at temperatures greater than $550 \mathrm{OF}$ ). Specimens will be sealed in helium filled capsules and then heat treated

Specimens irradiated in ETR cycle 89 have been received at Radiometallurgy, de-encapsulated, inspecte $\vec{a}_{\text {, }}$ and loaded in a shipping cask for transfer to 324 Bullding. All specimens survived their irradiation and handling ordeals without any obvious damage. Three low temperature and low neutron fluence level groups are included in this first group. The three specimens containing fusible sentinels did not allow conclusive interpretation. It appears that one wire (of fourl in one of the specimens partially melted ( $\left.318 \mathrm{O}_{F}\right)$. There was no evidence of melting in any of the remaining wires. The wire which appears to have partially melted is contained in a specimen which received less exposure (and hence should run at a lower temperature) than one of the other specimens which had no melted wires. Exposure recelved by the three groups are predicted to be about $2.7 \times 1018,4.5 \times 1018$, and $6.4 \times 1018$ nvt. A more accurate exposure will be obtained by analysis of the neutron flux monitor wires which were attached to the capsules at strategic locations.

Specimens irradiated in ETR cycle 90 were discharged from the reactor on July 24. Shipment to Hanford is expected soon. These specimens include three high-exposure, low-temperature groups; one high-exposure, high-temperature group, and one low-exposure hightemperature group.

Thermal Methods

Sinusoidal Thermal wave Technique. A new silicone rubber backed thermal wave transducer has been developed. This transducer should be more stable than the gas backed transducers employed in the past. 
Preliminary measurements on the transaucer show that it has satis= factory sensitivity. especially when used with a liquid couplant between the transducer and test object. Tests to determine the transducer's long term stability have been initiatea.

When helium was used as a couplant with the new transducer, a phase shift and amplitude change of about $2^{\circ}$ and $7 \%$, respectively; were obtained in the input thermal impedance of the transducer when the test object was changed from copper to aluminum. This sensitivity appears comparable to the results obtained with previous transducers. but further tests to determine the lift-off impeciance locl for the new transducer wlll be required to determine the true sensitivity

Although gas coupling is convenient, and would be required at high temperatures, or when test objects cannot be brought into contact with contaminating liquids, closer coupling and hence higher sensitivity will be obtalned using liquid couplants. The solid backed construction of the new thermal transducer makes it possible to use it with liquid couplants. Experiments using water as the couplant between the transducer and sample surface showed that a factor of five increase in phase sensitivity was obtalned. However. degassing of the water formed bubbles which greatly increased the nolse during the measurements. Vacuum degassing of the water prior to use seemed to lmprove the results, but reliable amplitude sensi= tivity measurements could not be obtained even after this refinement Electrolysis of the water is believed to play a part in the mechanism of bubble formation. Oil is believed to be a better liquia than water for use as a thermal transducer couplant.

Another coupling method would employ a thin rubber layer cast in place on the transducer by the same technique used to cast the rubber backing. This method, when used in conjunction with lift: oft compensation techniques to eliminate the effect of contact resistance variations, should allow convenient, highly sensitive measurements to be made by merely placing the sample in contact with the rubber coupling layer on the transducer.

A differentiator and schmitt trigger circult, to give improved accuracy in the starting pulse for the phase measuring clock in the thermal wave system; has been installed. Inltial tests showed. however, that lower accuracy was obtained than was obtained with the square wave generator internal to the standard oscillator originally usea for the starting pulse. The source of the difficulty is believed to be stray 60-cycle plckup, and work is under way to correct this problem. 


\section{Nuclear Ceramics (R.E. Nightingale)}

Pu-O=N Phase Equilibria

An electron beam gun was installed in the ternary evaporator for use in $\mathrm{Pu}-\mathrm{O}-\mathrm{N}$ phase studies. Cerlum metal; which is being used as a stand-in for plutonium, was successfully melted in a vacuum of about $10^{-6}$ torr. No reaction occurred with the water-cooled hearth. and the metal retalned a clean surface upon cooling

A titanium sublimator was added to remove the oxygen and nitro= gen which does not react with the cerium. Inltial tests indicated a vacuum of about 10-4 torr can be maintained in the absence of any reaction with cerium. When cerlum is being evaporated, the pressure should be at least an order of magnitude less. Following installation of a thickness monitor and controlier to measure and control the rate of evaporation of the cerium, direct evaporation of isothermal sections of ternary Ce-O-N phase diagrams will be started.

High Temperature Creep in Nuclear Ceramics

A high temperature creep loading apparatus was designed and is being tabricated. Samples will be stralned in three-point bending, and the amount of strain wlll be measured from the movement of the loading rod by a magnetic transducer. The loading apparatus will be used with a high temperature graphite furnace mounted on a table model mechanical testing frame Changing the sample will be possible without removing the furnace from the testing machine.

Compatibility Studies

Ten samples of $\mathrm{UO}_{2}-25 \mathrm{wt} \% \mathrm{PuO}_{2}$ of $\mathrm{O} / \mathrm{M}$ ratıo 1.96 and 1.97 sodium and helium bonded in 304 stalnless steel cladding, were placed in furnaces for heat treatments of 100 and 1000 hours at 650 and $1000{ }^{\circ}$ to determine the compatiblilty of these components. The samples were sealed in quartz envelopes containing helium to prevent oxidation of the stainless steel cladding at the elevated temperatures

\section{Scanning Electron Microscopes}

Tests were conducted on two types of secondary emission electron microscopes to determine applicabllity to PNL materials research programs Of these, the scanning microscope was shown to be well suited for study of a diversity of materials, including graphite fracture surfaces and particles; metal corrosion systems, and fast reactor fuel materials. A very long depth of field allows complete study of unpolished surfaces; a wide range of voltage control, specimen motions, readout modes and lmage displays contribute to the versatıbility as a research tool. 


\section{Nuciear (Grahite (R R. Nightıngale)}

High Temperature Irradiations

The leak detected in the $G E H-13-14$ capsule was repaired and the capsule has been inserted in the ETR. Startup began in midAugust due to an unexpectediy Iong outage. The capsule will operate at a maximum temperature of 1275 OC for a period of three reactor cycles and is scheduled for discharge in December.

\section{$E B R=I I$ Irradiations}

A subassembly containing two thermocouple pins, a dosimetry pin three graphite pins; and thirteen stainless steel. dummies is being loaded into the EBR-II core in a Pow 6 position. Only three graphite pins were included to satisfy conservative physics requirements. One of the pins contains irradiated graphite, while the others contain virgin material. The subassembly will probably remain in the reactor for many cycles. Since the maximum flux in Row 6 is about 8 x $1014 \mathrm{nv}$, the capsule shoujd accumulate $7 \times 10^{19} \mathrm{n} / \mathrm{cm}^{2}$ per operating day or on the order of $10^{2} \mathrm{i} \mathrm{n} / \mathrm{cm}^{2}$ per cycle

Graphite Compression Test

The constant load compression test experiment was designed to determine the eifect of external stresses on the contraction fates of graphite during irradiation. Previous data from these tests showed that stresses of only a few hundred psi can increase con. traction rates by a factor of two and that the increase in rate ls approxlmately proportional to the appiled stress

The ten boats; each contalning five stressed sampies, loaded at 150 to 300 psi. and ten unstressed control samples: were dis charged and measured atter 17.000 to 20,000 MWd, AT at about $625{ }^{\circ} \mathrm{C}$ The irradiation program on these samples has been terminated, and representative samples hive been seiected for turther examination Although the data analysis is not complete, the preliminary results agree wlth previous data obtalned at lower exposures.

The examinatior program will include annealing at temperatures up to 1800 oC Drevious experiments showed the same annealing be. havior for stressed samples as for the control samples. Slich results indicate that the imoosed stresses are not affecting crys. tallite dimensional changes

\section{Investigation of Graphite Structure}

Samples of SGBF graph1te were stressed to loads of $0 ; 702,1404$. and 2105 psi and checked for changes in length resistivity. Young "s modulus, and thermal expansion. The trend of the data was as expected, but scatter indicates that more data are required. The 
samples at the two intermediate stress levels were remounted and stressed to 2105 psi for further measurement. Unfortunately, five of the samples broke at 2000 psi and three others failed at the epoxy joint at 1500 psi

Similar tests were begun on POCO graphite having higher density and uniformity than SGBF. Four of the six POCO samples were stressed to 1404 psi; two were retained as unstressed controls. Properties of the stressed samples were remeasured and compared with the orlginal values; small percent changes were observed. The samples were remounted and the same four samples stressed to 2807 psi (147\% of the nominal tensile strengti of $6000 \mathrm{psi})$. Remeasurement of the samples is in progress.

Gas=Graphite Reactions

Experiments on high temperature thermal oxidation reactions in TSX graphite were conducteà at room temperature and at liquid nitrogen temperature.

For the room temperature experiments, a microscope specimen was made by oxidizing a standard mechanically prepared disk specimen in a modified spark machine until a hole was created in the thin central area of the specimen. Microscopic examination revealed that the edges of the hole were different from those of other disk specimens in which the hole was prociuced by a varlety of other chemical or mechanlcal treatments. The edges of the hole were smooth and contained few translucent areas in contrast to the typically rough. irregular hole profiles with frequent translucent eäges produced by other techniques. It appears that this condition was produced by the high temperatures in the spark zones and may involve vaporization and redeposition of carbon

Further spark oxidations were made at room temperature with other TSX disk specimens which contalnea a central hole made with a cutoff wheel. The sparking tool was directed to produce sparks along only part of the edge of the hole. The unsparked edge of the hole was positioned downstream: diametrically opposite the oxygen jet. oxidations were performed for periods ranglng from about one second to several minutes. The edge of the hole which was in the spark zone had the same appearance as the specimen with a complete spark-machined hole. The edge of the hole which was not in the spark zone had an entirely different appearance; It was essentially unchanged except for the prominent appearance of lace structures. Previously, such structures were obtained only from oxldations with microwave-excited oxygen. It appears that oxygen is being dissoclated in the high temperature spark regions and that oxygen atoms are then swept by the oxygen jet into the unsparked area of the hole where reaction occurs leading to lace structure development. 
The experiment was repeated with the specimen and spark zone immersed in liquid nitrogen. The flow rate in the oxygen jet was cut in half. All other conditions remained the same as for the room temperature oxidations. The results of the oxidation experlments at liquid nitrogen temperature were essentially the same as those at room temperature with one exception. For equal oxidation times, the density of lace structure was much greater for the lower temperature experiments. This may be due to the baffle effect of the liquid nitrogen cover in directing the active species produced in the spark zone into the unsparked hole area. While the low temperature would tend to favor the formation of ozone, in contrast to the conditions for the room temperature experiments, no evidence has yet been found for a different structural form of oxidation attack than that observed in the higher temperature experiments.

Radiation-Induced Reaction of a Mixture of Hydrogen and Carbon Dioxide

The radiation=induced reaction between hydrogen and carbon di= oxlde has been shown to lead to the formation of methane, carbon monoxide, and water by previous workers. However, the yield of methane was found to depend on the purity of the reactant, decreasing as the purity of the carbon dioxide increased. Tingey (BNWL=SA=591) found $\mathrm{G}\left(\mathrm{CH}_{4}\right)$ values (molecules of methane produced per hundred electron volts of energy absorbed) of 0.1 for $2 \% \mathrm{H}_{2}$ in $\mathrm{CO}_{2}$ at $350{ }^{\circ} \mathrm{C}$. Hummel (AERE-R-5286) went to greater lengths to purify the carbon dioxide and found a $\mathrm{G}\left(\mathrm{CH}_{4}\right)$ value of $0.025 \pm 0.005$. We have used hydrogen of at least $99.9995 \%$ purity together with $99.99 \%$ pure carbon dioxide which was further repeatedly purified by trap-to-trap distillation in the vacuum line. Quartz ampoules were outgassed at $800{ }^{\circ} \mathrm{C}$ at less than $10^{-5} \mathrm{~mm}$ pressure for one to six hours. Ampoules contalning the gas were then irradiated in the Co-60 gamma faclitty for one hour at a dose rate of $2.90 \times 10^{+7} \mathrm{R} / \mathrm{hr} \quad \mathrm{G}\left(\mathrm{CH}_{4}\right)$ values found for $3 \% \mathrm{H}_{2}$ in $\mathrm{CO}_{2}$ at $350{ }^{\circ} \mathrm{C}$ average less than 0.010 , a factor of at least two to three less than Hummel reported. This value implies that higher $\left(\mathrm{G}\left(\mathrm{CH}_{4}\right)\right.$ values observed may have been due to the reaction of impurities present in the system. The question is therefore. raised as to whether all methane produced in the radiolysis of $\mathrm{H}_{2}+$ $\mathrm{CO}_{2}$ mixtures is due to some very small concentration of organic $1 \mathrm{~m}=$ purities present in the mixture.

Irradiation Damage to Reactor Metals ( $\mathrm{A}$. I. Bement)

Alloy Selection

Liquid metal capsule GEH 22-5, containing nickel alloy specimens. has been discharged from the ETR after four days of operation. Early discharge was prompted by a capsule condition which caused excessive capsule temperature readings, blockage of gas flow, and evidence of reactivity in the gas inlet tube external to the reactor. From initial reports the fallure appears to be a malfunction of the primary 
sodlum containment vessel. Although such a condltion is not immedlately hazardous to the operation of the reactor " it effec tively terminates the irradiation test

The capsule 22-5 will be returned to Hantord for detalled examination to determine the speciflc cause for fallure.

In-Reactor Measurements of Mechanicai Properties

The purpose of the in-reactor measurements program is to determine the effects of Irradiation on the mechanlcal properties of reactor structural materials. The effort is involved in measuring creep in AISI 304 stainless steel, nickel-base alloys, and refractory metal alloys during neutron irradiation

Greater effects of Irradiation on creep rates of zirconium alloys have been observed during in-reactor creep tests at $300{ }^{\circ} \mathrm{C}$ and strain rates below $1 \times 10^{-6} \mathrm{hr}-1$ than at higher temperatures and faster strain rates. In-reactor creep tests conducted on 304 stainless steel have been at strain rates greater than $1 \times 10^{-6} \mathrm{hr}-1$. Tests are being conducted on 304 stainless steel at temperatures of 400 and $450{ }^{\circ} \mathrm{C}$ and at low stress leveis to determine if there may be greater effects of irradiation on creep rates at low strain rates.

Irradiation Effects in Structural Materials

Stalnless Steels. The purpose of this phase of the program is to determine the combined effects of irradiation and environment on the mechanical properties of stainless steels. Radiation-induced property changes will be determined from irradiations and tests con. ducted at various temperatures on several alloys. Particular emphasis will be placed on determining the existence of metallurgical insta bilities and the mechanisms by which they are enhanced in a nuclear envirunment.

Stain less steel specimens given experimental thermal-mechanical treatments have reached 1000 hrs toward a goal of 2500 hrs in a $1150{ }^{\circ}{ }_{F}\left(620{ }^{\circ}\right)$ thermal aging study. Optical metallography is in progress to characterize the microstructures resulting from the various thermal-mechanical treatments

Irradiations in the ETR G-7 loop at temperature above $390{ }^{\circ} \mathrm{C}$ are being initiated. The heat transfer calculations on the initial sheath capsules are complete, and capsule parts are being manufactured. The first two quadrants contalning 72 specimens should be ready for reactor insertion during cycle 93 shutdown

Nickel-Base Alloys. The purpose of this program is to determine the effects of modified microstructures on the irradiation stability of nickel=base alloys Microstructural modifications are made by 
pre-irradiation thermal or thermomechanlcal treatments and are evaluated by tensile tests, stress-rupture tests, and microstructural examinations.

The rmomechanically-treated "Hastelloy $\mathrm{X}=280$ " control specimens exposed at 1250 OF (675 OC) exhibited slight reductions in rupture life at $1350 \mathrm{O}_{\mathrm{F}}(732$ OC) compared with corresponding values representing exposure at $540{ }^{\circ} \mathrm{F}\left(280^{\circ} \mathrm{C}\right)$. Previously reported tensile properties also showed this effect; namely, that thermomechanically treated specimens were thermally stabie, resisting strength increase and ductility loss due to exposure-iriduced precipitation

Preliminary stress-rupture data for Hastelloy $X=280$ specimens 1 rradiated at $12500_{F}(675 \circ \mathrm{OC})$ to a fast fluence of $1 \mathrm{x} 10^{20} \mathrm{n} / \mathrm{cm}^{2}$ revealed a large reduction a factor of 10) in rupture life compared with values representing irradiation at $540 \mathrm{O}_{\mathrm{F}}\left(280^{\circ} \mathrm{C}\right.$ )

Transmission microscopy of the buttonhead from a Hastelloy $\mathrm{X}-280$ tensile speclmen whlch had been 1 rradiated at $12500^{\circ} \mathrm{F}\left(675{ }^{\circ} \mathrm{C}\right)$ to a fast fluence of $1 \times 10^{20} \mathrm{n} / \mathrm{cm}^{2}$ and then tensile tested at 1350 OF $\left(732{ }^{\circ} \mathrm{C}\right.$ revealed no helium bubbles Total elongations for these specimens were - $7 \%$, with nonuniform elongations ranglng from zero to $1.3 \%$.

Fast Reactor Supporting Studies

Structural Materials and Fuel Cladding Studies. The objective of this program is to determine the combined effect of environment and fast reactor irradiation on the mechanical properties of candidate fast reactor cladding and structural alloys. The program currently in progress is specifically directed at providing a basis sor selecting optimum alloys for FFTF applications and at providing a description of material behavior in fast reactor service

Four MK-A type irradiation pins, containing 22, tensile and 8 creep test speclmens of annealed AISI 304 stalnless steel have been charged into the EBR-II for fast neutron irradiation on a space avallable basis. Pins designated BNWL $A-18, A-19$, and $A-40$ were loaded into subassembly X027 which has been charged into row 4. Pin BNWL A-38 was loaded into subassembly X030 which was charged into row 6. The irradiation period for these subassemblies is in detinite

Filuence monitors in BNWL $A-38$ and $A-40$ are of several pure and unalloyed metals. selected and spaced throughout the length of the irradiation pin so as to provide a detalled description of the neutron spectrum within the EBR=II. It is expected that flux information derived from the testing of these monitors will assist in the analysis of the mechanical property changes occurring in materials Irradiated in these and other experiments in EBR-II. PIn BNWL-A-18 is perforated so that its contents are exposed to reactor bulk sodium, and pin BNWL $A=19$ contains an atmosphere of helium. 
A prototype biaxial stress test apparatus with static sodium environment has been assembled. This apparatus will be used for stress=rupture testing of tubular specimens in support of FFTF fuel ciading development. Trial tests in sodium wll begin. utilizing the capsule and stressing system previously evaluated. The test objectives are to evaluate problems which will arise with liquid sodıum, sodıum transfer, irradiated specimens; and remote handling.

Recent fast reactor Irradiation effects on 304 stainless steel have been described in two papers to be presented at professional soclety meetings. A paper entitled "Eitects of Fast Reactor Irradiation on the Tensile properties of 304 Stalnless Steel, "BNWL: SA=1335-A, will be given at the winter meeting of the ANS in Chicago. The paper deals with work hardening. temperature dependency of tensile properties, and fracture behavior. A second paper entitled "Elevated Temperature Radlatıon Hardenıng in Austenıtıc Steel." BNWL-SA-1318-A, which correlates properties wlth microstructure. will be presented at the fall meeting of rhe AIME

Fast Neutron Mechanisms. Fundamental studies of hydrogen behavior in reactor metals lising gas permeation and evolution techniques are continuing: An investigation of the hydrogen permeability. diftusivity. and solubility characteristics of quenched-andtempered $A 302$-B pressure vessel steel has been completed for the $250=525{ }^{\circ} \mathrm{C}$ temperature range. The permeability as a function of temperature and hyarogen pressure 15 glven by the expression.

$$
\mathrm{P}\left(\frac{\mathrm{atm}-\mathrm{CC}-\mathrm{cm}}{\mathrm{cm} 2-\sec }\right)=\times \mathrm{B}(\mathrm{T})+1.8 \times 10^{-3} \mathrm{P}^{1 / 2} \mathrm{exp} \leq-8.09 \times 10^{3} / \mathrm{Rr}
$$

where $\mathrm{p}$ is the pressure at the absorption surface in atmospheres $(\mathrm{p}=0$ at the desorption surface), $\mathrm{P}$ is the gas constant, and $\mathrm{T}$ is the absolute temperature. The term B(T) represents a smali; temperature-dependent deviation from normal Sievert's law type behavior that is common ly observed in metals at low hyarrogen pres sires and permeation rates. The values of $B(T)$ for $A 302-B$ range from approximately $6 \%$ of $\mathrm{P}_{1}$ l atm) at $250{ }^{\circ} \mathrm{C}$ to essentially zero at and above $500{ }^{\circ} \mathrm{C}$

The diffusivity of hydrogen in A302-B as determined from the kinetics of the hydrogen absorption/desorption process is.

(I) F, W Albaugh, S. $\bar{H}$. Bush, J. T. Cadwell, D. R de Halas, and D. C. Worlton, Quarteriy Progress Report. January. February March, 1967 . Reactor Fuels and Materials Branch of USAEC Division of Reactor Development and Technology BNWL-CC-957 Pacific Northwest Laboratory; Richland; Washington, inarch 1967. 


$$
\mathrm{D}\left(\mathrm{cm}^{2} / \mathrm{sec}\right)=4.6 \times 10^{-4} \mathrm{exp}=1.46 \times 10^{3} / \mathrm{PT} T
$$

The corresponding hydrogen solubllity was derived from the permeation and diftusion data using the relationship $S=\frac{P-B(T)}{D}$. The resulting expression.

$$
\mathrm{S}(\mathrm{ppm})=45 \mathrm{p}^{1 / 2} \exp \equiv-6.62 \times 10^{3} / \mathrm{RT} T
$$

is almost identical to that for the solubility of hydrogen in pure alpha iron. The permeation and diffusion results for A302-B are also consistent with literature values for hydrogen in alpha iron and the low alloy steels in general, although the observed activation energy for diffusion is somewhat less than the $2=3 \mathrm{kcal} / \mathrm{g}$-atom commonly reported for these materials.

Test Facilities Construction of the prototype creep-rupture cell in the $321-A$ Bullding is nearing completion. The work remaining consists of minor adjustments needed to assure proper operation of attached equipment and completion of electrical panels. A newly designed vacuum system which will provide adequate vacuum for inert gas and low vacuum tests and a sufflclently low back pressure for a high vacuum system (pressures lower than 10-8 torr) has been completed.

A test rig designed to operate remotely with an inert gas atmosphere is now undergoing final bench operational tests. The rig is being operated at temperatures up to $1832{ }^{\circ} \mathrm{F}\left(1000{ }^{\circ} \mathrm{C}\right)$ to test seals. the extensometer system, and temperature control. Design has been completed for a remotely operated stress rupture apparatus employing a static sodium environment. This design utilizes features already developed for other test environments.

Design for renovating Bullding 321 -A ls nearly complete, and construction will start within the next month. Development of speciailzed test equipment will continue during construction, utılızıng available space

The support system for the sodium loop has been thoroughly examined for shipping damage. This examination did not reveal any damage to the actual piplng. Insulation on the plping was heavily damaged in places, and four fan motors were knocked out of position and badly misaligned. This damage is now being repaired. To insure against hidden damage; the entıre system was leak checked with a helium mass spectrometer detector and the welded jolnts most vulnerable to damage were examıned by dye-check and x-rays. Design for the shielded portion of the flowing sodium test facility is being facilitated by the use of a model of the proposed piping assembly and the construction of a full scale mockup of the shielded zone. 
A unlaxial stress=rupture apparatus has been designed for inert gas testing in the 324 Bullding fuel cladding test facility. This machine is a miniature version of the type designed for installation in the prototype cell in $321-A$ Bullding. The completed prototype will be assembled during the next month.

\section{ATR Gas Loop Supporting Studies}

Model Gas Loop Studies. The model gas loop is a $2100{ }^{\circ} \mathrm{F}$ $(1093$ OC recirculating helium system which 1 s being operated to determine the effect of helium atmosphere on high temperature materials and specimen holders; and to determine if prolonged use will affect the operating characteristics of the new heater. This loop is a one-tenth size model of the gas loop being constructed in the Advanced Test Reactor at Idaho Falls

The model gas loop has operated a total of 4963 hrs since installation of the new heater with 80 thermal cycles from room temperature to various heater out let temperatures. Routine loop operation was discontinued in May 196\%, and resumed in July 1967. During this reporting period, about 240 hrs operation under varying conditions were accumulated.

The current test employs a device with which the specimens can be inserted into the throat of the horizontal test section without shutting down the system. The remote installation ailows the specimens to remain in a cool zone until gas quality conditions are met, at which time specimens can be moved into the hot zone $(2100 \mathrm{OF})$. This technique eliminates specimen exposure to low purlty gas during heatup This device has operated successiully on lts initial test

Superalloy and Refractory Metal Corrosion Studies. T'o investigate superalloy oxide degradation and reactive metal contamination in the presence of a reducing agent a treshly abraded niobium sample was "sandwlched" between two preoxldized Hastelloy X-280 coupons off the same size. A second nioblum sample was placed 0.20 inch above the "sandwich" and a third oxldized Hastelloy coupon 0.20 inch above that. This specimen assembly was placed in a furnace system. The system was evacuated. was brought to $1100{ }^{\circ}{ }_{C}$, and hydrogen at 80 Torr was introduced. After 45 hrs at temperature, the hydrogen was pumped from the system, and the system was cooled to room temperature under $10^{-5}$ Torr vacuum

The three superalloy samples were initially prefilmed to about $0.73 \mathrm{mg} / \mathrm{cm}^{2}$ oxygen pickup or a total of $13.8 \mathrm{mg}$. At the end of the exposure to 80 Torr hydrogen, the Hastelloy samples lost $26.1 \mathrm{mg}$ (total) while the two nioblum samples galned $26.9 \mathrm{mg}$ (total). The weight loss of the three superalloy samples is thought to be due to losses in oxygen, chromium and perhaps carbon. The weight gain of the niobium samples is thought to be primarily oxygen. 
Microhardness traverses across the 60-mil cross section of the two niobium samples gave average D.P. H, values of 220 and 245 . respectively. The hardness values suggest that oxygen accounts for approximately $70 \%$ of the total weight gain. The niobium contamination can be better evaluated when x-ray diffraction and metallographic data are available. The test indicates that oxygen, chromium, or carbon originating from an oxldized superalloy can be an lmportant source of nioblum contamination.

Corrosion Studies: A set of corrosion coupons has again been exposed in the ATR model gas loop to monitor loop contamination where several operating variables were adjusted during the test. Previously, corrosion samples were positioned in the heater discharge section, and loop was then sealed, pressurized and put in operation. This latter test was conducted as follows:

1. Monitor coupons were placed in the "throat" of the heater discharge section.

2. The main sample array was positioned in a static, water-jacketed leg of the loop for insertion into the heater discharge section at a time after startup.

3. The loop was sealed; pressurized, and slowly brought to temperature. The monitor samples were essentially exposed in a manner typical of previous loop tests: $i$. e. subject to cold loop startup and exposure to clean $2100{ }^{\circ} \mathrm{F}\left(1149{ }^{\circ} \mathrm{C}\right)$ helium gas. The sample array was held in the static leg at a temperature less than 600 OF $\left(3160^{\circ}\right)$ while the heater discharge section was at $2100{ }^{\circ}\left(1149 \circ^{\circ}\right)$.

4. After 123 hrs at temperature, the loop was cooled to $500{ }^{\circ} \mathrm{F}\left(260^{\circ} \mathrm{C}\right)$ and the main sample array pushed into the heater discharge section. The loop was pressurized during the operation, and no significant loss in pressure was observed.

5. The temperature was again raised to $2100{ }^{\circ} \mathrm{F}$ (il49 ${ }^{\circ} \mathrm{C}$ ) in the heater discharge section and the loop sealed from any gas bleed system. The helium makeup during this part of the test was adjusted manualiy.

Niobium samples are the most indicative of loop contamination in that previous loop exposures have shown the ability of niobium to getter contaminants from "clean" helium gas. The $\mathrm{Nb}$ monitor sample subjected to cold startup and positioned in the $2100{ }^{\circ} \mathrm{F}$ (1149 ${ }^{\circ}$ ) heater discharge section gained $1.79 \mathrm{mg} / \mathrm{cm}^{2}(11.42 \mathrm{mg}$ total) during $202 \mathrm{hrs}$ at temperature. The $\mathrm{Nb}$ sample used in the main sample array gained $0.68 \mathrm{mg} / \mathrm{cm}(7.31 \mathrm{mg}$ total) during a 79-hr exposure at temperature. Comparing these values to weight gains of 
niobium in previous $2100^{\circ} \mathrm{F}$ ( $\left.11490^{\circ} \mathrm{C}\right)$ loop tests, It would appear that the "cold startup" test procedure cut down the nlobium contamination only slightly since a previous exposure of a niobium sample at $2100^{\circ}{ }_{\mathrm{F}}\left(1149^{\circ} \mathrm{C}\right)$ for one hour showed a $0.35 \mathrm{mg} / \mathrm{cm}^{2}$ welght gain and another sample held for $228 \mathrm{hrs}$ showed a $1.1 \mathrm{lmg} /$ $\mathrm{cm}^{2}$ welght gain, whereas the sample in this test gained $0.68 \mathrm{mg} / \mathrm{cm}^{2}$ In a 79=hr exposure. Of the other metals exposed during this test. Hastelloy $\mathrm{X}-280$ and Haynes 25 lost welght in an amount predicted by previous work. $0.79 \mathrm{mg} / \mathrm{cm}^{2}$ and $0.94 \mathrm{mg} / \mathrm{cm}^{2}$. respectively, for the 79-hr exposure. Tantalum, on the other hand had a weight galn much less than predlcted. $0.19 \mathrm{mg} / \mathrm{cm}^{2}$ in this test for a $79=\mathrm{hr}$ exposure, compared to a sample galning $0.27 \mathrm{mg} / \mathrm{cm}^{2}$ in a $\mathrm{l}-\mathrm{hr}$ exposure; and a second sample gaining $0.73 \mathrm{mg} / \mathrm{cm}^{2}$ during a $228 \mathrm{hr}$ exposure

ATR Water Loop Supporting Studies

Corrosion studies. In some in tiux environments the corrosion rates of zirconlum alloys are very much higher than in comparable out-of-flux environments. In other environments, the corrosion rates are not enhanced by the flux. Fission fragments and water chemistry have both figured prominently in the proposed explanations for the cases of enhanced corrosion. It has not generaliy been possible to separate fission fragment and water chemistry factors, since corrosion tests are usually conducted in reactors or in loops which are potentially contaminated with fissionable species. Corrosion experiments are scheduled to be conducted in an Advanced Test Reactor (ATR) water loop to be operated by Battelie-Northwest. The "clean loop" tests will be conducted before fissionable materials are charged into the loop

Aluminum mockups of the ATR zircaloy holders and specimens have been sent to the National Reactor Testing station for testing in the ATR critical facility: The actual ATR "clean loop" test is scheduled for startup between November 24 and December 27,1967 . Among the several zirconium alloys to be tested are $\mathrm{Zr}=2.5 \mathrm{Nb}$, KAPI specimens and Battelle-Northwest alloy stock which has been characterized In the G-7 loop of the Engineering Test Reactor.

The proposed ATR water loop environment is $\mathrm{pH}=10 \mathrm{LiOH}$ i $1 \mathrm{ppm} \mathrm{O}_{2}$ 270 to 280 OC during the "clean loop" exposure. and other hardware for the tests will be loaned to Battelle-Northwest by KAPL.

Damage Mechanisms in Iron

The objective of this program is to determine how defects produced in iron by neutron irradiation interact with moving dislocations to modify the mechanical properties of the metal.

During this period several solutions were evaluatea to determine the feasibility of machining reduced sections on iron single crystals by electrolytic machining techniques A $5 \% \mathrm{HCl}$ solution was found to 
be the most satisfactory of four evaluated to date. It has a satisfactory rate of metal removal, and a sample was machined to $0.090 \pm 0.001$ inch using this solution

Installation and calibration of a control system for annealing studies to $1100{ }^{\circ} \mathrm{C}$ was also completed during this period.

\section{ATR Gas Loop Operation and Maintenance (G. A Last)}

\section{ATR Gas Loop Support}

Gas Cooled Loop Vendor Data Review. All contract submittals received to date (through No 4805 have been reviewed; and comments have been transmitted to Ebasco.

The Fansteel stress report on the stainless steel regenerative heat exchanger unit was reviewed by Teledyne, who recommended approval with minor comment

Gas Cooled Loop Design Review. A recommendation to relocate piping anchor points from the cublcle pipe chase was forwarded to Ebasco.

A Lockheed-Georgia proposal; submitted informally, to redesign the ball valve area of the transfer cask is currently under review. Their problem, briefly, is that a standard ball valve of the neces sary size is too large for the space alloted by the existing design. and that a specially=designed valve would take too long to procure. Their proposal uses a combined shield plug/seal arrangement.

\section{Transfer Facility Status. H. S. Wright and Associates have} accepted and instalied the viewing windows slave manipulators ; and periscope. Work still to be performed includes installation of the boom manipulator and $\mathrm{CC}$ testing.

The dummy inpile tube from the west reactor flux trap position is being modified to allow insertion of an ionization chamber for gamma heating measurements. These measurements will be performed during ATR Core I. At present, no flux measurements are planned in the ATR west position. However, rough flux information will be available by comparison with measurements taken in the north position.

The ATRC run that was to be performed in support of the gas loop has been postponed approximately six months. New estimated date is March 1968. It is presently planned to determine radial and vertical flux variations in a gas tilled mockup during this run

Thermocouples. Discussions with representatives of BMI=Columbus indicate that the 1 experience with Pt-Moly systems has been good. They have used this couple in the MTR at temperatures to 2600 OF for periods up to six months. 
Chromel-alumel appears encouraging for inltial specimen trains to operate at temperatures up to 2100 OF. Considerable long term work has been done by Pratt and whitney, however, with $\mathrm{Cb}-1 \mathrm{Zr}$ sheathing rather than our planned Inconel. Contacts with Pero Research and Thermo Electric have indlcated that Inconel sheathing should be adequate up to 2100 OF. Idaho Operations Office has issued a change order (No 3120 ) specifying chromel-alumel thermocouples for the initial trains.

Gas Loop Surveillance Program. Early in the design of the ATR gas loop it was recognized that several of the materials of construction would be pushed beyond past experience and available engineering data. It was also recognized that the behavior of these materials would be a complex function of temperature, corrosive environment. and Irradiation and that this behavior could best be determined in the gas loop itself. To assess this behavior, planning is presently under way on the formulation of an ATR gas loop survelliance program. Present material survelilance ltems being considered include:

1. Determination of the combined effects of long-term high temperature exposure; thermal cycling, and gas environment on Haste $110 y-X$ and Haynes 25.

2. Generation of long term creep rupture data on Hastelloy $=\mathrm{X}$, to be performed out-of-plle on representative Hastelloy-X samples.

3. Determination of the combined eftects of temperature. Irradiation : and gas environment on the $\mathrm{Cb}=1 \% \mathrm{Zr}$ Inconel insulation liner.

4. Determination of the behavior of thermocouple systems (Pt $=1 \% \mathrm{MO} / \mathrm{Pt}=5 \% \mathrm{MO}$ and chromel/alumel) under gas loop conditions.

Samples of all materials used in the construction of the gas loop have been requested from the vendors. These samples are now being delivered and will be used as control materials and test specimens for the surveillance program.

Accessible areas where test specimens may be positioned are somewhat limited. However. within these limits; samples will be located in areas with conditions most representative of actual loop operating environment. Areas under consideration for surveillance program sample location include in-core attachment to the specimen train, attachment to the lower shield plug and insertion in a special gas loop leg located in the cublcle piping. This latter iocation would necessitate a modification to the present gas loop design. Specimen train decay heat and ATR operating cycle length necessitates multı-train operation for the gas loop irradlation program. If surveillance program samples are attached to the specimen traln, it will 
be necessary to have at least two sets of samples; therefore; no sample would be representative of the entire gas loop operating history. A gas loop leg for the survelliance program would glve more representative long-term samples with relatively easy accessibility.

Since surveiliance specimens would not be subjected to mechanical loads, they will not be completely representative of actual loop materials. Consideration is being given to the possibility of perlodic removal of piping sections for metallurglcal examination and testing. Location of these piping sections would be determined by reference to loop stress calculations and local operating conditions. It is also possible that following the attainment of its estimated design lifetime; the in-pile tube will be removed for detalled examination of its components.

Besides material surveillance this program will also include monitoring of the performance characteristics of such loop equipment as primary heater, gas bearing circulators, and helium analytical and purification system. All of this equipment is somewhat unique and experimental. It is also of such size and characteristics that pre-installation testing is not feasible. Performance data. estimated lifetime, maintenance requirements: etc. : must be established as a result of a planned program combining initial systems. operation testing. and contınual surveil lance.

It should be emphasized that the gas ioop surveiliance program does not reflect a lack of conflaence in the design or materials of the gas loop. Rather, it is a program to gain more know ledge about the design and materials and to help anticipate any required replacements.

Metallic Fue ls Development iG A Lasti

Irradiation of Thorıum-Uranium-Zirconium Fuel Elements

Three thorlum $=2.5$ wto uranium $(932 \% \mathrm{U}=235)=10$ wto zirconium tubular fuel elements ciad in zircaioy-2 are under irradiation in the $\mathrm{P}=7$ loop in the ETR. Three fuel elements which were being irradiated are being stored in the viewing basin at the ETR site

The current status of the six test elements is summarized in the table. The temperature data for fuel elements GEH-10, 64, 65, and 71 are corrected for a temperature rise across an oxide buildup on the clad. The temperature data for the other fuel elements are not corrected for oxide buildup. The behavior of the elements continues to be excellent with $3.6 \%$ swelling being observed on the element with the maximun exposure of 2.1 at. $\frac{\circ}{b}$ burnup. 
Irradiation Data on Th=2.5 wt: U = I wt: Zr Fuel Elements

\begin{tabular}{|c|c|c|c|c|c|c|c|c|}
\hline $\begin{array}{c}\mathrm{GEH}- \\
10 \\
\end{array}$ & $\begin{array}{l}\text { Percent } \\
\text { Fuel } \\
\text { Swelling } \\
\end{array}$ & $\begin{array}{l}\text { Burnup } \\
\text { Fissions } / \mathrm{cm}^{3} \\
\text { (Mvd/ton) }\end{array}$ & $A \pm$. & $\begin{array}{c}\text { Surface } \\
\text { Temp. } \\
\text { OC } \\
\end{array}$ & $\begin{array}{l}\text { Max } \\
\text { Core } \\
\text { Temp } \\
\text { OC } \\
\end{array}$ & $\begin{array}{l}\text { Spec } \\
\text { Power } \\
\text { w/gm }\end{array}$ & $\begin{array}{l}\text { Surface } \\
\text { Heat Flux } \\
\text { Btu/hr/ft }\end{array}$ & $\begin{array}{l}\text { Thermal } \\
\text { Cycles }\end{array}$ \\
\hline 65 * & 3.6 & $\begin{array}{l}6.4 \times 10^{20} \\
113.9001\end{array}$ & 2.1 & 295 & 460 & 39 & $5.7 \times 10^{5}$ & 390 \\
\hline $64 *$ & 2.0 & $\begin{array}{l}4.5 \times 10^{20} \\
(13.200)\end{array}$ & 15 & 285 & 420 & 31 & $4.5 \times 10^{5}$ & 329 \\
\hline 71 * & 1.5 & $\begin{array}{l}3.3 \times 10^{20} \\
9,700)\end{array}$ & 1.1 & 295 & 480 & 45 & $6.4 \times 10^{5}$ & 190 \\
\hline $72 * *$ & 0,1 & $\begin{array}{l}1.5 \times 10^{20} \\
(4.300)\end{array}$ & 0.49 & 300 & 490 & 43 & $6.2 \times 10^{5}$ & 103 \\
\hline $70 * *$ & -0.5 & $\begin{array}{l}1.3 \times 10^{20} \\
13,9001\end{array}$ & 0.45 & 295 & 470 & 39 & $5.6 \times 10^{5}$ & 102 \\
\hline $84 * *$ & 0.1 & $0.9 \times 10^{20}$ & 0.29 & 290 & 440 & 33 & $1.5 \times 10^{5}$ & 58 \\
\hline
\end{tabular}

* Temperatures, corrected for oxide bulidup, and heat generation condltions during ETR Cycle 30.

**Temperatures not corrected for oxide bullaup, anc heat generation concittions during ETR. Cycle 84.

+ A thermal cycle 15 defined as a change from 90=100\% of maximum power to $0=10 \%$ of reactor power and return to $90-100 \%$ of reactor power.

\section{H1gh Exposure Uranıum Irradiation Test}

Hollow core uranium fuel elements being tested in the $M=3$ hot water loop of the ETR have, for the maxinum power elements, exceeded $5580 \mathrm{MiNd}$, ton with all elements still showing volume decreases. The accumulated exposures for the 34 elements in the test range from 575 to 5585 Mwa/ton. Ner measurements of the Ilux alstribution in the $M=3$ facllity showed that the burnup rate on the hlohest exposure elements was less than expected. The new calculated maximum exposure of $5585 \mathrm{Min}$ /ton at the end of ETR Cycle 90 is therefore somewhat less than was preaicted last month. The maximum tuel core temperatures range from approximately 360 to $540{ }^{\circ} \mathrm{C}$.

These fuel elements: 0.45-inch alameter by 6.25 -inch long and clad with Zr-2, are part of an irradiation test that has been designed to operate uranium fuel rods at elevated alpha phase tem" peratures to burnups greater than $10.000 \mathrm{MWa} /$ ton 16 x 1020 issions/ $\mathrm{cm}^{3}$ ) The variables being studied in this test include fuel composition. 
external restraint, and internal vold volume. The combined effects of the plastic character of uranium during irradiation and the restralnts from the cladding and system pressure are expected to cause the uranium swelling to be accommodated by a central hole Two uranium compositions are being used. A.lloy 1 , containing U +

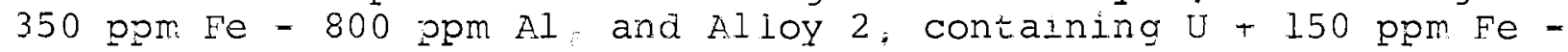
$100 \mathrm{ppm} \mathrm{S1.} \mathrm{A} \mathrm{fuel} \mathrm{enricinment} \mathrm{of} 4.5 \%$ U-235 is being used to achieve the desired burnup rate $110,000 \mathrm{MWd} /$ ton $1 \mathrm{n}$ one calendar yearl and temperatures. Fuel rods of both compositions were fabricated by coextrusion to 0.450-inch diameter with 0.025 -inch and $0.050-1$ nch thick $\mathrm{zr}=2$ cladäing.

At the end of ETR Cycle 90, welght measurements were macie in the reactor basin on all of the elements irradiated thus far in tils test. Volume changes calculated from these weight measurements showed that all elements continue to exhlbit small volume decreases From the data obtalned a reversal of volume decrease has been established as occurring between 1000 and 2000 Mwdicon on elements claci with $0.050=$ Inch thick Zr-2 with nominal 5; 10, and 20\% initial vold volumes. For the elements clad. with 0.025 -inch $\mathrm{Zr}=2$ the volume decrease reversai is also occurring but at a much slower rate with burnup. Extrapolation of the swelling rates indicates that the element clad with 0.050-inch thick $\mathrm{zr}=2$ and having initial vold volumes of 10 and $20 \%$ will not reach their preirradiation volumes again until their respective exposures are 7000 and 10,000 Mid/ton.

Hot cell measurements of àameter, length, and alr welght were made on three elements that have been irradiated in tils test. The measurements inalcate diameter changes from 0 to $=0.002$ inch. $\mathrm{Al}$. though the 0.002 ciecrease 1 s within the accuracy of hot cell micrometer measurements, this decrease is equivalent to a 1 to $1.2 \%$ decrease in area of the rod. Length changes rangea ثrom 0 to $=1.85 \%$ This would also account for part of the volume decrease. The direction of the combined length and diameter changes is in agreement with the volume change measurement's by water immersion. Air measurements indicated a slight increase of 0.003 to $0.005 \mathrm{gram}$. This increase, which is not compensated for in the volume calculations from Immersed weights: affects the volume changes by less than 0 . I\% A very thin readish film seen on the cladiing. which could be easily removed by brushing, may account for the welght increase Aadr= tional hot celi measurements are planned for other elements in this test Visual examination of the elements in the hot cell showed no unexpected degradation of the cladding or weld of the fuel elements.

Examination in the reactor basın of the elements irradiated during cycle 90 showed no unusual or unexpected changes in the cladding of the elements. Warp measurements indicated that no significant change had occurred during the irradiation cycle. 
Fast Reactor Dosimetry and Damage Analyses

(R.E Nightingale)

Spectrum Analysis by Neutron Detector I I Computer Code (SAND II)

A computer code. SAND II; developed by Atomics International to determine neutron flux spectra by a fully automated Iterative method and three smaller associated codes, named SCTAPE; SLACTS. and SLTAPE: (Ref. Air Force Technical Report No. AFWL-TR-67-4l. Volumes I through IV, July 1967) are being adapted to operate on the CSC computer tacilities. A new subroutine named GRAF has been added to provide graphical plots for the SAND II input and output flux spectra. The GRAF subroutine is also being incorporated into the SAND I code for purposes of obtaining graphical piots of foll re= action cross sections and sensitivity iproduct of flux and cross section) curves. The SAND I code is already operational on the CSC computer facilities

Neutron Spectral = Fluence Monitor for Fast Reactors

Consideration is being given to the ldea of using a set of relatively short half-life reactions (say: a few days) along with one or two reactions that produce stable products to provide a spectral-fluence monitor package for fast reactor irradiation tests and survelliance studies. The intent would be to use a properly selected set of relatively short half*ilfe foll reactions that would reacin saturation during the last few days or weeks of reactor operatıon. The measured values of saturated activity would be used with an initial spectral approximation ipreferably a precilction based on reactor physics calculationsi as input to the SAND II code to obtain an improved Iteratıve solution flux spectrum. This solution flux spectrum would then be used to calculate the spectrum-averaged cross sections that would be needed for the proper interpretation of the fluence monitor(s)

A preliminary study indicated that reactions such as $U=235(n, f)$. $U=238(\mathrm{n} ; \mathrm{f})$, and $\mathrm{Np}=237(\mathrm{n}, \mathrm{f})$ would be satisfactory for the fluence measurements. For example, If $\mathrm{U}-235 \mathrm{in}$ :f) were used, existing methods of burnup analysis for the stable reaction product $N d=148$ (or the very long-lived fission product Cs:137) would be used to determine the number of tissions during the total irradiation time. The iterative solution flux spectrum plus the spectrum-averaged cross section for the $U=235(n, f)$ reaction would provide all of the information necessary for determining the total fllience for the neutrons above any specified energy such as l MeV 
ENGINEERING DEVELOPMENT

Neutron Flux Monitors (W G Spear)

Thermal Neutron Flux Detectors

Regenerative Detectors. Ten detectors including four $\mathrm{U}=234$ U-235 regenerative, one $\mathrm{U}=235$ fission, one gamma, and four $\mathrm{Rh}=103$ self=powered beta current devices are being assembled into a singìe test capsule for 1 rradiation testing at the ETR. Primary effort has been directed toward capsule fabrication and test instrumentation assembly in preparation for the comprehensive reactor in.core tests. This program is to evaluate performance characteristics of the regenerative thermal neutron flux detector and to compare operational performance with the other detector types.

Reference bench measurements of insulation resistance and detector capacitance were made on ali ten detectors preparatory to capsule assembly. Capsule body; lead flange, flange adaptor and lead tube were fabricated In addition, progress was achieved on the assembly and wiring of electronic components for use in performing the extended measurements of detector performance during irradiations

The regenerative detector offers extended life characteristics by overcoming the usual rapid burnout of U.235 detectors in high neutron flux levels. This is accomplished by the use of a sensitive $\mathrm{U}-234$ - U=235 detector material in which U-234 transmutes to U-235 to replenish fissioned atoms. thus providing a long lived and more constant sensitivity during reactor in-core use

Microwave Detectors. A plasma created within a microwave resonant cavity will shift the resonant frequency and change the cavity $Q$ by amounts determined by the plasma free electron density. By using an appropriate reaction with thermai neutrons, such as the $(n, p)$ reaction $w i t h H e=3$, the resulting charged particles will cause ionization of the gas. thus producing a plasma density related to neutron flux density. The resulting cavity frequency is then a measure of the neutron $f l u x$ density

During previous in-core experiments, a reduction in sensor sensitivity was observed due, in part, to the inclusion of a dielectric capsule gas container. Neutron flux sensors with increased sensitivity are expected by containment of the He=3 gas within the resonant metal cavity. Several cavity designs which should provide both the required vacuum integrity and the signal coupling capability are being fabricated. Minor mechanical changes to the cavity should permit their successful completion Effort is also being directed to the completion of a separate cavity design which. If successful: would alleviate certain of the fabrication and assembly problems 
One detector has been assembled with low temperature soldering techniques, but it is anticipated that "bake out" may be incompiete. During in-reactor experiments it may be possible to exchange the gas contalned in the detector to reduce the contamination problem.

\section{East Neutron Flux Detectors}

To achieve rugged, long-lived reactor in-core detectors for fast neutron flux. Significantly more difficult demands are placed on the characteristics of a detecting material and device. Under anticlpated reactor conditions the detectors $w i l l$ operate in severe temperatures, under high fast flux densities, and in high gamma exposure levels. Of the techniques used in thermal flux detectors. It appears that several methods are worthy of exploration for adaptation to fast flux measurements. Beta current detectors, regenerating types, and microwave detectors appear sultable for this further study. Each of these methods depends upon finding an appro* priate isotope or combination of lsotopes to produce the desired effect in a detector. Therefore, the capture and fission charac* teristics of various isotopes and other neutron reactions are under investigation

Regenerating Detectors For regenerative detecting techniques computer analysis methods, arawing upon an extensive library of tast flux data; are being used to Identify posslble candidate lsotopes for sultable regeneration with appropriate sensitivity. Many of the heavy elements capture and fission characteristics are being explored.

Beta Current Generator Detectors It appears that the $(\mathrm{n}-\boldsymbol{x})$ reaction of $\mathrm{Be}=9$; which has 0 l barn cross section at $3 \mathrm{MeV}$. is a possible candidate material for a fast flux beta current generator detector. In this detector the resulting beta emission (.3.5 MeV); which occurs within the short half life of 0.8 second, will generate a signal proportional to neutron flux density. It is anticipated. that $B e-9$ in a metal oxide form can be encapsulated in a sheath which is opaque to the alpha particles but allows the betas to pass through. The loss of charge results in a signal current A signal current of $1 \times 10=6 \mathrm{~A}$ from one $\mathrm{cm}^{3}$ of Be-9 is expected in a fast flux of $1015 \mathrm{nv}$. To reduce the effects of gamma-induced currents balanced twin-lead and twin-chamber concepts, as developed during thermal flux detector investigations: will be used.

Evolved Gas Detection Concept. This technique, in which gamma interference is greatly minimized by locating all instrumentation external to the reactor core; is based on measuring an evolved gas released in an $(n ; x)$ or $(n, p)$ reaction with $B=10$ or other material. The gas would be collected through a simple evacuation tube connected to the detector assembly. Several methods to measure the evolved gas include the use of mass spectrographs; optical spectrographs; or microwave resonant cavities. Calculations indicate about 1011 atoms sec-1 of hellum could evolve from 1 gram of $B=10$ in fast flux of $1013 \mathrm{nv}$. 
Microwave Detectors. To achieve an appropriate plasma in a microwave cavity from fast neutron flux. many of the techniques developed for use in thermal flux will apply directly. The basic difference will be in the materlal used to react with the fast neutron to create the energetic charged particles necessary for ionization. Fissioning $\mathrm{U}=238$ or proton recoll in hydrogen appear to be likely candidates. The use of a gas such as hydrogen, would allow cavity purging and replenishment if necessary Due to the considerably reduced neutron cross sections at fast $f$ lux energies, gamma caused lonization will be significant and compensation techniques will be necessary

To measure evolved gas by microwave techniques, the gas is either evolved into or collected by the microwave cavity. The resulting frequency shift is a measure of the neutron flux density. It has been shown theoretically that measurements of fast flux down to $10^{1} 1$ ny could be achieved for a gas evolution rate of $10^{-2}$ atoms $\sec ^{-1} n v^{-1}$.

$\frac{\text { Microwave and Infrared Detection of Coolant Impurities }}{\text { and Measurement of In }=\text { Reactor Temperature }}$ (W. G. Spear)

Microwave Detection of Impurities in Coolant Gases

An atmosphere inappropriate to reactor operation can be created when reactor coolant gas is contaminated with water vapor. propagation properties of electromagnetic waves in microwave structures are affected by the dielectric constant of the propagation medium.

Therefore, the dielectric constant of a reactor coolant gas such as helium, through whlch microwaves are propagated may be determined by measuring the phase or attenuation of the microwaves. Because the dielectric constant of a gas mixture is related to the number of gas molecules of each gas present and to their molecular poiarluabilıtıes; It is possible to determine the impurity concentration from the measured microwave effects.

A microwave interferometer operating at 30 to $35 \mathrm{GHz}$ is being assembled to determine experimentaily the sensitivity of detecting water vapor in helium. One arm of the interferometer is a section of wavegulde through whlch the gas samples are passed. Phase changes due to the addition of selected samples will be measured by nulling the detector output with a precision variable phase shifter in the balance arm. To provide maximum sensitivity, initial effort is directed to the reduction of the background or noise signal present for a balanced interferometer. Theoretical calculations indicate a phase shift of $1.2 \times 10^{-6}$ degrees/ppm/cm for water vapor in helium.

Also envisioned during this experimental effort is a second scheme providing direct readout of phase shift by using a ratio meter. 


\section{High Temperature Measurements}

Because of lts relation to reactor power level, it is required that temperature of in-core components be measured accurately and precisely. Long=lived sensors are desired to reduce maintenance and replacement costs. Several methods appropriate to the measurement of reactor temperatures using microwave techniques are being investigated.

One method, which depends upon the shift-of-frequency of a microwave cavity as temperature changes, ylelded a nearly linear temperature-frequency response of $300 \mathrm{kHz} /{ }^{\circ} \mathrm{C}$ during several experlmental tests to $1000^{\circ} \mathrm{C}$. By using an assembly made entirely of nickel-chromium steel these tests have been extended in temperature to $1300{ }^{\circ} \mathrm{C}$. Sensitivity increased to $330 \mathrm{kHz} /{ }^{\circ} \mathrm{C}$, although linearlty of response is maintalned only to 1200 OC. Above $1200{ }^{\circ} \mathrm{C}$, the sensor material becomes mechanically weak and is deformed. Higher melting point metals will be required to extend these tests above $1200{ }^{\circ} \mathrm{C}$.

Another microwave method of measuring temperature employs a radiometer which detects the electromagnetic energy emitted from any heated body. Experiments in which the emissive power from a nearly black body immersed in an oven was measured indicated a sensitivity of $0.175 \mathrm{mV} /{ }^{\circ} \mathrm{C}$ for temperatures to $9500^{\circ} \mathrm{C}$. Several attempts to measure the emissive power directly by using a horn receiver antenna demonstrate the need for a more directive antenna. By narrowing the fleld of view, it should be possible to measure specific body temperatures more accurately

\section{Infrared Techniques}

Preliminary calibrations of the second experimental infrarea absorption hygrometer were initiated following incorporation of several moalficatıons. Further developmental effort centers on the determination of an optimized, combined wedge filter and filter wheel assembly. The system is being developed to measure the molsture content of high temperature helium used as a nuclear reactor coolant.

Electronic modifications have made the hygrometer less sensitive to line voltage changes and considerably easier to use. The voltage applied to the source lamp is now regulated after tests demonstrated that line voltage variations could shift the calibration because of the source lamp temperature change and consequent change of its black body curve. The regulator effected an improvement such that a $10 \%$ change in the line voltage to less than $1 \%$ change on the lamp fllament voltage. At the same time this eliminated the $120 \mathrm{~Hz}$ nolse signal from the lamp to the Pbs detector cell. Following modifications of the servo position indicator clrcult, the full range of the meter can now be used for servo motor rotations of less than 10 degrees. Instead of the 360-degree rotation previously required. This serves to improve the resolution of the instrument. Other changes 
included incorporation of a latching relay for changing the phase on one winding of the servo motor and, consequently, its direction of rotation, A cam on the motor shaft actuates microswitches; thereby energizing the relay. which was installed to more easily obtain the initial null with the filters. Previously, the rotation could be changed only tiwlce at most, and if the null were not obtained by then, the cover had to be removed from the source-motor chamber to reset the rotating filter into a workable position.

The source-motor chamber can now be flushed with ary carbon dioxide this technique reduces system sensitivity to normal amounts of carbon dioxide. After chamber flushing, an amount of $\mathrm{CO}_{2}$ equal to 50 times that which a normal atmosphere would introduce was inserted into the absorption cell with no effect. Thus; the $\mathrm{CO}_{2}$ interference problem appears to have been solved.

Investigations were initiated towards computer programming the various parameters of the system to help analyze, explain. and predict system behavior. It may be possible to employ this program to aid in determining optimum shapes for new wedge filters and filter wheels for future experiments.

\section{PLUTONIUM UTILIZATION PROGRAM ( $F, G$. Dawson)}

\section{Fuels Deve lopment}

Instrumented Fuel Rods

Two of four fuel rods instrumented to measure fuel rod gas pressure and temperature continue to operate satisfactorily in PRTR. The instrumentation on the other two fuel rods is inoperable due to elec= trically shorted pressure sensing lines. The electrically shorted pressure sensing lines, which are on the high power fuel rods, were damaged during charge discharge operations. An attempt to repair this instrumentation will be made during early september. Two of the fuel rods are operating at maximum linear power ratings of approximately $16.2 \mathrm{~kW} / \mathrm{tt}$ and two are operating at $8.4 \mathrm{~kW} / \mathrm{ft}$. Calculated burnups achieved in the two sets of fuel rods are $1900 \mathrm{MWd} / \mathrm{ton}$ and $880 \mathrm{MWd}$ /ton, respectively. The maximum pressure reading in the high power fuel rod is much greater than that in the low power fuel rods 165 psi versus 18 psi, respectively?

As previousiy reported; the data indicate that the pressure increases in a stepwise manner during subsequent reactor startups and then remains constant during steady power operation after shortterm, steady power operation $(.50 \mathrm{hrs})$. Although it is difficult to confirm gas release trends at the low burnups, it appears that the fission gas pressure increases as a function of burnup and average volumetric fuel temperature (this is close to the expected trend): 
However the pressure increase due to sorbea gases and moisture in the fuel is much less than would be predlcted from the analysis of the fuel material. Although PRTR steady power operation has been $11 \mathrm{mlted}$. It appears that gas release occurs during shutdown rather than during startup after longer periods of steady power operation (150 hrs; No significant gas release has been observed during steady power operation.

Handling Equipment for FERTF Fuel Elements

Equipment is being installed in the new basin facility of the PRTR to handle the elghtm rod FERTF fuel elements. It is planned to complete the equipment installation and dry runs (to demonstrate the manipulating ability of the equipment) with dummy fuel elements during this month

TREAT Transient Testing

High speed motion pictures were taken of two vibrationally com pacted $\mathrm{UO}_{2}(5.01$ at. $\mathrm{U}-235)$ fuel rods whlle undergoing transient irradiation in the TREAT Facility. One fuel rod was subjected to a fission energy input of about $280 \mathrm{cal} / \mathrm{g} \mathrm{UO} 2$, and the second rod was subjected to a fission energy input between 300 and $350 \mathrm{cal} / \mathrm{g} \mathrm{UO} 2$ The films of both tests have not yet been developed. Visual observation of the rods through a serles of mirrors in the transparent autoclave was possible after each experiment. Both rods appear to have developed three high temperature bands during irradiation. The bands are at the top, center, and bottom of the fuel columns. The cladding of both rods appears to be split open in the area of the bottom high temperature bands. A better understanding of the transient behavior of the two rods will be obtalned upon receipt of the developed films and examination of the rods.

A series of experiments was formulatea to establish the failure threshold of thermal reactor oxide fuel rods undergoing power transients. Approval in principle to conduct such tests was obtained from the Laboratory Director's office of ANL. The design of two pressure autoclaves for use in this program is nearing completion. Approval to use the autoclave designs will have to be obtained from the Director's Office of $\mathrm{ANL}^{\prime}$ 's Idaho Division before experiments can be conducted under this program.

Radiation Effects in oxide Fuels

A document describing a proposed irradiation testing program for evaluating some of the radiation effects in oxide fuels $\left(e . g . " \mathrm{UO}_{2}\right.$. $\mathrm{UO}_{2}-\mathrm{PuO}_{2}$, $1 \mathrm{~s}$ being prepared.

The trend in oxide fuel design is to higher linear powers. longer fuel $11 \mathrm{fe}$, and greater reliability included in the fuel design objectives are lower fuel cycle costs and optimization of 
design, process, and quality control parameters which affect reli= ability

A number of problem areas must be investigated to achieve the desired lmprovements. Included in the problem areas are questions, for example, on the change in melting point of $\mathrm{UO}_{2}-\mathrm{PuO}_{2}$ as a function of burnup. on the microstructural features of the fuel as a function of time and temperature, and reproducibility of fission gas release in high burnup fuel. The experiments being planned will provide data to aid in the solution of some of these problems and will furnish justification for further and more extensive studies.

Irradiation of Low Density Mixed Oxide Pellets

An experimental seven-rod cluster fuel element containing low density mixed oxide pellets was fabricated. The element is to be irradiation tested in the $\mathrm{P}-7$ loop of the ETR, Each rod in the 33-inch long cluster contains 0.500-inch diameter $\mathrm{UO}_{2}-0.5 \mathrm{wt} \% \mathrm{PuO}_{2}$ cold pressed and unsintered pellets. The pellet densities are approximately 73\% TD. Fuel movement restrictors of various forms (elther tungsten disks or depleted $\mathrm{UO}_{2}$ pellets) are included in each rod. The cluster will be irradiated for one cycle in the ETR at a linear rod power of $: 16 \mathrm{~kW} / \mathrm{ft}$.

A second; identical fuel element is being fabricated. It will be Irradiated under the same conditions but to a burnup of approximately $10,000 \mathrm{MWd} / \mathrm{ton}$.

\section{PRTR Testing}

Six additional PRTR fuel rods were destructively examined in Radiometallurgy to provide additional information on the reactor power calibration and on some of the apparent anomalies observed during the previous fuel examinations. Some of the tentative conclusions derived from the most recent examination are as follows.

Ceramographic evidence of typical oncem molten fuel. structures formed during irradiation are erased by time temperature dependent diffusion phenomena in less than 72 hrs of Irradiation under nonmolten but high temperature conditions.

Fission product distribution patterns typical of molten fuel operation as indicated on $B=y$ autoradiographs are not completely eradicated during 72 hrs of subsequent nonmolten irradiation.

Fuel structures formed in different roās irradiated under the same nonmolten conditıons are comparable. 
There was no evidence of fuel melting in the rod 12 inches each side of the section that indlcated $10 \%$ of the radius moiten. In another rod approxi = mately 10 of of the fuel radius was molten in a section 12 inches below the section that indicated $33 \%$ of the radius molten at the maximum flux position: These observations indicate that the extent of fuel meling axially, was not very extensive

The 8-rod FERTF test element has been tested in a hydraulic test loop under PRTR conditions for 84 days with no evidence of wear between components within the assembly and only minimum wear or fretting between the protective sleeve and zircaloy pressure tube The flow tests have been temporarliy discontinued to permit fueling vehicle cooling studies with the assembly

The summary of a paper titled "Plutonlum Fuel Irradiations in PRTR-Present Status, "by M. D. Freshley T' B. Burley, and S coldsmith has been accepted for presentation at the forthcoming winter seeting of the ANS and publication in Transactions.

ETR Testing

Postirradiation examination of an intentionally defected fuel rod containing vibratıonally compacted enrlched UO2 was started. Preliminary observations indicate no change in appearance on fuel rod diameter. The rod was irradlated for nine effective full power days as part of a 7 -rod cluster in the ETR $\mathrm{P}=7$ loop at a inear rod power of 28 to $29 \mathrm{kw} / \mathrm{ft}$. At this rod power an estimated 60 to $65 \%$ of radius was molten. Postirradiation examination is continuing.

High Exposure Plutonium Studies

Adaption of the Lawrence Radiation Laboratory's computer program for energy spectra photo peak integration and analysis is now partially operational. Photo peaks separated by as few as eight channels can be identified by the program.

Surface dose rate measurements were continued on Shippingport and Dresden $\mathrm{PuO}_{2}$ samples to follow the dose rate increases with time Measurements were also made on a relatively low exposure $\mathrm{PuO}_{2}$ sample containing approximately 88\% pu-239 which gave a considerably lower suriace dose rate as expected in relation to lts isotopic composition. Ilowever preliminary shielding measurements revealed an interesting reverse pattern. The radiation from the low exposure $\mathrm{PuO}_{2}$ was more difflcult to shield out than from the high exposure $\mathrm{PuO}_{2}$ - Attenuation was obtalned in decreasing amounts for shippingport (65\% Pu-239). Dresden 169\% Pu-239), and the low exposure (88\% Pu-239) material, incilcating the hardest gamma spectrum for the lowest exposure $\mathrm{PuO}_{2}$. Gamma spectra measurements will be made to determine the source of the higher gamma energy contributions. 
FERTF FueI Roc̈s

A total of $22 \mathrm{UO}_{2}-2$ wto $\mathrm{PuO}_{2}$ and $12 \mathrm{U}-235$ enriched $\mathrm{UO}_{2}$ vipaced FERTF fuel rods were fabricated during the month of August.

ETR Clusters

An experimental 7-rod cluster, $\mathrm{UO}_{2}-0.5$ wto $\mathrm{PuO}_{2}$. 73 \% density, for irradiation in the ETR, was completed. A second cluster was completed to the autoclaving operation.

\section{Physics Measurements}

Commercial Fabrication of PRCF Fuel Rods

Commercial procurement is nearing completion under the two-step procurement procedure to obtain a large quantity of (4 wt: $\mathrm{PuO}_{2}=\mathrm{UO}_{2}$ test fuel rods required for critical experiments in the $\mathrm{PRCF}$.

All five technical proposals received from commercial fabricators under step one were found to be technically acceptable on July 27. The request to the Commission to proceed with requesting prices under step Two was delayed pending clarification of questions recelved by the Commission on the plutonium supply agreement. Also, information was requested by BNW on "in"house" costs for various forms of plutonium to be used in evaluating bids under step Two. After a series of meetings with the Commission, these questions and costs were resolved, ana the costs were received.

One key question from commercial fabricators involved the question of the AEC revising the Pu Supply Agreement to permit scrap material to be returned by the contractor. It was decided that contractors must process the scrap material and return the Pu as nitrate as speclfied in the original agreement.

Permission was then received from the Commission that step one was acceptable and that step Two was authorized subject to inclusion of new information about the plutonium supply agreement in BNW"s requests for pricing.

On August 23, Step Two was initiated. Requests for pricing, and including the new information about the piutonium supply agreement, were sent to the five commercial fabricators. Bids are due back by september 15 . About 200 test rods are being requested for delivery on November 30 1967 ; other options are included about possible delivery dates for additional fuel rods. 


\section{Reactor Physics}

\section{D20 Moderated Systems}

Batch Core Experiment in the PRTR. Performance of Batch Core Power Tests in the PRTR has continued. Power Test Number 6 , the xenon transient test, has been repeated under more optimum condl= tions of moderator sampling. The moderator samples have been compared in the Thermal Test Reactor to determine their boron concentrations. Analysis of the xenon transient test is in progress. The computer code XRST, Whlch calculates fission product poisoning in PRTR, has been converted for use on the UNIVAC 1108

Preparations for the first set of Batch Core Interim Critical Tests are nearly complete. These tests are scheduled to be performed during the first half of september.

The summary entitled "Power Tests with the $\mathrm{UO}_{2}-2$ wto $\mathrm{PuO}_{2}$ Batch Core in the PRTR" by $J$. W. Kutcher, R. E. Harris; and R. I. Smith, has been accepted for presentation of a paper at the 1967 winter Meeting of the ANS

Technical Assistance to PTU. Technical assistance is being furnıshed to the Process Technology Unıt, PRTR Section, Engineering Services Department. Efforts have continued to determine the maximum allowable spike power in a fuel rod which wlll not produce fuel melting. Gamma scanning of several specially selected fuel element bands is planned for the next scheduled reactor outage.

PRTR Test Number 116, Testing of the Pneumatic Faclilty, is in progress. Pins of $A 1$ - 0.1 wto $C o$; lrsadiated at a reactor power of $50 \mathrm{MW}$ : failed to yield sufficlent long-lived activity for counting A second Irradiation has been made using pins of Zr $=0.5$ wto Co.

Calculations have been made with the computer code XRST to provide information on changes in axial flux peaking factors with changes in reactor power. Under certain conditions an increase in reactor power will produce an initial decrease in fission product polsoning: thus causing an increase in axial flux peaking and a reduction in allowable reactor power

$\underline{\mathrm{H}_{2} \mathrm{O} \text { Moderated Systems }}$

Reactor Application Studies Fabrication of the structural hardware for the $\mathrm{P} R \overline{C F}$ core to be used in the joint USAEC-CNEN COoperative program is about $80 \%$ complete. The major uncompleted Items are the top and bottom templates. Modiflcation of the poison sections of the control rods and of the $\mathrm{UO}_{2}-2$ wto $\mathrm{PuO}_{2}$ fuel followers has been completed. Modification of the enriched $\mathrm{UO}_{2}$ fuel followers has not yet started. Shortening of the 600 enriched $\mathrm{UO}_{2}$ fuel rods has been delayed by problems with off-gasing during the welding of the new end caps 
Analysis of reactor excursions is being performed for the $0,75-1 n c h$ and the 1,06-inch square lattices. using the MIDAS analog simulation code. The studies will include ramp and step reactivity insertions for both lattices, with two fuel compositions, $\mathrm{UO}_{2}=2$ wt\% $\mathrm{PuO}_{2}$ and $\mathrm{UO}_{2}=2,3 \% \mathrm{U}=235$.

$\mathrm{UO}_{2}=4$ wt: $\mathrm{PuO}_{2}$ Fuel Rods: The planned experiments in the Critical Approach Facility (CAFF) using the $\mathrm{UO}_{2}-4$ wto $\mathrm{PuO}_{2}$ fuel rods have been delayed, pending acceptance by the AitC of the CAF Final Safeguards Analysis document. The modification and improvement work on the CAF has been completed, and experiments will proceed immediately upon acceptance of the safeguaras documentation.

Gamma Scanning of EBWR Fuel Pirs. The scanning of the first group of $\overline{1} 7$ EBWR fuel pins has been completed, using a NaI(TI) detector. These pins were removed from EBWR on February 11,1967 , and have an exposure of approximately $1300 \mathrm{MW} d / t o n$. Each pin was scanned to determine the relative distribution of fission products along the pin. Also, gamma-ray spectra were obtained using a multichannel analyzer, with the NaI(Tl) detector, from each of the six different fuel compositions available. A set of six readings from eaci pin. taken over a two-day period, will be used to normalize all the data. The results from gamma scanning have been utilized to select rods and sample locations for destructive analysis.

Scanning has started on a second group of 17 pins which were removed from EBWR April 29. 1967, with an average exposure of about $2300 \mathrm{MWd} / \mathrm{ton}$

A Ge(Li) detector has been installed in the gamma scanner. Gamma ray spectra obtained with the new detector will be compared with the spectra obtained with the NaI(Tl) detector.

Analysis of Clean Lattice criticais The analysis of $\mathrm{UO}_{2}$; $\mathrm{Al}-\mathrm{Pu}$, and $\mathrm{UO}_{2}=\mathrm{PUO} 2$ Eueled ${ }_{20}$ moderated lattice criticals has continued A systematic evaluation of the effect of neutron leakage on reactor multiplication values, keff is bejng made. The objective of this evaluation is to determine the degree of theoretical sophistication required to accurately compute the neutron leakage from these finite assemblies.

Temperature coefficients of $\mathrm{PuO}_{2}, \mathrm{UO}_{2}-\mathrm{H}_{2} \mathrm{O}$ Lattices. A summary of a paper entitled "Temperature coefficients of PuO 2 - $\mathrm{UO}_{2}-\mathrm{H}_{2} \mathrm{O}$ Lattices" has been accepted by the ANS for presentation of a paper at the winter Meeting of the ANS. The paper will give analytical correlations for temperature coeificients measured in a number of $\mathrm{PuO}_{2}-\mathrm{UO}_{2}-\mathrm{H}_{2} \mathrm{O}$

lattices. 


\section{$\underline{\text { PCTR Light Water Moderated Core Tank }}$}

Experiments in the PCTR with $\mathrm{H}_{2} \mathrm{O}$ moderated mixed oxide fueled lattices have been initiated. The request for authorization and experiment authorization letters were issued complete with an experiment outline covering the first loading and control system reactivity worth measurements. The water core tank was installed in the test region complete with its associated plumbing, filled with water, and leak checked. The installation of the electrical controls for the pump and valves was partially completed. The initial loading of reactor was started. First test fuel is 0.9 wt: low exposure Pu, mixed oxide, 0.5 inch diameter and is loaded in a l-inch square lattice. This was chosen for the low multiplication to enhance the safety of these $1 n \perp: i a l \mathrm{H}_{2} \mathrm{O}$ tank experiments.

PCTR Water Tank Calculations

A series of calculations to study the reactivity of half inch 0.90 wto $\mathrm{PuO}_{2}$ mixed oxide rods at various square lattice spacings in light water in the PCTR water tank have been completed. The density of the rods is $9.637 \mathrm{gm} / \mathrm{cm}^{3}$ and the $0 . D$. Of the Zircaloy cladding is 0.565 inches. The isotopic composition of the mixed oxide plutonium and uranium is listed in the table below:

\section{Mixed Oxide Plutonium and Uranium Composition}

\begin{tabular}{lccc} 
Isotope & Atom Percent & Isotope & Atom Percent \\
\cline { 2 - 4 } & & Atom & \\
Pu-239 & 92.139 & $\mathrm{U}-234$ & 0.005 \\
$\mathrm{Pu}-240$ & 7.241 & $\mathrm{U}-235$ & 0.234 \\
$\mathrm{Pu}-241$ & 0.595 & $\mathrm{U}-236$ & 0.006 \\
$\mathrm{Pu}-242$ & 0.025 & $\mathrm{U}-238$ & 99.755
\end{tabular}

Considerable effort has been made in the development of a onedimensional calculational model of the PCTR and to compare the results with experiment, including the effect of the shutter type control rods. A second generation calculational model that seems to represent the PCTR quite well has been used for these PCTR water tank calculations. Group constants for the HFN 4-group diffusion theory calculations were obtained using TEMPEST, modified THERMOS, DANCOF, and HRG.

The following table lists the calculated values of $k_{\text {eff }}$ for the PCTR with no drivers and all control rods open. These calculations were made with the inner (1l.5 inch) water tank only 
(outer tank dry) loaded with mixed oxide fuel at various square lattice spacings in light water.

$\frac{\text { PCTR keff for Inner Water Tank Fully Loaded (Control Rods Open - }}{\text { No Drivers) }}$

Lattice spacing

(Inches)

$$
\begin{array}{lc}
\text { Inches) } & \mathrm{k} \text { eff (PCTR) } \\
\cline { 2 - 2 } 0.65 & 0.85967 \\
0.80 & 0.88277 \\
0.95 & 0.83128 \\
1.00 & 0.80730 \\
1.05 & 0.78176 \\
1.15 & 0.72828
\end{array}
$$$$
0.80 \quad 0.88277
$$$$
1.00 \quad 0.80730
$$$$
1.15 \quad 0.72828
$$

Thus, it is predicted that the PCTR cannot be made critical by loading only this mixed oxide fuel into the central water tank.

The following table gives the effect on the PCTR of collapsing the lattice spacing in the inner tank of an initial just critical loading of the mixed oxide at the 1.0 inch pitch (outer tank empty). A predicted 32.4 driver column is required for critical in this initial case with all control rods open and no flux modifiers. The lattıce was then collapsed uniformly keeping the number of rods and the moderator volume constant.

\section{Effect of Collapsing the Water Tank Lattice}

Description of the Mixed Number of PCTR Oxide in the Water Tank Drıver Columns

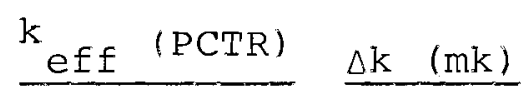

32.39

32.39

32.39

32.39
1.0000

0.9965

0.8871
0.9463 $-\quad 3.5$

$-53.7$

$-112.9$

These results indicate that a collapse of the lattice spacing from 1.0 inch in the center tank loading will not result in a PCTR reactivity increase even at the more optimum 0.80 inch spacing.

Values of $\ell=9.63 \times 10^{-4}$ seconds and $\beta=4.63 \times 10^{-3}$ were calculated, respectively, for the PCTR prompt neutron lifetime and effective delayed fraction under the following conditions: L0 inner water tank loaded with the 1.0 inch square pitch mixed 
oxide; 2) all control rods are open; 3) no flux modifiers used; and 4) 32.4 driver columns are loaded.

PCTR Spectral Matching in the Water Tank

The use of the two foll method to determine spatial variations of the flux spectra in the water tank is under investigation. An $\mathrm{Au} / \mathrm{Dy}$ activation ratio is presently being given major consideration as a spectral indicator, but other resonance and $1 / \mathrm{v}$ detectors may also prove to be useful. An irradiation is being planned to determine the practicability of using these and other detectors.

Lu has already been ruled out as a possible candidate due to the necessity of having to walt three to four days to count the Lul77 activity. The short half life of Dy (and Mn) makes it necessary to be able to remove these folls soon after rod drop. A means of doing this without opening the PCTR face has yet to be devised.

In the interlm we plan to use the standard gold cadmium ratio technique. The 4 rod central cell and 12 rod radial buffer will be loaded with bare and cadmium covered 0.036 inch diameter, 1/4 inch long gold pins. Measurements further out in the radial buffe will also be made during the first experiment. This latter data will supplement that obtained from the radial tube traverses with bare and cadmium covered $20 \mathrm{mil}$ gold wires.

Spherical $\mathrm{PuO}_{2}$ Particle Fuels

A set of four mixed oxide test plns, contalning 2 wto $\mathrm{PuO}_{2}$ spheres, enriched $24 \% \mathrm{Pu} 240$, uniformly distributed in $\mathrm{UO}_{2}$ powder, were fabricated and delivered to the PCTR. The pins were made up of one-half inch diameter pellets in a 20-lnch long column, and clad with zircaloy. The spheres of 100 micron size were made by the Induction-plasma process.

Progress in fabricating 350 micron size spheres is being restricted because of a melting problem in the quartz confining tube when higher power is used to spheroidize the longer particles. Methods of improving the heat transfer characteristics of the confining tube and within the shroud are in process. 


\section{Code Development*}

BARNS-II. BARNS-II has recently been revised to permit numerical integration of group cross sections in energy ranges which use resonance parameter tables. Some calculations using this option have converged slowly in the integration over the wings of a resonance when a broad group is used. Several methods for improvIng this convergence are being examined in an effort to speed the calculation.

Background calculations done by BARNS-II for some nuclides for the HRG data tapes have been higher than expected. A probability of reducing this background by including parameters for lower energy resonances which have been omitted from the resonance parameter tables for these nuclides is being tested. A special operating procedure for BARNS-II has been developed for these tests.

HRG Data Tapes. Some users of HRG have reported details of errors in data for some isotopes; there errors have apparently been introduced during several special-purpose data manipulations during the past few months. While known errors can readily be corrected, their unexpected presence raises the serious question that other errors have been introduced that are not yet detected. To check this possibility, a short code has been written to compare data on HRG library tapes in some detail and provide information on points of disagreement. The code is being debugged.

ETOM. Recent modifications received from WAPD have been incorporated into the computer program ETOM, which calculates multi-group cross sections for MUFT and HAMMER from the ENDF/B library. Previously, ETOM generated incorrect output when the input data contained negative or thermal resonances. The calculations now appear to be correct.

EDIT. The computer program EDIT which is used to print, punch, or copy an ENDF/B neutron cross section library tape has been modified to allow the manipulation of the secondary energy distributions contained in File 5 on the library. The necessary programming to handle File 5 was not included in EDIT as it was originally distributed. Several successful debug runs have been made to test the modifications.

* Partially supported by DUN. 
Space-Time Kinetics. A modified version of the WIGLE ${ }^{1}$ code, written for the IBM 7040, has been made operational on the 1108 . Only a few minor changes need to be made before the code will be completely available for use. The WIGL 2 code has been received from Philco and has been compiled on the 1108. All compiler differences between the Philco-2000 and the 1108 have been corrected. The WIGL 2 code also requires some supplementary routines, which have been ordered from Argonne Code Center. These routines are necessary before WIGL 2 can be made operational on the 1108 .

A point kinetics code, called $\mathrm{RTS}^{3}$ has been received from Los Alamos. This code solves the point kinetics equations for any form of reactivity input. The basic code is now available for use, but it also has some supplementary routines which are not yet operational.

A computer code, called NODE, is now avallable for solving a set of $N$ linear differential equations. The routine employs the method of Runge-Kutta and is written completely in Fortran IV. It is believed that this code is superior to other similar codes available for use on the 1108 .

A trip was made to Oak Ridge National Laboratory for the purpose of discussing their space-time kinetics program. Currently they are working on a code to solve the 2-group diffusion equations, including xenon feedback. The code seems to work quite well for l-dimensional problems, but the running times and core storage requirements for multi-dimensional problems seem to be excessive. They are sending their routine for solving the complex elgenvalue and eigenvector problem.

1 M. F. Radd. "WIGL 40, A Two-Group, Time Dependent Diffusion Theory Program for the IBM-7040 Computer," IDO-17125, December 1965 .

2 A. F. Henry and A. V. Vota, "WIGL 2, A Program for the Solution of the One-Dimensional, Two-Group, Space-Tıme Diffusion Equation Accounting for Temperature, Xenon, and Control Feedback," WAPD-TM-532, October 1965.

3 G. R. Keepin and C. W. Cox, "General Solution of the Reactor Kinetics Equations," Nucl. Sci.\&Eng. 8, 670 (1960). 
FLANGE-I. The code, FLANGE-I ${ }^{1}$ has been compiled for use on the UNIVAC-1108 and a test problem has been run successfully. This code generates a scattering kernel from thermal neutron scattering law data for crystalline and molecular bound moderators.

RIBOT. The code, RIBOT $^{2}$ has been converted from Fortran-II to Fortran-IV and compiled for use on the UNIVAC-1108. This code is a point reactor burnup code.

Program DAFFY. Program DAFFY has been compiled and debugged for use on the UNIVAC-1108. Some modifications have been made and the tape appears to be in operable condition. Program DAFFY allows increased precision in the determination of gamma-ray energies, their associated errors and intensities from pulse height analysis data. Test cases of experımental data have been run for as many as six unknown peaks and all indications suggest that the code is mathematically correct.

A formal description of DAFFY is currently being written.

THERMOS/BATTELLE Improvements. Several improvements have been introduced into the THERMOS/BATTELLE ${ }^{3}$ code. The Improvements are in the calculation of the currents, including the average fission cross section in the output and expanding the limit on the number of mixtures.

The flux gradient (current) calculation has been replaced by a more promising routine. This routine is based upon the information contained in the transport matrix, T( $\left.\underline{r}, \underline{r}^{\prime}, \mathrm{V}\right)$.

Fission cross section averaging both microscopically per isotope and macroscopically for the cell has been included in the editing routines.

The code is now equipped to handle up to 8 mixtures.

1 Appendix E, Integral iveutron Thermalization Annual Summary Report, October 1964 through September 1965, GA-6824.

G. Buffoni and S. Lopez, IL Programma RIBOT, C.N.E.N. Laboratorio Fisica E Calcolo Reattori, Doc. Int. LFCR (66) 26 ottobre, 1966 .

3 D. R. Skeen and L. J. Page, THERMOS/BATTELLE: The Battelle Version of the THERMOS Code, BNWL-516. Pacific Northwest Laboratory, Richland, Washington, June 1967. 
Battelle Revised Hammer Improvements. Several improvements were made to the Battelle Revised Hammerl Code. These improvements are listed below.

Scattering Correction. A problem of balancing the scattering cross section with the scattering matrix was solved. If a scattering matrix is available the scattering cross section is computed as

$$
\sigma_{S}(E)=\int_{E^{\prime}} \sigma_{S}\left(E \rightarrow E^{\prime}\right) d E^{\prime}
$$

If a matrix is not available then the diagonal terms are set up as

$$
\sigma_{S}(E \cdot E)=\sigma_{S}(E)
$$

Other Miscellaneous Items.

1. DTF Punched Card output was corrected so that the first moment scajter cross sections would be punched properly.

2. The input was rearranged slightly so that it is not always necessary to mount an edit restart tape.

3. Certain output labelling was also clarified.

HTH Improvements. Improvements and additions were made to the $\mathrm{HTH}$ code. ${ }^{2}$ These are listed below.

THERMOS/BATTELLE Improvements. Certain revisions placed in the THERMOS/BATTELLE code were also placed in the HTH overlay version. Revisions included here are those of the revised current calculation and fission cross section averaging (see another section of this report for discussion).

1 L. J. Page and D. R. Skeen, The Battelle Revised Hammer Code. To be Published.

2 D. R. Skeen and W. L. Purcell, "HTH, Computer Overlay Programs HRG, THERMOS/BATTELLE, and HFN, Users Manual" (To be published). 
HRG Updating. HRG revisions to date were placed in the code.

Program S Transmutation Punch. The program S punched card output routine was revised to include punching of the transmutation matrix so that burnup studies could be performed with these codes. A standard burnup table is included in the code which can be overwritten with a table of the user s choice.

\section{Reactor Engineering Development}

Pu Optimization Studies

In preparation for examining the use of mixed oxide fuels in existing reactor designs, the General Electric $1000 \mathrm{MW}$ boiling water reactor described in GEAP $=4476$ is in the process of duplication using the thermal hydraulics design code, REPP. Due to the absence of some important specifications in the GE report--particularly dimensional core data--this duplication has been more difficult than other existing reactor designs studied using REPP.

Once this basic duplication is set up, examination of the thermal hydraulic aspects of this reactor design using mixed oxide fuels will be undertaken.

This same type duplication is also planned for the Westinghouse $1000 \mathrm{MW}_{e}$ pressure water reactor design. Thermal hydraulic behavior of this reactor design using mixed oxide fuels will then be undertaken.

As a result of the boiling water reactor work on $\mathrm{REPP}$, a slight simplification of this code was made resulting in reducing the time per boiling water case by a factor of approximately one fourth.

Rupture Loop Particle Separator

Axial. Flow Separator Installation of plastic and aluminum collection tanks on the plastic test section was completed. This installation allowed the slot width to be varied and tested.

Initially: only the upper collection tank was installed and tests were conducted with slot width varying from $1 / 8$ inch to a maximum of $1-1 / 8$ inch.

The results of these tests and the operating conditions are as follows : 


\begin{tabular}{|c|c|c|c|c|c|c|c|}
\hline $\begin{array}{l}\text { Run } \\
\text { No. }\end{array}$ & $\begin{array}{l}\text { UO2 Particles } \\
\frac{\text { Injected }}{\text { gms }}\end{array}$ & $\begin{array}{l}\text { Loop } \\
\text { Flow } \\
\text { gpm }\end{array}$ & $\begin{array}{l}\text { Bypass } \\
\frac{\text { Flow }}{\text { gpm }}\end{array}$ & $\begin{array}{l}\text { Water } \\
\frac{\text { Temp }}{\mathrm{O}}\end{array}$ & $\begin{array}{l}\text { Slot } \\
\frac{\text { width }}{\text { in. }}\end{array}$ & $\begin{array}{l}\begin{array}{l}\text { Particles } \\
\text { Removed }\end{array} \\
\text { gms }\end{array}$ & Efficiency* \\
\hline 1 & 58.54 & 162 & 8.0 & 18 & $1 / 8$ & 25.85 & $44.4 \%$ \\
\hline 2 & 60.29 & 158 & 7.8 & 18 & $3 / 8$ & 30.09 & $50.0 \%$ \\
\hline 3 & 59.97 & 160 & 8.0 & 18 & $9 / 16$ & 34.7 & $58.5 \%$ \\
\hline 4 & 60.93 & 161 & 8.2 & 18 & $7 / 8$ & 44.26 & $72.8 \%$ \\
\hline 5 & 59.37 & 158 & 8.0 & 18 & $1-1 / 8$ & 42,10 & 70.5 \\
\hline
\end{tabular}

*Weight removed divided by welght injected $\mathrm{x} 100$.

Next, the upper and lower collection tanks were installed. These were conducted with an upper slot width of $7 / 8$ inch and a variable lower slot width from the orlginal design of $5 / 16$ inch to a maximum of $7 / 8$ inch. The results of these tests are as follows:

$\mathrm{UO}_{2}$

Run Particles Loop No. Injected Flow

\section{Upper Lower}

water Slot slot Particles Temp. Width Width Removed Eff.

$\begin{array}{lllllllllll}1 & 61.22 & 158 & 8 & 8 & 18 & 7 / 8 & 5 / 16 & 39.14 & 72.3 \% \\ 2 & 60.32 & 160 & 8 & 8 & 18 & 7 / 8 & 7 / 8 & 45.12 & 75.2 \% \\ 3 & 60.32 & 160 & 8 & 8 & 18 & 7 / 8 & 7 / 8 & 45.12 & 87.3 \%\end{array}$

*The latter efficiency is equal to weight of particles removed, weight of total accountable partıcles (normaliy 90\%).

The results of these tests indicate a substantial increase in separator efficiency with slot widths of $7 / 8$ inch.

Presently, a particle stripping device is being fabricated. This device will be inserted into the flow stream below the upper slot and will reduce the cross sectional area of the flow tube by $15 \%$

Fuel Element Testing

Testing of the basket type FERTF element was discontinued on August 11 , so that the fuel pins could be removed for hydraulic testing at 100-D. Total testing time on this element is 2019 hrs at $475 \mathrm{OF}$, $1050 \mathrm{psig}$, and $70 \mathrm{gpm}$. The fuel pins will be returned when hydraulic tests are completed; and fretting tests will be resumed in EDEL-I 
During this interim period some tests are being run which will correlate orifice size and pressure drop across the tube. Operating conditions for these tests are $100 \mathrm{OF}, 1075 \mathrm{psig}$ " and various loop flows required to produce 29,32 , and 35 psi differential across the tube Differential pressure is being measured from inlet header to outlet header. A standard PRTR element is installed in the pressure tube while these tests are conducted Testing is currently $60 \%$ complete.

Cooling of FERTF Fuel Elements in the Fueling Vehicle

In the PRTR fueling vehicle an emergency water spray system is used as backup for the normal air cooling system. To enable the handling of the irradiated FERTF 8-rod bundle fuel element, it will be necessary to modify this water spray system because of two principal reasons.

The FERTF element basket tube will prevent the direct impingement of the spray on the fuel rods and will make the emergency system ineffective.

Some form of continuous water cooling will have to be provided during the discharge of defected fuel elements to malntain their temperatures below $212{ }^{\circ} \mathrm{F}$. This temperature hunt is required to prevent vaporization of water absorbed through the defect and the subsequent escape of fission products from the fuel rods.

It has been proposed that this water cooling be effected by introducing water in the form of a stream from above the fuel element. Earlier, it was determined that a flow rate of 0.5 gallon per minute spread evenly over all fuel element sirfaces would hold fuel temperatures below 212 of. At this low flow rate it would be difficult to assure that the proposed method of water introduction would produce such an even water distribution. Therefore, experiments were undertaken in the 189-D Building Hyaraulics Laboratory to determine flow patterns and distributions as functions of flow rate and to investigate the effects of various methods of water introduction on these parameters.

In preliminary experiments conducted thus far, water was introduced from above through a 3/4-inch hose. With the water stream falling parallel to the fuel element hanger and impinging on the top fuel element fittings, at a llow rate of about 2 gpm the water flowed preferentially down fuel rods beneath the falling stream. Rods on the other side of the assembly were only partially wetted. The hose was then deflected so that the water stream was striking the hanger rod about six inches above the top of the fuel assembly. With this arrangement, the following observations were made: 
At a flow rate of $2.2 \mathrm{gpm}$ all fuel rods were wetted by flowing streams.

At a flow rate of about $1 \mathrm{gpm}$ fuel rods beneath the hose were wetted over their full lengths. Fuel rods on the far side showed alternate wetting and drying of the top 3 to 4 inches with continuous wetting over the rest of their lengths.

At a flow rate of $0.27 \mathrm{gpm}$, fuel rods beneath the hose were wetted over their entire lengths. Observable surfaces tuel rods on the far side of the assembly were largely dry down to the position of the top retaining bands. Below this position, these rods were wetted over their entire surfaces.

At flow rates of 5 to $10 \mathrm{gpm}$ all fuel rod surfaces were covered with heavy layers of flowing water. Spaces between fuel rods and the basket tube were filled with a flowing air-water mixture

The retalning bands around the fuel rod bundle appear to act as flow distribution devices, spreading the water film over the fuel surfaces.

The flow rates referred to above are flow rates inside the basket tube.

Further experiments will be conducted to obtain quantitative measurements of flow distributions and to investigate flow introduction devices of more practical interest than a garden hose. However, from the work done so far it appears that adequate cooling can be furnished by flow rates of 2 to $3 \mathrm{gpm}$ inside the basket tube.

\section{Materials Development}

Deuterium Absorption in Zircaloy 2 Corrosion specimens in the PRTR

Tubular Zircaloy-2 corrosion specimens from PRTR Test 72 were analyzed to determine the relative amounts of deuterium and hydrogen. The hydrogen was absorbed during fabrication and prefilming opera= tions. The deuterium was absorbed during a 209-day in-flux exposure in the PRTR $\mathrm{D}_{2} 0$ coolant. One specimen prefilmed at $400{ }^{\circ} \mathrm{C}$ in steam and one specimen exposed as-etched were selected for the $\mathrm{D}_{2} / \mathrm{H}_{2}$ determinations. The gases were extracted from specimens induction-heated in a vacuum system. The relative concentration of deuterium and hydrogen in the two samples are shown below. 
Sample No $2 \mathrm{~A}-14$

Preautoclaved: Welght Gain. In $=$ flux PRTR Exposure. Weight Gain:

Gas Analysis:

Weight Gain Ratio.

Gas Ratio:
$400{ }^{\circ} \mathrm{C}, 1500$ psi steam; 72 hrs $18.0 \mathrm{mg} / \mathrm{dm}^{2}$

209 days in $\mathrm{D}_{2} \mathrm{O}$. $\mathrm{pH}-10$ lithium hydroxide $26=0 \mathrm{mg} / \mathrm{dm}^{2}$

$\mathrm{H}_{2}=39.6 \mathrm{~mol} \%$

$\mathrm{D}_{2}=58.3 \mathrm{~mol} \%$

$\frac{\text { In }=\text { flux }}{\text { Out }=\text { of }-\mathrm{flux}}=1_{0} 44$

$\frac{\mathrm{D}_{2}}{\mathrm{H}_{2}}=1.47$

Sample No. $2 \mathrm{U}=\underline{5}$

Exposed as etched In-flux PRTR Exposure: 209 days in pH-10 lithium hydroxide Weight Gain: Gas Analysis: $16.4 \mathrm{mg} / \mathrm{dm}^{2}$

$\mathrm{H}_{2}=81.5 \mathrm{~mol} \%$

$\mathrm{D}_{2}=18,5 \mathrm{~mol} \%$

Gas Ratio.

$\frac{\mathrm{D} 2}{\mathrm{H}} 2=0.22$

Hydrogen Blank:

$15 \mathrm{ppm}$

Coupling between the Zircaloy specimens and the induction heater was poor resulting in low extraction temperatures (estimated to be 4.700 $\left.{ }^{\circ} \mathrm{C}\right)$. Calculations indicate that only about one-third of the total gas was extracted from each sample.

The prefilmed sample plcked up hydrogen and deuterium in the same ratio as the $\mathrm{nn}-\mathrm{flux}$ and out=of-reactor weight gains.

On the etched specimen the calculated deuterium pickup was : 8 ppm, based on the hydrogen blank value. This corresponds to pickup of $2 \%$ of the deuterium generated by corrosion, which is in general agreement with low pickups observed for similar as-etched specimens in the same test.

Zircaloy Corrosion Test in the Neutral pH PRTR Coolant

The PRTR has operated with two coolants. $\mathrm{pH}=10$ lithium hy= droxide $\left(\mathrm{D}_{2} \mathrm{O}\right)$ and recently at neutral $\mathrm{pH}\left(\mathrm{D}_{2} \mathrm{O}\right)$. The corrosion properties of $\mathrm{Zircaloy}-2$ and $\mathrm{Zircaloy}-4$ were determined in the pH-10 coolant. Tubular corrosion specimens were exposed at a position normally occupied by a fuel rod (Test No, 72). The corrosion rate of both alloys was accelerated by the flux. The change in coolant to neutral pH prompted interest in an evaluation of the effect of the new environment on the in-flux corrosion of zirconium alloys $A$ test 
assembly similar to the Test 72 assembly has been prepared for insertion at a fuel rod position. The assembly consists of tubular Zircaloy-2 specimens cut from PRTR fuel sheathing stock. Zircaloy=2 and Zircaloy-4 specimens from the Test 72 stock will also be included in the assembly. The specimens will be exposed as-etched and in two autoclaved conditions: $400{ }^{\circ} \mathrm{C}_{\text {: }} 1500$ psi steam; and $300{ }^{\circ} \mathrm{C}$ water followed by $400{ }^{\circ} \mathrm{C}$ steam.

PRTR Pressure Tube Evaluation

Pressure tube surface replication techniques were improved; and test specimens were being prepared during the period. No new results were developed during the period

\section{Cycle Analysis}

$\underline{\text { Reduced Density }}$

There has been some renewed interest of late in reduced density plutonlum fuels: Reduced density is one method to reduce the black= ness of plutonium fuels and obtain a more optimum spectrum for plutonlum. The range of spectrum change with reduced densities is not as great as with lattice pitch changes or rod diameter reductions: However, all of these methods have penalties associated with them. If the fabrication penalty for reduced density can be small enough, then it may compete very favorably with these other methods.

Recent interest is centered around room temperature compaction of $\mathrm{PuO}_{2}-\mathrm{UO}_{2}$ pellets to about $60 \%$ of theoretical density. A cost reduction estimate is not yet available; however, some Idea of the cost savings with reduced densities is shown in the table for a fixed fabrication cost and four densities. From this table it is apparent that savings of 0.05 to $0.1 \mathrm{mills} / \mathrm{KWh}$ are attainable by this method.

Fuel Cycle costs for a PWR and Four Fuel Densities

$\begin{array}{cr}\begin{array}{c}\text { Density: } \\ \text { g/CC }\end{array} & \begin{array}{r}\text { Optimized Fue } \\ \text { milis/kW }\end{array} \\ 9.256 & 1.944 \\ 8.750 & 1.937 \\ 7.206 & 1.915 \\ 6.245 & 1.893\end{array}$

Fabrication Cost $=\$ 100 / \mathrm{kg}$

$\mathrm{Pu}$ Composition - 62\% $\mathrm{Pu}-239 ; 17 \% \mathrm{Pu}-240 ; 16 \% \mathrm{Pu}-241,5 \% \mathrm{Pu}=242$ M/F ratio approximately 1.6 . 
Test Reactor Operation

Operating Experience

Pertinent data for the month are as follows:

1. Production.

2. Hours Critical

3. Critical Efficiency

4. Total Experimental Time Efficiency

5. $\mathrm{D}_{2} \mathrm{O}$ Losses

a. Indicated Stack Loss $(7 / 26-8 / 25)$

$\mathrm{b}$. Physical Inventory $(7 / 23-8 / 23)$

911,88 MWd

463.7

$62,3 \%$

$66,9 \%$

$762 \mathrm{lbs}$

$1,662 \mathrm{lbs}$

6. Helium Loss

97,770 sCf.

The Plutonium Recycle Test Reactor operated at a maximum power level of 51.5 MW this month, which corresponds to a maximum specific rod power of $17.1 \mathrm{~kW} / \mathrm{ft}$. Reactor operation continues to be at this reduced power pending resolution of the 5\% rod power difference reported last month. Total production since the start of the batch core experiment is 2813 MWd or 14 . 1\% of the batch core goal exposure. The 55 fuel element core has accumulated $2360 \mathrm{MWd}$. PRTR operation was interrupted by 10 shutdowns. Six were scrams associated with the FERTF caused by sudden flow changes, and four were intentional shutdowns to correct operating conditions. A brief description of the outages occuring during this report period follows:

Date

July 27

July 28
Reason for Shutdown

Scrammed by flow monitor 1550 low flow. Flow monitor was found to be tripping two units early. The outage required 1.4 hrs.

The phosphate addition iine to the primary heat exchanger, $\mathrm{HX}=1$, plugged on $7 / 28 / 67$, and the reactor was shut down. Efforts to clear the phosphate addition line, which was found to be plugged inside $\mathrm{HX}-1$, were unsuccessful. A temporary phosphate addition line was tied into the feed water supply line. The outage was extended when, on 7/31/67, a leak was observed on the $\mathrm{HX}-1$ steam export line at the gasketed 26" flange between the heat exchanger and the export line containment vessel penetration bellows. Addl= tional tightening of the flange bolts did not reduce the leakage. After removing the gasket, it was necessary to dress the flange face because of steam cutting. Following completion of the gasket change, a 400 psi hydrostatic pressure test revealed some leakage from the previous leak point. This outage required 195, 5 hrs. 


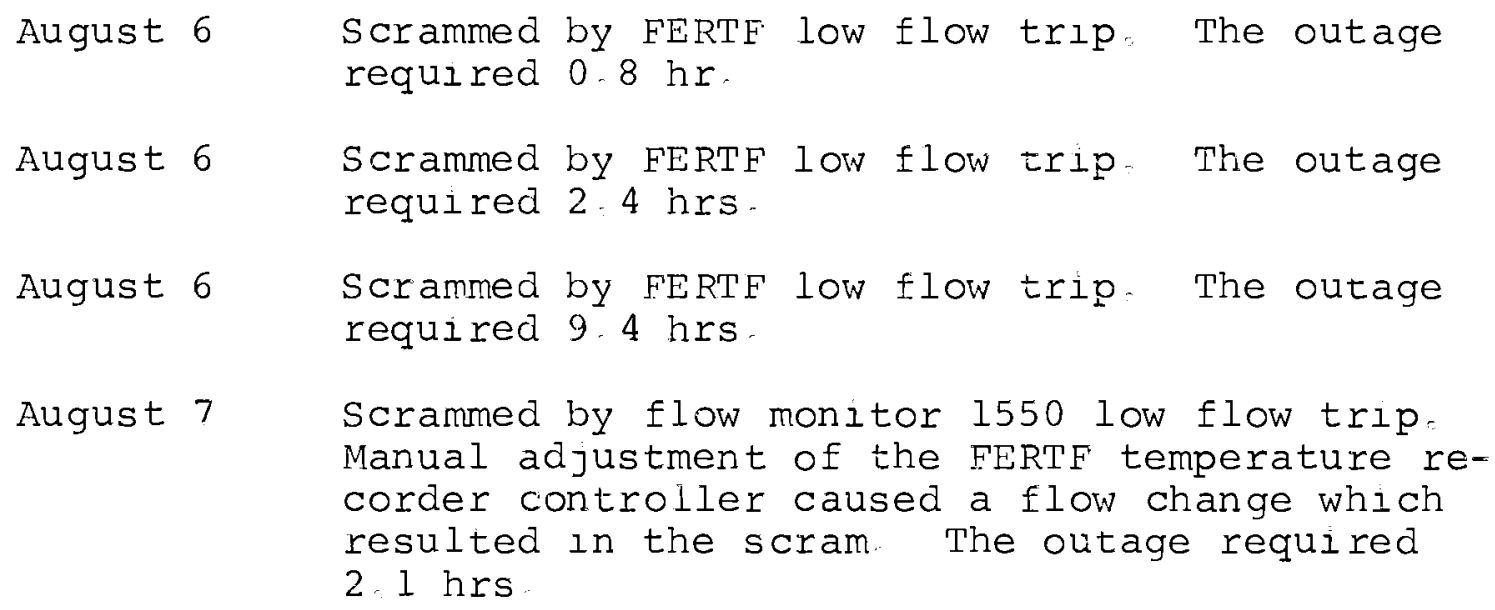

August 8 Shut down for 16.1 hrs to correct high D20 losses.

August 9 Scram of the FERTF when an instrument craftsman, attempting to silence a FERTF alarm annunciator; inadvertently pushed the manual scram button Instead of the acknowledge button. The outage required 6.8 hrs. The FERTF was cooled and depressurized for a pump switch

August 16 Shut down after losing the primary heat exchanger liquid level indication. The liquid level indication. The liquid level indlcation trouble was traced to black sludge plugging the level sensing line. Correction of leaking nozzle caps, including the cap from one instrumented fuel element required 28.1 hrs

August 23 Shut down for 17,7 hrs to ocrrect excessive leakage to TKA-1. Replaced four leaking nozzle caps, including a repeat of the cap on the instrumented tuel element.

As shown above, the reactor experienced six FERTF scrams during this report period. Three scrams were caused by the test section low flow trips. two were caused by the 1550 flow monitor low flow trips, and one was an unintentional manual scram. Four of the five low flow scrams resulted from sudden flow changes associated with unexplained changes in loading of the bypass flow control valve. $\mathrm{RL}=1$. As long as RL-I ls on manual control and no more than half open, flow control is satisfactory. The test section temperature control has also been ragged this month. Manual adjustment of the temperature recorder controller, during one of the temperature cycles. resulted in a large temperature change which lowered the indicated flow and resulted in one of the five low flow scrams. One of the vent lines from the regenerative heat exchanger falled because of escessive vibration. The line broke at the weld on the high pressure 
side of $\mathrm{RL}=213$. The line was rewelded and $\mathrm{x}$-rayed with satis= factory results.

During a routine heavy water leak check in the lower access space, the flow sensing line from process channel 2053 was found to be leaking. A hole had been worn in the stainless steel sensing line by rubbing on the 2053 in let jumper. This rubbing had also worn $18 \mathrm{ml}$ ls off the jumper. The jumper and the flow sensing line were replaced. Complete inspection of all jumpers and tubing disclosed minor fretting between five other jumpers and flow monitor sensing lines. This fretting was not severe enough to require replacement of elther jumpers or tubing at this time.

During the outage of $8 / 16 / 67$; the reactor was depressurized to correct leaking nozzle caps on process channels 1548, 1748, 1847 1849. and 1851. The collection rate during the previous six-day operating period had increased to 998 pounds per shift. It Is significant that the reactor was scheduled to be shut down at 0600 to correct these cap leaks but was forced down three hours early when the $\mathrm{HX}-1$ level indication was lost.

On $8 / 23 / 67$, the collection rate was again up to 720 pounds per shift, so the reactor was shut down to correct the leaks. Again. the leaks were cap leaks on process channels 1647, 1548, 1554, and 1053--the worst being 1548. Close inspection of both caps and gaskets revealed that the gasket seating surfaces had been mechan $1=$ cally damaged causing the gaskets to roll or bunch when forced into place. New cap parts have been obtained and will be used to replace damaged ones.

A bed of ion exchange resin removed from the top and bottom shield cooling system was found coated with a black deposit through about three-quarters of the bed. In let water to the 1 on exchanger also contained black solids material and reglstered a $\mathrm{pH}$ of 8.5 . Since the top and bottom shield cooling water is routinely deoxy genated with a copper-base resin and adjusted to $\mathrm{pH} 9.5$ to 10 with $\mathrm{NH}_{4} \mathrm{OH}$, an investigation was begun to characterıze the black deposit and determine the reason for the low $\mathrm{pH}$.

The deposit was essentially iron oxide, with negligible copper present Repeated sampling of the coolant for four days following resin replacement showed a $\mathrm{pH}$ of 9,35 to 9,78 with 1 ron concentrations less than $0.6 \mathrm{ppm}$. The $\mathrm{NH}_{4} \mathrm{OH}$ used in the frequent additions required to maintain $\mathrm{pH}$ was apparently consumed in saturation of the new resin. since conversion to nitrates was barely detectable ( $35 \mathrm{ppb}$ )

Low crud levels in the PRTR primary system were indicated by the continued steady flow through the new primary system filters. Flow decreased less than 4.5\% in the 10-micron pore size filters and about 
9\% in the 40-micron filter during a full month of operation. The reactor was at equilibrium power during more than $60 \%$ of this period.

Radiation measurements at selected locations of the PRTR systems showed moderate increases in radiation levels since May 1967 (typıcal increase from $60 \mathrm{mr} / \mathrm{hr}$ to $100 \mathrm{mr} / \mathrm{hr}$; at a few locations in the primary and moderator systems other locations in the primary, moderator, reflector, and core blanket systems showed negligible increase.

Seven process tubes were examined. There were no significant changes observed since their previous examination.

We received 27,500 pounds of new $\mathrm{D}_{2} 0$ from Savannah River. This $\mathrm{D}_{2} 0$ had a high tritium content lout of five drums checked. the tritium content ranged from 556 microcurles/mi to 808 microcurles/ml) and wolid increase the sadlological problems associated with the operation of PRTR if it were added to the primary system which is currently 450 microcuries/ml.

During the month 7100 gallons of liquid waste were passed through the cleanup ion exchanger and sent to the river. Only 5000 gallons of storage basin ion exchange regeneration waste solution required disposal through the 340 Bullding.

Process Technology

The shutdown phase of Batch Core Power Test No. 6 i Transient Fission Product Polsoning, was rerun. completing this power test. Performance of Test No. 5 (Reactor Total Power Generation Measurement, continued Performance of Test No. 4 , Temperature Coefficients of Reactivity) at full power was unsiccessful as moderator liquid level limits were reached before the moderator temperature reached an iniet temperature of $140^{\circ} \mathrm{F}$. A supplement is being written to run this test at slightly reduced reactor power

A detalled description of the planned Batch Core Interim Critıcal Test Program was issued for comments This program outline contalned the detalled procedures for the actual critical measure. ments as well as an over-all program description

The investigative study of the molten fuel event and the reevaluation of the long term program for administering fuel tempera= ture limits continued during the month. The specific rod power limit remained at $17 . \mathrm{l} \mathrm{kW} / \mathrm{ft}$ on a "maxlmum tube" basis for the entire month. Measurement of hanger lengths of fouc Ring One elements under Supplement No 4 PRTR Test No 136; showed that all hangers were $65 \frac{1}{2}$ inches ldistance from bottom edge of the lower pin hole at the upper end of the hanger to the top edge of the upper pin hole at the bottom of the hanger: The switching of two Ring one fiow monitors 
per this supplement was under way at month's end as part of the study of instrument errors

Investigation was begun on a method of calibrating the process tube outlet RTD $s$ in place under reactor operating conditions This method involves extrapolation of data on delta temperature versus reactor power back to zero power from data points obtained over the range from ? MW to full power. Adjustments in RTD padding resistances can then be made to force the delta temperature response curves to pass through zero at zero power

Preparation of PRTR Test No. 140 was begun. This test will return the measurement of primary in let temperature to the averageof four inlet RTD $s$ from the presently used single RTD; obtain the necessary delta temperature versus power level data, and adjust the process tube out let RTD padding resistances

The fission gas pressure measuring tuel element \#6519 in process channel 1245 continued to perform satısfactorliy, and 33 pressure and temperature measurements were made on each of the two test rods. The fission gas pressure measuring element \#6520, in process channel 1548. was discharged twice during the month to replace the leaking nozzle cap gasket. Following the first gasket replacement, difficulty was experienced with both thermocouples and with both null balance electrical leads. Since 8/23/67 when the second gasket change was made, the temperature and pressure measuring leads for rods 7 and 8 have been out of service. While the instrumentation for $F E-6520$ was in service, 19 pressure and temperature readings were obtained. The maximum pressure observed was $58 \mathrm{psig}$ in rod 8 " while the maximum temperature observed was $496^{\circ} \mathrm{F}^{*}$ in rod 7

The initial testing of the pneumatic accessory is $60 \%$ complete. Twenty-one 1 rradiation runs were made using an empty carcier and four irradiation runs were made with the carrier containing flux samples There were no unusual or detrimental effects roted after these 1 rradiations

The gear box on the strain measuring system falled, terminating the data gathering portion of in-reactor creep experiment IPRTR Test 99: The capsule will remain in the reactor under 250 psig helium pressure to protect the specimen from corrosion until a replacement capsule is avallable for charging.

Irradiation of the 19-rod 2 wt: $\mathrm{PuO}_{2}-\mathrm{UO}_{2}$ pel let element con* tinued in the FERTF. Dissolved oxygen concentration in the coolant has not been a problem during the operation of the FERTF since its reactivation 
Improvement Work status

Work Physically Completed

S-8I Valve Mechanical Latch Removal. The main steam containment valve has failed several times on test due to a latching mechanism which would not release. The mechanism was modified twice but still was not entirely reliable. It has been removed. and the valve is now held open by keeping air pressure in the cylinder that opens the vaive. The containment circuit now releases the air on recelpt of a containment trip and the valve is closed by springs. This is the same principle as used on the ventilation containment valves

Expanded Range for the Conductivity Recorder: $\mathrm{pH}$ instrumentation on the primary system is unsatisfactory. Wi th the recent change to neutral $\mathrm{pH}$, the conductivity recorder becomes a more sensitive indlcator of $\mathrm{pH}_{\text {, and }}$ it has been provided with an expanded scale on the low range.

Alarm Annunciator on the Tritium Monitor. An annunciator has been provided on the tritium monitor to call attention to changes in the amount of tritium going to the stack.

Disposal of Regeneration Water from Basin IX. Regeneration effluent from storage basin ion exchange units contains small amounts of radioactivity and when mixed with sump wastes makes the whole amount unacceptable for river äısposal. A separate line has been installed which permits the IX wastes to be discharged to a tank truck for underground disposal.

Design Work Completed Underwater lights in the new basin have proved to be high maintenance items because of leakage at numerous electrical fittings. A design has been prepared that encloses ballast, fluorescent tubes, and all wiring in a single sealed compartment

Work Partially Completed.

Project $\mathrm{AEC}-193$. Fire Protection Improvements. Physical work started on this project during August with the excavation for new water lines. Detall design for work inside 309 Bullding has not been completed; and interior work has not started.

Project $\mathrm{BCP}-013$. Contamination and waste Control. Physical work started on this project during August with excavations for the lines to the new Manhole \#3 monitor 
NUCLEAR SAFETY

Containment Systems Experiment (J M. Batch)

Contalnment Leakage Studies = Task A

Effect of Temperature Sampling Errors on Leakage Rate Measurements One significant source of error in determining the leakage rate of containment vessels is use of erroneous average containment air temperatures. Such errors may resuit from inadequate sampling of the air voiume. The magnitude of these errors has not been examined in many previous vessel leakage rate tests

During the air leakage rate tests on the CSE vessel; air temperatures were measured by precision resistance temperature detectors (RTD"s) distributed to provide one RTD for each $1600 \mathrm{ft}^{3}$ of contaln= ment volume. In addition, four RTD's were fixed to the surtace of the 3/4-inch diameter reference vessel tubing to measure its temperature. The reference tubing is suspended along the contalnment vessel axlal centerline and temperature lags could exist between the average containment air temperature and the reference tubing temperature

Test data were analyzed to evaluate the significance of the slight temperature differences between the reference tubing and the average containment air temperatures. Computation of leakage rates by the reference method, using a form of the equation including both reference vessel and contalnment alr temperatures, ylelded leakage rates not signiricantly different from those calculated earlier. It is concluded that the temperature lag ervors compensated over the test duration for the periods covered.

Fission Product Transport Studies - Task B

Aerosol Transport Test in the Containment Vessel preparations continued during the month for the first large scale test in the contalnment vessel Run $A-1$ will investigate aerosol removal by the natural processes of deposition on surfaces and steam condensation. Containment atmosphere WIll be 1 sothermal and isobaric at 170 OF and 8.5 psig. The tests aerosol will have an initial concentration of about $1 \mathrm{mg} / \mathrm{m}^{3} \mathrm{I} .5 \mathrm{mg} / \mathrm{m}^{3} \mathrm{Cs}$. with fumes from moiten Zircaloy-clad $\mathrm{UO}_{2}$

Objectives of the test, in addition to evaiuation of aerosol removal, include determination of convection current velocities in the vessel, measurement of heat transfer rates through the vesse 1 wall, and determination of steam-air leakage rate at selected penetrations 
Two runs. $A-1$ and $A-2$ are planned to investıgate aerosol removal by natural processes in condensing steam plus alr atmospheres: The contalnment vessei is not insulated and relatively high steam condensation rates will exist

Aerosol Sampling Equipment Comparisons Run 85 in the SAT istainless aerosol tank" was made using $\overline{\mathrm{Zr}} \mathrm{Clad} \mathrm{UO}_{2}$. I, Cs, and ruthenlum aerosols in steam and air at $80^{\circ} \mathrm{C}$. The primary objec= tive was to compare ORNL and ADF laerosol development facllityi sampling devices when being used under similar conditions. Other objectives were to assist in model development of mass transport in unagltared tanks and to provide additional information about the characteristics of a typical ADF aerosol

The ORNL samplers were at tashed to a heated manıfold which entered the SAT near the normal ADF Maypack port. Both the ADF and ORNL Maypacks were analyzed for lodine, cesium, and ruthenium. Because of Maypack component difference the comparison of distribu* tion may not be quite correct, however, the totals should check The ORNL samples give concentrations which are below those indicated by the ADF Maypacks early in the run when the concentrations are high. Later in the run: reasonable agreement was obtained for all isotopes if the in let check valve was included as part of the total sample

The charcoal components of the two types of Maypacks show good agreement later in the run Early ADF charcoal paper valves glve a high concentration. Thıs may be due to lodine penetration of the screens. Large difference of eiemental iodine isilver screens) were indlcated, ayaln, the ORNI samplers ylelded lower concentrations. The activity on the ORNL Maypack filters was lower than that on the $A D F$ fllters, and this may be related to the large tup to $50 \%$ of the totajj amount of activity found on the iniet check valve. This was al jowed for in calcuiation of the total concentrations but is, of course: not identified as to species

Other ORNL sampling devices were a diffusion tube and a fiber filter analyzer. No treatment of this data has been made by us.

To summarıze, the ADF and ORNL Maypacks showed nearly equal alrborne concentrations iater in run 85 Eariy ORNL samples were lower than the ADF Maycacks. This is thought to be due to in let manitold losses

Coolant Blowdown Studies : Task C

B Lowdown Experimerts. A similated reactor vessel with a capacity of $150 \mathrm{tt}^{3}$ of water with initial conditions of $600{ }^{\circ} \mathrm{F}$ and 2500 psig is being used to study the blowdown rates and transient pressures and forces that may result from a loss-ot-coulant accident in an operating power reactor. The reactor simulator vessel is mounted on a test 
framework and is instrumented to measure thrust, internal pressures and temperatures, flow rates, etc. "whlle the heated water in the vessel is suddenly blown out through a rupture disk opening which simulates a piping break. Tests to date have been with blowdown of the empty vessel through a bottom nozzle. The information in the table summarizes the test conditions and some results of the high temperature blowdowns that have been done to date. The diameter of the nozzle is 6.813" (the ID of a sch $1608^{\prime \prime}$ pipe). To the nozzle is connected a $30^{\circ}$ elbow and a straight extension piece of the same diameter. giving about 4.1 feet of pipe extending to the location of a square edge orlfice which is used to give break areas of various sizes. The rupture disk assembly is located beyond the orifice and is diametrally larger than even the largest orifice used.

\section{Summary of High Temperature Blowdown Runs}

$\begin{array}{lccc}\text { Run Number } & \text { B } 7 & B=8 & B=12 \\ \text { Description } & \text { Saturated } & \text { Saturated } & \text { Subcooled } \\ \text { Pressure (psia) } & 665 & 665 & 1565 \\ \text { Temperature(OF) } & 490 & 495 & 400 \\ \text { Orifice area(ft }{ }^{2} \text { ) } & 0.0643 & 0.253 & 0.0643 \\ \text { Iniative mass of water(1bsm) } & 7300 & 7100 & 6600 \\ \text { Initial volume of water(ft3) } & 147.5 & 145 & 122 \\ \left.\text { Initial volume of steam-nitrogen(ft }{ }^{3}\right) & 5 & 7.5 & 30 \\ \text { Time to water exhaustion(seconds) } & 27 & 8 & 12 \\ \text { Time to end of run(seconds) } & 39 & 19 & 27\end{array}$

Comparisons have been made of the data from Run $B=7$ with blowdown prediction method of $B$. M. Johnson. (I) His basic procedure was used and his blowdown code modified slightly to separate input constants and leave out the effect of a containment vessel.

The measured flow rates were lower than predicted by Moody's model used in Johnson"s code. In order to get agreement with the blowdown data from Run $\mathrm{B}-7$, a nozzle coefficient for the 4" orifice had to be used. The coefficient used was 0 648. since this coeffi= clent gave a best fit of the data in previous 4" single-phase flow tests.

The Johnson computer code has an adjustable parameter to allow for the degree of subcooled flow which may occur depending on the degree of equilibration that has time to take place. The relative

(I) Johnson, $\bar{B}, \bar{M}$. "Containment systems Experiment - Part III = Mathematical Models of Pressure-Temperature Transient, "BNWL.233; May 1966 . 
break size to tank volume has an effect on this time. For the 4" break diameter of Run $B=7$, it was found that a full volume equilib. rium layer gave the closest agreement. Indeed the effect of varying the depth of the equilibrium layer suggests that additional steam i e higher quality than available even by allowing full volume equilibrium would improve the fit even further. Another mechanism would have to be invoked to provide the higher quality than equilibrium alone. Nevertheless: the results produced by the code show good agreement for Run $B=$ ?

In the subcooled Run $B=12$, the results indicated again that an orifice coefficient of 0.61 to 0.64 should be used to correct standard prediction formulas, such as saloudek"s 12 ,

$$
G=c / \overline{\frac{2 g_{c}}{v_{f}}\left(\bar{P}_{t}-\overline{P_{s}}\right)^{\prime}}
$$

where $G$ is the mass flow rate; $C$ the nozzle coefflcient, $v_{f}$ the liquid specific volume, $P_{t}$ the upstream or vessel pressure; and $\mathrm{P}_{\mathrm{S}}$ the saturation pressure.

PDP 7 Multiplexer Codes. The PDP 7 has been programmed to operate as a dual multiplexer , 3) in the reference it was stated that the low speed multiplexer had a maximum speed of 2000 points per sec. This figure was based upon the maximum hardware speed Under control of the program it was discovered that only about 1200 points per second could be selected and logged. This lower figure was due to the large number of program steps between point selection. Extensive revisions of the program in order to minimize the time between point selection has increased this figure to 1800 points per second. This figure is probably the best obtainable due to the program steps necessary to select. log and write the data from the point out to magnetio tape.

The data collected by the multiplexer program is written onto DECTAPE magnetic tapes. In this form no other computer can be used to process the data. Recently an incremental tape unit capable of

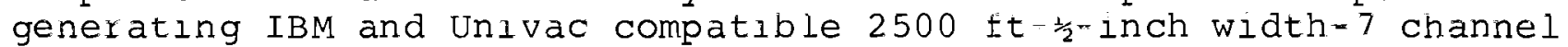
tapes was added to the PDP 7. A code has now been written and de= bugged to transcribe the multiplexer data tapes onto the large scale computer compatible tapes

\footnotetext{
(2) Zaloudek; F. R "Steam Water Critıcal Flow from High Pressure Systems; "HW=80535. January 1964

3) Wilburn, $\mathrm{N}_{\mathrm{P}}$ " "Multiplexer Codes for the PDP=7," BNWL-CC-796, August 1966 .
} 


\section{Radioactive Residue Process Development (A. M. Platt)}

Pot Calcination

Radioactive Demonstration. Pot Calcination Run 5 (PC-5) was successfuIly completed in WSEP using a modified PW-1 feed composition. As in Run $\mathrm{PC}=4$; excessive sodium in the Purex IWW used for feed makeup required the addition of an equivalent amount of sul= iate to prevent volatility of the alkail oxides. The resultant sodium and sulfate concentrations were 0,64 and $0,35 \mathrm{M}_{-}$respectively: rather than 0,14 and 0,10 as intended.

A total of $1,200,000$ curies, including 18,000 curies of radioruthenlum, was fed to the 8 -inch pot in 28 hours at an average feed rate of $19 \mathrm{l} / \mathrm{hr}$. The final ll-hour drying period reduced the over all average feed rate to $14 \mathrm{l} / \mathrm{hr}$. Although foaming of the feed $\mathrm{ln}$ the pot was a continual problem, foaming was controlled by reduced feed rate so that no foam was expelled from the pot as had happened during Run PC-4. The foaming made control of the level in the pot more difficult than in previous runs. The level control became so difficult near the end of the run that the feed rate was reduced to the low rate of $2=3 \mathrm{l} / \mathrm{hr}$. Consequent $\mathrm{ly}_{i}$ the feed was turned of $\mathrm{f}$ after about $80 \%$ of the intended feed was in the pot. The temperature. type of pot level probe was completely unreliable during the last half of the run. The cause of the foaming is being investigated.

Eighty-six $\mathrm{Kg}$ of calcine was netted with an internal heat generating rate of 4300 watts. This heat produced a pot centerline temperature of $725{ }^{\circ} \mathrm{C}$ and a centerline-to=wall $\Delta \mathrm{T}$ of $495{ }^{\circ} \mathrm{C}$ with the pot suspended in $38{ }^{\circ} \mathrm{C}$ air. The internal heat was approximately 65\% of that required for a thermal maximum pot. I A thermal maximum pot is one in which elther the maximum centerline temperature reaches $900{ }^{\circ} \mathrm{C}$ or the wall temperature reaches $425^{\circ} \mathrm{C}$ under alr-cooling conditions - )

As in Run $\mathrm{PC}=4$, the process equipment was set up for Mode $=\mathrm{C}$ operation. This consisted of feeding the pot from the bolling waste evaporator and returning all of the pot condensate to the evaporator for recycle with the feed Fresh feed was continualiy fed to the evaporator from a batch teed tank. Unlike Run $P C=4$, where essentially no ruthenium was volatilized from the pot, initial data indicates that as much as $12 \%$ of the 18.000 curies fed to the pot. were volatilized during PC-5. The data have not yet been analyzed to determine the effect of recycle on the volatilized ruthenium. The decontamination factor for ruthenium across the acid fractionator was approximately $1 / 30$ th that during $\mathrm{PC}=4$ when a caustic additive stream was added to the top plate of the fractionator tower. No additive was introduced to the fractionator during $\mathrm{PC}^{m} 5$. 
The only problem encountered with the auxiliary equipment was plugging of the speclfic gravity dip tube in the waste evaporator. Plans to purge the dip tube with steam were foiled when the dip tube became completely plugged midway through the run

The GE $=412$ process control computer is connected to 90 electrical signals from the instruments and equipment associated with the Waste Solidification Engineering experiments A program has been written to monitor those signals associated with the pot Solidification Process. Aside from a minor problem in getting the computer started, the performance of the machine was without fault during the execution of Run PC-6. The bulk of the logged data, in particular the power consumption data, was accurately recorded for the duration of the run. A change in the mode of process equipment utilization comprised a small portion of the logged data

Phosphate Glass Solidification

Corrosion of Candidate Waste Evaporator Materials of Construction. Corrosion rates of Uranus SD alloy and Haynes 25 were determined in $\mathrm{P} W=1$ solution ( $\mathrm{Meq} / \mathrm{p}=$ one) at 120,130 , and $140{ }^{\circ} \mathrm{C}$. Rates for both alloys varied from about three $\mathrm{mlls} / \mathrm{mo}$ at $120^{\circ} \mathrm{C}$ to about $\mathrm{six} \mathrm{ml}$ ls $/ \mathrm{mo}$ at $140^{\circ} \mathrm{C}$. In similar tests with HAPO-20. Corronel 230 $50 \mathrm{Cr}=50 \mathrm{NI}$, and Incoloy 804 alloys, corrosion rates of about $20 \mathrm{mils} / \mathrm{mo}$ were obtained. The corrosion resistance of these alloys is being investigated in the vapor phase auring concentration, denitration, and melting of PW l solution

\section{Spray Solidification}

Process Technology Development of a spray solidifier fiowsheet for processing Durex Waste $=5$ (PW-5) was started. PW-5 is a high Al, low $\mathrm{Fe}$, low Na waste which does not contain sulfate

The initial series of melts utilized $0.5 \mathrm{M} \mathrm{Li,} 0.5 \mathrm{M} \mathrm{Na}$ and varying amounts of phosphate as additives similar to the PW-1 flowsheet. A minimum in the calcine melting curve occurred at an $\mathrm{M}^{+} / \mathrm{P}$ ratio of about 3-4 versus 2.8 for $P W=1$. The minimum melting point for $\mathrm{PW}-5$ was about 75 OC higher than that for $\mathrm{PW}-1$. Once melted. the $\mathrm{PW}=5$ products were somewhat glassy and consequently had slump points some $200^{\circ} \mathrm{C}$ below the salt-like $\mathrm{PW}-1$ products. The next step in the flowsheet development work will be to obtain a lower melting point by use of boron and/or alkali metal additive

Englneering Development. During the month Run DSC-7 was carried out: with the following primary objectives:

1. Evaluate the performance of the spray calciner and continuous platinum melter on a PW-2 flowsheet isame as Run CSCM-9) using an internal mix spray nozzle (Spraying Systems Co. Setup \#42) and alr atomization. 
2. Evaluate the performance of the WSEP vibrating trough solids feeder with the solid flux (3-8 mesh NaPO3) being added through the melter cover.

3. Supply the melter heat requirements via an induction heated susceptor.

4. Evaluate both weir and freeze valve melt discharge.

5. Evaluate the use of a carbon steel receiver pot

Pertinent run conditions and results are presented in the first table. The run was terminated after 8.5 hrs when the melt receiver pot foamed over. Thirty-five percent of the pot"s contents foamed either through the sample chamber into the melter furnace or out through the sample chamber window, where it solidified as an extremely porous, greenish solid. Earlier in the run, there was an indlcation of foaming since the melt discharging from the melter appeared quite frothy.

The presence of only $2.5 \%$ of the total sulfur in the condensate and caustic scrub solution indicate that the over-all volatilization was apparently not excessive and probably occurred only periodically during the run.

\section{Run Conditions and Results for Run DSC-7}

Feed Type

Atomizing Gas

Calciner Furnace Temp ${ }^{\circ} \mathrm{C}$

Melter Furnace Temp. "OC

Melt Temp. "OC

Receiver Pot Temp. ${ }^{\circ} \mathrm{C}$

Feed Consumed; liters

Feed Concentration. liters/tonne 454

Feed On-time, hrs

Average Feed Rate, liters/hr

Solid Flux ( $\left.\mathrm{NaPO}_{3}\right)$ Added, $\mathrm{kg}$

Solid Flux $\left(\mathrm{NaPO}_{3}\right)$ Desired, $\mathrm{kg}$

Product Collected: $\mathrm{kg}$

Pot Material

Pot Diameter, in.
PW-2 (s ame composition as Run $\mathrm{CSCM}=9$ )

Air

680

$950-1000$

$880-910$ (1)

$650=750$

131

8.5

15.4

17.4

14.0

46.9

Mild steel

8

(1) These temperatures were noted near the surfaces of the melt, and thus the temperature lower in the melt may have ranged higher than this but was not detected due to the thermocouple being shorted out at this point. 
The second table presents a comparison between the analyzed and desired concentration of the major components in the feed. Although there are some deviations, they are not in a direction which would promote sulfate volatilization in the third table the analysis of three melt samples taken of the melter discharge during the run reveals a loss of sultate during periods of relatively high flux $13-8$ mesh $\mathrm{NaPO}_{3}$ : addıtıon

The present assessment of the situation is that the foaming resulted from the particular combination of a relatively high flux concentration, a relatively high melt temperature and the geometry (high L/D ratio) of the recelver pot The discharge of a melt having a high gas content into the recelver pot, a finite sulfate volatilization in the recelver pot, and the geometric factors of a relatively long escape path and small escape area for gas leaving the pot. caused the viscous melt to ralse out of the pot in a manner similar to the ralsing of bread dough

Samples of the feed have been glven to Materials and Process Chemistry personnel for laboratory scale evaluation. The phenomena will be thoroughly explored to define more closely the parameters affecting foaming in this system and thus minimize the possibility of such an occurrence during the hot cell demonstration runs.

Other observations made during the run were:

1. The atomization of the PW-2 feed was adequate as no gross deposition of calcine occurred in either the calciner barrel or cone.

2 During post-run inspection of the calciner it was noted that the spray nozzle alr tip was partially plugged with calcined feed whıch reduced the oriflce flow area substantially. Calcined feed was also noted inside the alr tip. Testing of the nozzle revealed that the calcine had reduced the air flow at a given nozzle pressure by $40 \%$ and also deflected the spray 10 degrees off vertical. As no decrease in alr flow was noted during the run and since no localized deposition was noted on the calciner walls, It was concluded that the blockage occurred after the run and was the result of inadequate flushing of the nozzle as indicated by the presence of feed solution in the feed line This emphasizes the importance of adequately water flushing the nozzle immediately after discontinuing feed.

3. Control of the solids addition rate was ragged as the calibration of the feeder was not established immediately and a period of overteeding was experienced during the first half of run. This points out the necessity of establishing the feeder s calibration shortly after the start of the run as indicated by the hopper drop-out rate. 


\begin{tabular}{|c|c|c|c|}
\hline & $\begin{array}{l}\text { son of Analyzed } \\
\text { Composition for }\end{array}$ & $\begin{array}{l}\text { and Desired } \\
\text { Run DSC-7 } \\
\end{array}$ & \\
\hline & Concentration in & moles/liter at 100 & gal/tonne \\
\hline Element & Analyzed & Desired & \\
\hline $\mathrm{Fe}$ & 0.425 & 0.445 & \\
\hline $\mathrm{Na}$ & 0.92 & 0.930 & \\
\hline Li & 1.49 & $1=17$ & \\
\hline $\mathrm{Ca}$ & 0.74 & 0.6 & \\
\hline Al & 0.23 & 0.25 & \\
\hline $\mathrm{P}$ & 1,38 & 1.62 & \\
\hline$S$ & 0.79 & 0.87 & \\
\hline
\end{tabular}

Melt Sample Analyses

(Concentrations referencea back to feed at $100 \mathrm{gal} /$ tonne)

\begin{tabular}{|c|c|c|c|c|c|}
\hline $\begin{array}{c}\text { Sample } \\
\text { No. }\end{array}$ & $\begin{array}{l}\text { Total } \\
\text { Sodium } \\
(\text { moles } / 1) \\
\end{array}$ & $\begin{array}{l}\text { Sodium } \\
\text { Added } \\
\text { as } \mathrm{NaPO}_{3} \\
\text { (moles/1) } \\
\end{array}$ & $\begin{array}{c}\text { Sulfur } \\
\text { (moles/1) }\end{array}$ & $\begin{array}{l}\text { o Deviation of } \\
\text { Sulfur Content } \\
\text { From Feed } \\
\text { Composition }\end{array}$ & $\begin{array}{l}\text { Appearance } \\
\text { of the } \\
\text { Solidified } \\
\text { Samples } \\
\end{array}$ \\
\hline $\mathrm{M} 1$ & 3.5 & 2.6 & 0.66 & $=17$ & $\begin{array}{l}\text { Very porous } \\
\text { Dark Green }\end{array}$ \\
\hline M2 & 2.6 & 1.7 & 0.65 & -16 & $\begin{array}{l}\text { Very porous } \\
\text { Dark Green }\end{array}$ \\
\hline M3 & $1=6$ & 0.7 & 0.85 & +8 & $\begin{array}{l}\text { Dense } \\
\text { Light Greer }\end{array}$ \\
\hline
\end{tabular}

4. No bridging or plugging problems were experienced at the solids addition port in the melter cover as the solid $\mathrm{NaPO}_{3}$ particles (3-8 mesh) had sufficlent velocity that they did not reside on the hot surfaces of the port long enough to stick. Problems experienced in the past probably resulted when melt splashed up into the port causing the $\mathrm{NaPO}_{3}$ to adhere and melt.

5. An ultrasonic scan of the mild steel receiver pot after the run indicated that several areas on the pot wall had been reduced in thickness as much as $15 \mathrm{mils}$. Considerable oxidative attack was noted on the outside of the pot; the pot had been at temperature for approximately 12 hrs.

\section{Atomization Studies}

The analysis of sources of error in drop sampling technique was continued. The air-flow rotameter was calibrated with water 
to make certain that the proper float was being used. The pressure gages were found to be accurate within $\pm 1 / 4$ psi when checked against a U.S. Bureau of Standards calibrated gage It is still not known why our results do not agree more closely with the tests made by Delavan except that at a given nozzle air pressure they report a considerably different alr flow. We obtain good agreement if we compare results at the same air pressure, but poor agreement if we compare drop sizes at same (as reported) air flow rates:

Statistics personnel are determining the number of droplets that must be counted to obtain a desired reproducibility, $e . g$. $\pm 5 \%$. The standard statistical tests do not apply because these droplet sizes are not normally distributed.

The deviation from spherical shape of samples water droplet in kerosene was determined to be less than $10 \%$, which is within measurement error.

In-Pot Melting

A run was made with a $\mathrm{PW}-1$ flowsheet wherein a considerable amount of melt leaked through one of the thermowells inserted from the pot bottom. The pot is being $x$-rayed to determine if and where the thermowell failed. A complete ultrasonic scan is also being made to look for pot wall corrosion and the thermowell tubing is being analyzed to conflrm whether the alloy is the specified $304=\mathrm{L}$ SS. The results of these tests are not yet available

A program has been scoped for laboratory study to improve inpot melting compositions. The program will be conducted by Materials and Process Chemistry personnel.

Radioactive Demonstration

Electrical continuigy checks of the failed melter furnace for the spray solidifier have shown that the heating elements are sound The fallure was in the copper leads from the furnace junction box to the individual phase terminals. The leads were badly oxidized from excessive heat from the furnace. All six of the leads will be replaced and rerouted outside the furnace to keep the leads cool.

Product Characterization and Storage

Measurement Techniques and Equipment. The fabrication and instllation of equipment for destructive and nondestructive testing of waste pots is continuing The equipment includes.

1. A rotary core drill unit, including off-gas cleanup system. 
2. A tungsten=inert gas (TIG) welder system for demonstration of pot rewelaing following core drill sampling.

3. A vacuum leak-test cart, for mass spectrometer leak test of waste pots.

4. A new ultrasonic probe support mechanism for pot wall thickness testing. The new support is adjustable for more accurate probe positioning.

Activation of the equipment during the coming month is anticipated.

Solids Storage Engineering Testing Modifications to controlled environment test pods \#I and \#2 have been completed to prepare the pods for possible installation in B-Cell. Modifications include addition of an air-cooling line for the pot thermocouple connector and addition of new pod heater electrical connectors

Actual installation of the pods has not been scheduled. Other incell work connected with repair and replacement of solidification equipment has a higher priority.

The project for modification of $A$-Cell to receive the SSET pods has continuea with the completion of wall coring for in-the-wall intercubical piping. The way is now clear to proceed with the piping and to begin installation of the wall liner ard the second floor window. At latest report, the window frame for the first floor is aue to be shipped in mid-October, so the estimated beneficial occupancy date of January 1968, still appears to be attalnable

Calorimetry Tests. Calorimetry tests on WSEP Runs PC-5 and SS-2 show that they contain 4.3 and 1.5 kilowatts, respectively, of heat from radioactive decay. Radial thermal conductivity tests on a pot of simulated solidified $\mathrm{PW}-1$ waste from the developmental spray solidifier pot are being conducted. The thermal conductivity lies between 0.55 and $0.70 \mathrm{BTU} / \mathrm{hr}-\mathrm{ft}-{ }^{\circ} \mathrm{R}$ in a temperature $\mathrm{range}$ of 175 to $412{ }^{\circ}$. Samples of simulated solidified waste have been fabricated in preparation for thermal conauctivity measurements with the newly acquired TC-2200 thermal conductivity instrument.

Fission Product Aerosol Containment ( $\mathrm{L}, \mathrm{C}$. Schwendiman)

Removal of Organic Iodıdes with Hydrazine

The washout rate of $\mathrm{CH}_{3} \mathrm{I}$ by 140 drops of hydrazine solution was calculated assuming that gas phase mass transfer resistance was negligible and that drops were stagnant. A temperature coefficient for the reaction had to be assumed since the washout takes place in the experiments at an average temperature in the range of 50 to $60^{\circ} \mathrm{C}$. Practically all the available reaction rate data were obtained at 
around $20{ }^{\circ} \mathrm{C}$. The predicted washout time was 580 minutes compared with a measured half-tıme of 400 minutes. Agreement is good considering the accuracy of the experimental measurements. This calculation showed that better measurement of liquid temperature in the spray is needed and that the activation energy should be measured.

Development of a suitable model has been hampered by the lack of an equation for estimating absorption with chemical reaction for a falling film. Attempts were made to solve the differential equation which describes this process, using integral transform methods and the separation of variables techniques. These attempts have not yet ylelded a solution, and it appears likely that a numerical (computer) solution will be required.

Equipment required for increasing spray density was specified and anticlpated alterations were reviewed

Physical Chemistry of Reactions of Spray Additives with Methyl Iodide

The determination of rates of reaction of various reactive compounds with methyl lodide continued. The results, though preliminary. can be used to help select the more promising candidate reactive compounds which may be used in reactor containment water sprays

The fraction of methyl lodide or of lodide ion was determined as a function of time for the various solutions. The reaction is assumed to be of second order. The scavenger is present $1 \mathrm{r} 50$ times (or more) the amount of methyl lodicie which is present so that the fraction of methyl iodıde, $f$; is given as a function of $t i m e, ~ t$, by

$$
-\frac{d(\ln f)}{d t}=k \nabla t
$$

where the pseudo-first order rate constant, $k$. Is given by equation (2):

$$
\mathrm{k} \nabla=\mathrm{k}(\mathrm{X})
$$

where $(x)$ is the molar concentration of the scavenger and $k$ is the second-order reaction rate constant.

In the table are presented values of the second-order reaction rate constant which were determined during the present reporting period. Comparison of the reaction rate constants in the table with the second-order reaction rate constant of the hydrazine $1 \mathrm{ca}$, $3 \mathrm{x}$ $10^{-2}$ liter mole $\mathrm{s}^{-1} \mathrm{sec}^{-1}$ and of thiosulfate ion (ca. $3 \times 10^{-2}$ liter mole-1 $\mathrm{sec}^{-1}$ ) reveals that the reaction rate constant for ammonium sulfide and dimethylhydrazine are larger than those of hydrazine or sodium thiosulfate. Both the ammonium sulficie and the dimethylhydrazine will be examined in more detall 


\section{Reaction Rate Constants}

\begin{tabular}{|c|c|c|c|c|}
\hline Reactant & $\begin{array}{l}\text { oncentration } \\
\text { f Reactant, } \\
\text { oles/liter }\end{array}$ & Conditions ${ }^{1}$ & $\begin{array}{l}\text { Temp. } \\
{ }^{\circ} \mathrm{C} \\
\end{array}$ & $\begin{array}{l}\text { Second Order Reaction } \\
\text { Rate Constant, } \\
\text { liter moles } \\
\end{array}$ \\
\hline $\mathrm{Na}_{2}\left(\mathrm{~S}_{2} \mathrm{O}_{3}\right)$ & 0.045 & & 25.1 & $3.7 \times 10^{-2}$ \\
\hline $\mathrm{Na}_{2}\left(\mathrm{~S}_{2} \mathrm{O}_{5}\right)$ & 0.09 & & 21.5 & $\mathrm{n} \cdot \mathrm{r} \cdot(18 \mathrm{~min})$ \\
\hline$\left(\mathrm{C}_{2} \mathrm{H}_{5}\right)_{3} \mathrm{~N}$ & 0.117 & & 22.5 & $3.8 \times 10^{-3}$ \\
\hline$\left(\mathrm{C}_{2} \mathrm{H}_{5}\right)_{3} \mathrm{~N}$ & 0.117 & $\mathrm{H}+$ added & 21.6 & n.r. (106 min) \\
\hline$\left(\mathrm{C}_{2} \mathrm{H}_{5}\right)_{3} \mathrm{~N}$ & 0.116 & $0.0025 \mathrm{M} \mathrm{OH}-$ & 21.6 & $2.8 \times 10^{-3}$ \\
\hline $\mathrm{Na}_{2}\left(\mathrm{~B}_{4} \mathrm{O}_{7}\right)$ & 0.09 & & 21.9 & $3.3 \times 10^{-3}$ \\
\hline$\left(\mathrm{CH}_{3}\right)_{2} \mathrm{NNH}_{2}$ & 0.009 & $0.050 \mathrm{M} \mathrm{OH}^{-}$ & 22.4 & $7.4 \times 10^{-2}$ \\
\hline $\mathrm{CH}_{3} \mathrm{NHNH}_{2} \cdot \mathrm{H}_{2} \mathrm{SO}_{4}$ & 40.009 & & 21.0 & n.r. $(81 \min )$ \\
\hline$\left(\mathrm{NH}_{4}\right)_{2} \mathrm{~S}$ & $0.009^{2}$ & & $\mathrm{RT}$ & $1.3 \times 10^{-1}$ \\
\hline$\left(\mathrm{NH}_{4}\right)_{2} \mathrm{~S}$ & $0.009^{2}$ & & $\mathrm{RT}$ & $1.2 \times 10^{-1}$ \\
\hline$\left(\mathrm{NH}_{4}\right)_{2} \mathrm{~S}$ & $0.009^{2}$ & $0.050 \mathrm{M} \mathrm{OH}^{-}$ & $\mathrm{RT}$ & $1.6 \times 10^{-1}$ \\
\hline$\left(\mathrm{NH}_{4}\right)_{2} \mathrm{~S}$ & $0.009^{2}$ & $0.1 \underline{\mathrm{M}} \mathrm{Na}_{2} \mathrm{~B}_{4} \mathrm{O}_{7}$ & 21.5 & $1.4 \times 10^{-1}$ \\
\hline $\mathrm{NH}_{4} \mathrm{SO}_{3} \mathrm{NH}_{2}$ & 0.009 & $0.050 \mathrm{M} \mathrm{OH}^{-}$ & 22.4 & $\mathrm{n} \cdot \mathrm{r} \cdot(35 \mathrm{~min})$ \\
\hline $\mathrm{NaN}_{3}$ & 0.009 & $0.5 \mathrm{M} \mathrm{OH}^{-}$ & 22.5 & n.r. (33 min) \\
\hline
\end{tabular}

$1 \mathrm{CH}_{3} \mathrm{I}$ Conen. $<1.4 \times 10^{-4} \mathrm{M}$.

n. r. no detectable reaction in the number of minutes shown.

2 Approximate concentration, all solutions prepared from stock solution of $\left(\mathrm{NH}_{4}\right)_{2} \mathrm{~S}$. 
The lack of reaction in the monomethyl hydrazine experiment was surprising. The sulfate; however, may have complexed this hydrazine derivative preventing or inhlbiting the reaction with methyl lodide.

A correlation of the reaction rate constant with the nucleophilic constant (a non-kinetic parameter) was made. The correlation was excellent for $\mathrm{H}_{2} \mathrm{O}, \mathrm{Br}^{-}, \mathrm{OH}^{-}, \mathrm{CN}^{-}, \mathrm{I}^{-}, \mathrm{S}_{2} \mathrm{O}_{3}$; and $\mathrm{S}^{*}$. The correlation is given in equation (3)

$$
\log -\frac{k}{k_{W}}=a E_{n}+\beta H
$$

where $\mathrm{k}, \mathrm{E}_{\mathrm{n}}$, and $\mathrm{H}$ are the reaction rate constant, nucleophilic constant; and basicity of the reacting species; $k_{W}$ is the reaction rate constant of water; and $\alpha$ and $\beta$ are constants for a speclfic class of reactions. The term $3 \mathrm{H}$ can be neglected for the nucleophilic displacement of lodide from methyl lodide. The correlation was found to be

$$
\log \frac{\mathrm{k}}{\mathrm{k}_{\mathrm{W}}}=2 \cdot 0 \mathrm{E}_{\mathrm{n}}
$$

The nucleophilic constant can be obtalned for some compounds from the potential of the oxidative dimerization of the compound "i.e."

$$
2 x^{-}+x_{2}+2 e^{-}
$$

by equation (6)

$$
E_{n}=E^{O}+2.60
$$

where EO is the hali-cell potential of equation (5), the oxidative dimerization.

The reaction of phosphines; arsines; or their alkyl or aryl derivatives with methyl lodide has not been examined experimentally because of the low solubility of these compounds in aqueous solution and the ease of oxidation iby atmospheric oxygen) of the alkyl derivatives. The relative rates of reaction with methyl iodide of the phosphine derivatives may be 10 to $10^{2}$ times faster than for hydrazine or thiosulfate ion based on the relative nucleophilic character of the compounds.

\section{Columbia River Sedimentation Studies ( $D, R$, Kalkwarf)}

The measurements of depletion of 10 radionuclides from solution onto river seaiment were complled on a weekly basis for the 19651966 period and used to calculate the inventories of these substances in Columbia River sediment between the reactors and Pasco, Washington. The total inventory of radionuclides varied from 2000 curies in July 
to 20,000 curies in the following April. Cr51 accounted for 0,8 of the total during the winter and spring, while $2 n 65, M n 54$, Sc46, and Co $^{60}$ made up over $99 \%$ of the remainder. Immediately following the spring freshet, the inventory of $\mathrm{Cr}^{51}$ fell to near zero and $\mathrm{Zn} 65$ became the predominant radionuclide in sediment during the summer months. Inventories of radionuclides in each mile of river bed between Ringold. Washington, and MCNary Dam are also being calculated using data obtained from bottom-sediment core samples, and these values will be compared with those obtained from depletion data. These core samples clearly showed the gradual increase in radionuclide concentration expected in bottom sediment with distance downstream, reflecting the settling of the finer particles.

\section{Soil Chemistry and Hydrology}

A soil column test was conducted in which the influent was an April=July composite 340 Building waste. After a throughput of 104 column volumes the highest strontium breakthrough concentration in one sample was $4 \times 10^{-6} \mathrm{Cl} / \mathrm{mi}$. Most effluent breakthrough concentrations were less than $5 \times 10^{-7} \mathrm{Ci} / \mathrm{ml}$. These concentrations include both strontium-89 and 90 expressed as strontıum=90. A substantial fraction of this is strontium- 89 .

Equilibrium distribution coefficients were determinea for cesium-137 adsorption on soil from 340 Bullding wastes. In general, adsorption of cesium-137 was greater than strontium in all solutions studied. Distribution coefficients ranged from 238 to $1270 \mathrm{ml} / \mathrm{g}$ in actual wastes. Cesium adsorption is affected by sodium to a greater extent than by calclum. The two $\mathrm{Kd}$ values glven above were obtained for wastes containing 1150 and 490 ppm sodium, respectively.

Based on the results of these and previous studies, the following conclusions can be made:

1. If radionuclide concentration limits are not exceeded. the current 340 Building waste is suitable for ground disposal.

2. Early crib breakthrough in the past could have been caused by insufficient neutralization in addition to high strontium-90 concentrations.

3. Neutralization increases soil strontium retention by increasing $\mathrm{pH}$-dependent charges in the soll and by reducing the calcium ion concentration in solution

4. Sodium and calcium specific ion electrodes can be used to monitor concentration levels found in the waste: however the concentration of sodium is not a limiting factor. 
5. Cobalt-60 in 340 Building wastes is retained in soil by filtration.

Signiflcant rises in the water table elevation will likely result from irrigation of 1 and located in the cold Creek Valley and Riverland areas (northwest sector of the project) Predicted final steady-state elevations will be 40-80 feet higher than the present water table beneath 200 west Area and from $10-15$ feet higher beneath 200 East Area. The estumated combined increases in water table elevations (steady state) resulting from a 400-foot Ben Franklin Dam reservoir, irrigation of the Horn Rapicis triangle and the Cold Creek Valley-Riverland areas are 60-95 feet beneath 200 West Area and 35-40 feet beneath 200 East

\section{Pressure Vessel Crack Monıtoring (J.C. Spanner)}

Detection of Metal Overstress by Acoustic Emission

Effort has been directed towards the development of a tensile loading system to test reactor plping metals for acoustic emission. The work involves the fabrication of a statıc load fixture, fatigue load fixture, and single edge notch (sen) fracture toughness specimens

Sen specimens made from $\frac{1}{2}$ inch thick $A 212 B$ steel have been fabricated and will be fatıgue-cracked to enhance the tendency for brittle fallure. Piezoelectric cyrstals will be used to detect crack formation and growth. Both load and acoustic emission will be measured simultaneously during loading to fallure.

In addition, plans are being made to fatigue-crack and pressure-load to fallure notched; 3-1nch diameter A212B steel pipe specimens

Participation with Battelle-columbus in a burst test of a 12-ft long section of 24" diameter by 1.64" wall, A-106-B carbon steel pipe was successfully concluded. The specimen contained an installed flaw and failed at approximately 2600 psig pressure and $6750_{\mathrm{F}}$ temperature. The acoustic emission monitor system permitted confident anticipation of the failure by some minutes. In the final 10 minutes of the test the emission rate increased by a factor of 17 Boiling was occurring through much of the test sequence--first around the heater elements and later at the free surface of the water. This was of considerable interest since it was an opportunity to obtain acoustic data from boiling for comparison with other reactor nolse, and It was determined that boiling noise was below $18 \mathrm{kHz}$. All of the high temperature; $\mathrm{PZT}-5$ transducers, fabricated locally for this test; functioned satisfactorily. There was ample sensitivity when using 25-ft cable lengths from the transducer to the preamplifier and 300 ft cable lengths from the 
preamplifier to the amplifier. One of the transducers was recessed 3/16" below the pipe surface to study wave propagation modes by comparison with the surface mounted transducers Detalled analysis of these test data are being accomplished.

Initial functional tests of a new data interpretation technique adequately demonstrated its feasibility. The results of limited data analysis compare quite favorably with those from more sophis ticated commercial analyzers in producing both count rate and frequency information. Questions such as bandwidth versus resolution are being evaluated. Details to be made available at a later date.

On the basis of fabrication problems being experienced in development of the electrostatic transducer, the design and development approach is being re-evaluated in an effort to circumvent these problems. Concurrently. fabrication of an operational lithium niobate transducer is in progress. This piezoelectric material has a functional temperature range up to 1000 to $1200{ }^{\circ} \mathrm{F}$.

Work is in progress on a system analysis study of acoustic emission monitor techniques in support of the end objective of this program. The design of a failure monitor system depends upon the separation of reactor noise from actual flaw growth. It is therefore necessary to determine such parameters as acoustic pulse frequency, length, and amplitude during specimen flaw growth, pulse rate accumulation for various known acoustical emissions, and other parameters yet to be specified. A set of basic assumptions was generated around which parametric data are being derived. As an example, one assumption states that acoustid "signatures" exist for all fallure deformations and can be separated from all other signals. Analysis of pressure vessel rupture test data indicate that acoustic bursts occur at frequencies up to $300 \mathrm{kHz}$ which is the practical upper limit of the recording equipment. The major amplitude peak is in the 20-30 kHz range with the higher frequencies being at a lower level.

Parallel specimen tests are being prepared using plates and pipes of appropriate materials, size, and ductility. Data collected from identically mounted transducers on both flawed and unflawed specimens will be cross-correlated to isolate acoustic signature data from test noise. These test specimens will be investigated preliminary to testing to identify resonances. 


\section{DISTRIBUTION}

Number of Copies

8

1
$\frac{A E C-A E C L, \text { Chalk River, Canada }}{\bar{M}_{0} \bar{H}_{0} \text { Hudson }}$

AEC Division of Technical Information Extension

Aerojet-Nucleonics

$\overline{\mathrm{P}}=\mathrm{O} . \widehat{\mathrm{BOX}} 7 \overline{7}$

San Ramon, California

F, W. Titus

$\frac{\text { Aeroprojects, Inc }}{\text { W. B. Tarpley }}$

Air Force Materials Laboratory

Wright-Patterson $\overline{A F B}$

$S$. W. Bradstreet

Allis Chalmers Manufacturing Co.

Virginia D. Rose

Ames Laboratory

F. H. Spedaing

Argonne National Laboratory

R. M. Adams

L. R, Link (4)

$C$. $E$. Stevenson

$R$ \& $C$ Vogel

$\frac{\text { Armour Research Foundation }}{W}$

Atomic Energy Commission Division of Compliance Region IV, $\mathrm{P}=\mathrm{O}$, Box 15266, Denver

Atomic Energy Commission: DRD\&T Site Representative P. G. Holsted

Atomic Energy Commission, Washington

Advisory Committee on Reactor Safeguards R. F, Fraley (17)

Division of Compliance

L。 Kornblith, Jr.

Division of Licensing and Regulation (7) S. S. Pawlicla (1) 
Division of Operations Analysis and Forecasting

Division of Production

F. P. Baranowski

Division of Reactor Development \& Technology

$R_{\text {。 }} A$. Brodsky

Col, Ko Cooper

A. Gi ambusso

J. E。 Robb

S。A. Szawlewcz

$M$. Shaw (16)

$G$. Wo Wens ch

Division of Research

G. A. Kolstad

Division of Safety Standards

$M_{c}$ Bolotsky

$A$. B. Holt

Office of Assistant General Counsel for Patents $R$. A. Anderson

Space Electrical Propulsion Office Col. G. K. Dicker

1

Atomic Power Development Associates, Inc. $\bar{W}_{\odot}^{-} \cdot{ }^{-}$Jens

Atomics International

A. $\bar{A}_{\text {. Jarrett }(2)}$

$\mathrm{H}$, Pearlman

Babcock and Wilcox Company Lynchburg, Virginia

$\mathrm{H}$. $\mathrm{S}$. Allen

R。 A. Webb

Battelle Memorial Institute D. L. Morrison

Bechtel Corporation $\mathrm{R}_{*} \mathrm{~F}_{0}$ Griffin

Brookhaven National Laboratory

$\bar{A}_{\text {. }}$ 。 Castleman

Elizabeth J Edwards

C. J. Raseman

D. $G$. Schweitzer 
1

2

1

1

1

1

17

1

4
Canoga Park Area Office

R. W. Richards

Carolinas-Virginia Nuclear Power Associates $\mathrm{H}_{\circledast} \mathrm{T}_{\varepsilon} \mathrm{Babb}$

Chicago Operations Office

Ärgonne; Ilínois

D. M. Gardiner

Columbia University, New York

J. E. Casterline

Combustion Engineering

$\mathrm{P}, \mathrm{O}$ BOX 500

Windsor, Connecticut

W. P. Chernock

$\frac{\text { Dow Chemical Company } \text {. Rocky Flats }}{\mathrm{J}_{\mathrm{f}} \mathrm{R}_{\mathrm{J}} \text { Seed }}$

DUN

$\bar{P}$. A. Carlson

$\mathrm{J}, \mathrm{R}$. Carrell

$W$. J Dowis

$R . E$. Dunn

G. C, Fullmer

A. E, Guay

D. $R_{\text {. Hogle (Atomics International) }}$

C. G. Lewis

M. Lewis

W. M. Mathis

$\mathrm{J} . \mathrm{S}$. MCMahon

Jo W. Nickolaus

$J$, $W$. Riches

$\mathrm{J}, \mathrm{H}$. Soehnlein

$\mathrm{H}$. $\mathrm{G}$ 。 Spencer

J. R, Spink

$W$ K . Woods

Ebasco Services, Inc.

T. A. Flynn, Jr.

E. I. duPont de Nemours and Co, Aiken

General Atomic Division
$D_{*} B_{2}$ Coburn
E. Creutz
A. $J$ = Goodjohn
S. I. Koutz
J. F. Watson 
General Electric Company. Cincinnati S. Naymark, NMPO

$\frac{\text { General Electric Company }{ }_{\mathrm{L}}, \mathrm{Pl}_{\mathrm{P}} \mathrm{Bupp}}{\mathrm{Bu} \text { anton }}$

General Electric Company, San Jose

K., Cohen
E. R. Kilsby
R. B. Richards
C. H, Robbins
E. L. Zebroski

General Electric Company, Schenectady W. M, Cashin, KÄPI

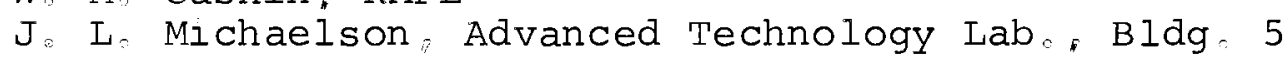

Idaho Operations office

Nuclear Technology Div.

$\mathrm{J}$. F, Kaufman

D. S. King

D, E。 Wiliiams

1

IIT Research Institute

$\overline{\mathrm{P}}=\overline{\mathrm{O}}, \overline{\mathrm{BOX}} 32 \mathrm{~T}$

Argonne, Illinois

W. J. McGonnagle

1

IIT Research Institute

I0 $W .35$ th street

Chicago, Illinois

T. A, Zaker

ARHCO

$\widetilde{\mathrm{H}} \cdot \mathrm{H}$, Hopkins

$R$. $E$. Tomlinson

Los Alamos Scientific Laboratory

$\mathrm{H}, \mathrm{F} \cdot \operatorname{Redman}$

D. B。 Hall

1

Massachusetts Institute of Technology Manson Benedict

1

National Bureau of Standards

C. Mueh Ihause

National Reactor Testing Station (INC)

J. A. Buckham

D. $R_{\approx}$ de Boisblanc 
New York Operations Office

$$
\begin{aligned}
& \text { A. J Rizzo } \\
& \text { C. Stahle }
\end{aligned}
$$

Nuclear Development Corporation of America W. $\bar{A}: \overline{L O E b}$

Nuclear Materials and Equipment Corporation

$$
\text { C. } \mathrm{S} \text { : Caldwell }
$$

Oak Ridge Operations Office

D. F Cope

$$
\text { W. J. Larkin }
$$

Philips Petroleum Company

Atomic Energy Division, Idaho Falls

G. O: Bright (2)

S. G. Forbes (2)

E. O, Meals

F. Schroeder (2)

$T$. R. Wilson (2)

Richland Operations office

$$
\begin{aligned}
& \text { P. M Mikiff } \\
& \text { C. L. Robinson } \\
& R \text {. K. Sharp (2) }
\end{aligned}
$$

$\frac{\text { Sandia Corporation }}{\mathrm{J}}$

Sargent and Lundy

$$
\text { W. A. Chittenden }
$$

$\frac{\text { Union Carbide Corporation (ORNL) }}{\mathrm{F}_{\mathrm{L}} \text { Culler }}$

$$
\begin{aligned}
& \text { W. B. Cottrell } \\
& \text { J. H. Frye } \\
& \text { R. W McClung } \\
& \text { O. Sisman } \\
& \text { D. B Trauger (2) } \\
& \text { M. S, Wechsler }
\end{aligned}
$$

$\frac{\text { United Nuclear Corporation }}{\text { C. Graves }}$

University of California

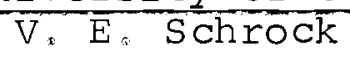


1

5

84 $\frac{\text { University of Texas }}{G_{0} \text { Watt }}$

Westinghouse Electric Corporation
R. Ho Filinow
E。 J, Kreh
$R$, G, MCGrath
$R$. Miller
$R$, A. Wiesemann

Battelle-Northwest

F. W. AIbaugh

Go J. Alkire

$R$, $T$, Anicetti

$J=M_{8}$ Atwood

$J$. A. Ayres

$Q=L$, Bairà (ANL Liaison, Idaho Falls)

$J$. M* Batch

A. I, Bement

Ca. A. Bennett

$T$. K. Bierlein

J. G. Bradley

$\mathrm{S} . \mathrm{H}$ 。 Bush

G. J. Busselman

J。 J. Cadine 11

T. T. Claudson

E. D. Clayton

T. B. Correy

R. E: Dah 1

$F=G$, Dawson

I. I. Defferding

$D, R$, de Halas

R. F, Dickerson

$R$, L。 Dillon

$K$. Drumheller

$E$. A. Eschbach

E. A. Evans

P. I. Farnsworth

$\mathrm{J}, \mathrm{R}_{\text {s }}$ Fishbaugher

$J=C_{0}$ Fox

M. D. Freshley

E. P. Galbraith

S. M. Gill

S. Goldsmith 


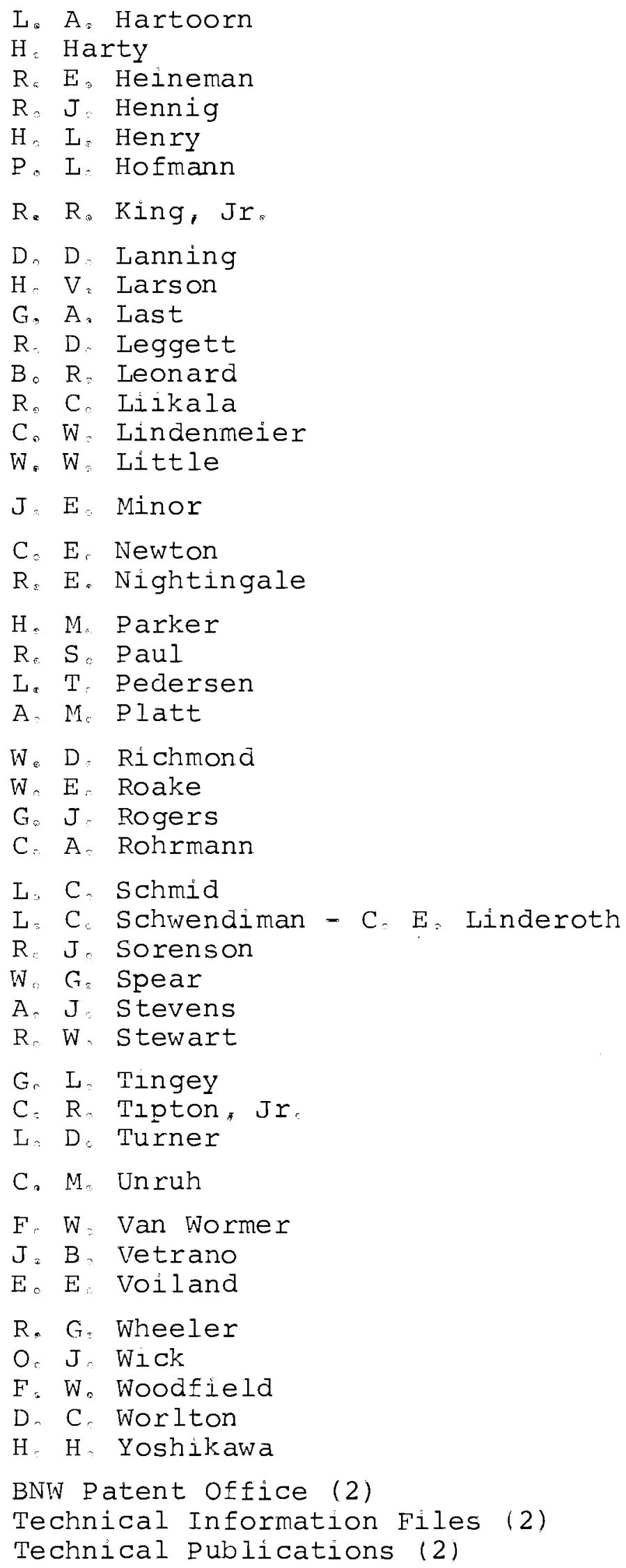

